\title{
Safe Motherhood Applied Research and Training (SMART) Report 3: Changes in knowledge and behavior of women and families
}

Muhammad Shafique Arif

Peter C. Miller

Population Council

Nayyer Munir

Irfan Masood

Population Council

Follow this and additional works at: https://knowledgecommons.popcouncil.org/departments_sbsr-rh

Part of the Demography, Population, and Ecology Commons, Family, Life Course, and Society Commons, Gender and Sexuality Commons, International Public Health Commons, Maternal and Child Health Commons, and the Medicine and Health Commons How does access to this work benefit you? Let us know!

\section{Recommended Citation}

Arif, Muhammad Shafique, Peter C. Miller, Nayyer Munir, and Irfan Masood. 2006. "Safe Motherhood Applied Research and Training (SMART) Report 3: Changes in knowledge and behavior of women and families." Islamabad: Population Council. 
Safe Motherhood Applied Research \& Training SMART

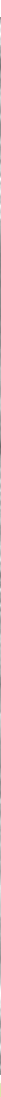

\section{Changes in Knowledge and \\ Behavior of women and Families}

(1) Population Council

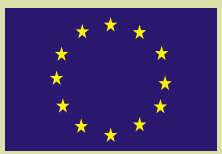





\title{
Safe Motherhood Applied Research \& Training Project SMART
}

\section{SMART Report 3. \\ Changes in Knowledge and Behavior of Women and Families}

\author{
Muhammad Shafique Arif \\ Peter C. Miller \\ Nayyer Munir \\ Irfan Masood
}




\section{(2) Population Council}

The Population Council, an international, non-profit, nongovernmental organization established in 1952, seeks to improve the well-being and reproductive health of current and future generations around the world and to help achieve a humane, equitable, and sustainable balance between people and resources.

The Council analyzes population issues and trends; conducts research in the reproductive sciences; develops new contraceptives; works with public and private agencies to improve the quality and outreach of family planning and reproductive health services; helps governments design and implement effective population policies; communicates the results of research in the population field to diverse audiences; and helps strengthen professional resources in developing countries through collaborative research and programs, technical exchanges, awards, and fellowships.

\section{For inquiries, please contact:}

\section{Population Council}

House \#7, Street 62, F-6/3, Islamabad, Pakistan

Tel: 92512277439

Fax: 92512821401

Email: info@pcpak.org

Web: http://www.popcouncil.org

Layout \& Design: Mehmood Asghar \& Ali Ammad

Printed by: Crystal Printers

Published: October 2006

The Population Council reserves all rights of ownership of this document. No part of this publication may be reproduced, stored or transmitted in any form by any means - electronic, photocopying, recording or otherwise - without the permission of the Population Council. 


\section{Acknowledgements}

The Population Council would like to thank the European Union for its generous funding and support for this project.

We would also like to thank the Departments of Health of Dera Ghazi Khan and Layyah Districts for their willingness to allow these surveys to take place within their jurisdictions.

This report was drafted by Mr. Shafique Arif, Field Operations Manager, wrote the first draft of this report, and worked closely with Mr. Peter Miller, Deputy Country Director, to produce the final product. Ms. Nayyar Farooq, Field Research Officer, supervised the fieldwork on most rounds of these surveys. Mr. Irfan Masood, Data Quality Officer, oversaw the data input and management operations, and produced most of the tables for this report.

Dr Zeba A. Sathar, Country Director, Population Council provided overall guidance for the successful completion of the project, and in particular provided valuable advice throughout for the implementation of the research components of the SMART project.

This research would have not been achievable without the involvement of Dr. Gul Rashida, who not only provided full cooperation and support as Project Director but also provided valuable input in questionnaires and in training of the enumerators. She also created an overall environment of commitment and enthusiasm within which the whole SMART project flourished.

Dr. Farid Midhet conceptualized this project, designed the research strategy and developed the household survey questionnaire. His guidance during the design and early implementation of the SMART project set the core directions and standards for the project.

We are also thankful to the members of Reproductive Health Research Working Group (RHRWG) for their input on design and questionnaires.

Dr. Ubaidur Rob of the Council's Dhaka office provided valuable comments on an earlier draft of this report, and Ms. Sabiah Askari edited this report. They provided the fresh, outside eyes that every publication needs.

In any field endeavor such as this, the contributions made by such a large number of individuals cannot be acknowledged individually, but the contributions of some require special mention. Mr. Mumraiz Khan, Assistant Program Officer, ably directed round 2 of the KAB 
survey. We are thankful to Mr. Abdul Rashid Bhatti, the Field Administration Officer of the SMART project office, for his continuous commitment and support. Mr. Kamran Shafi, Field Coordinator, who coordinated field activities, was invaluable in establishing the underpinnings of activities for the baseline survey.

Training of 50 young women who were fresh university graduates to become skilled interviewers was not an easy task. It was only possible with the tireless efforts and strong commitment of Ms. Azra Noreen, Ms. Rabia Tahir, Ms. Sumaira Mushtaq, Ms. Shabana Sharif and Ms. Irum Baloch. These team members not only contributed in producing highly committed and dedicated enumerators but also supervised them in one of the most difficult areas of Punjab during long, hot summers. These team members also helped in pretesting the questionnaire in local areas, translation the questionnaire into local language and development of the instruction manual.

The careful editing and entry of survey data was only possible because of a dedicated team. We would particularly like to acknowledge Mr. Rehan Niazi who assisted Mr. Irfan during the entire task of data entry and cleaning,

The actual collection of data, of course, required the hard work and tireless efforts of the large group of female interviewers and male logistics coordinators. They completed the fieldwork on time, despite atrociously hot weather, unfriendly dogs and other impediments. Individually and collectively, their contributions were immense. Their names and contributions are given in Appendix 3.

Finally, but most importantly, we are grateful to all of the respondents who took the burden of our detailed enquiry and remained involved during the often tedious interview process. We hope that the work of the project has helped to repay them. 


\section{Table of Contents}

I. Introduction ..................................................................... 1

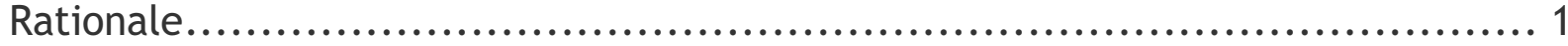

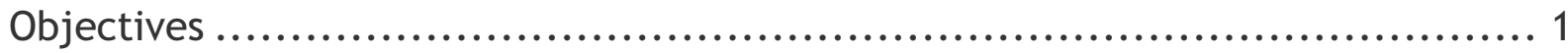

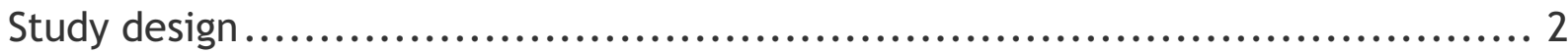

Site selection.................................................................... 2

Evaluation design ................................................................ 3

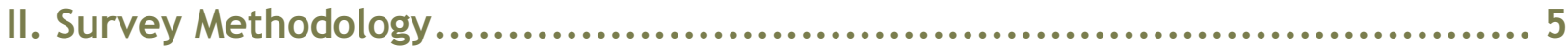

Sample design ............................................................... 5

Sample size .................................................................... 6

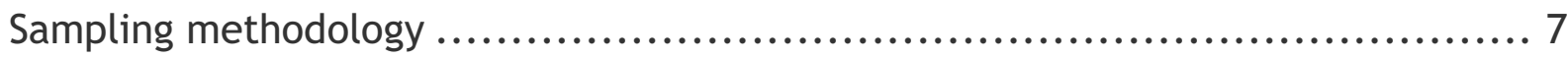

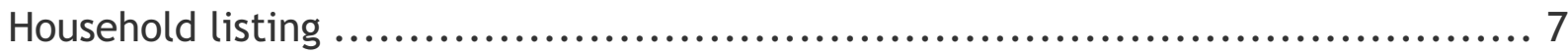

Questionnaires ................................................................... 7

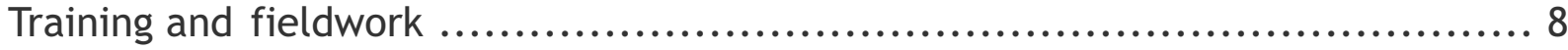

Quality control.............................................................. 8

Sample coverage ............................................................. 9

KAB survey..................................................................... 11

A note on sampling errors and statistical significance ........................... 11

III. Household Characteristics...........................................................13

General characteristics and facilities ....................................... 13

Household assets .......................................................... 16

Ethnicity ................................................................. 18

IV: Demographic and Social Characteristics of Married Women of

Reproductive Age ................................................................. 19

Demographic characteristics .................................................. 19

Social characteristics of women and their husbands ........................... 21

V: Family Planning ..................................................................27

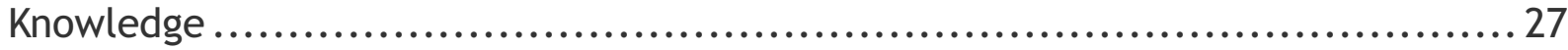

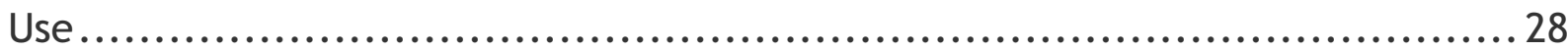

Response to program inputs ............................................. 32

VI: Knowledge of Maternal and Neonatal Health ......................................35

Knowledge of potentially serious complications ................................ 35

Knowledge response to program inputs in $\mathrm{CBI}$ communities .......................4 43 


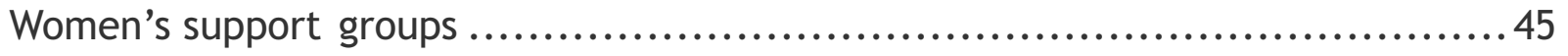

Information, education, and empowerment for change (IEEC) material ............46

Training of lady heal th workers (LHWs) ..................................... 49

VII. Routine Maternal and Neonatal Health Practices..................................55

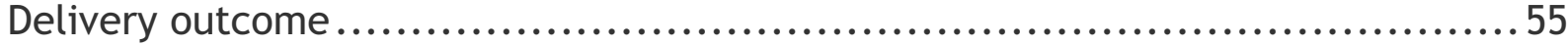

Use of maternal health care services ........................................56

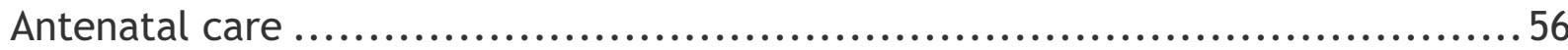

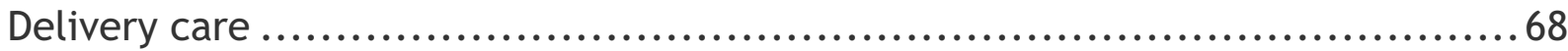

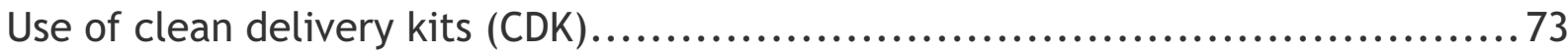

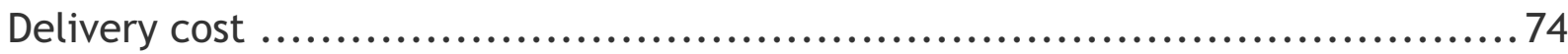

Care of the newborn ........................................................... 75

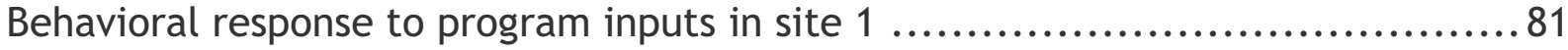

Women's autonomy and $\mathrm{MNH}$ care ......................................... 86

VIII: Maternal and Newborn Emergencies ..........................................8 89

Experience of life threatening maternal complications.........................8 89

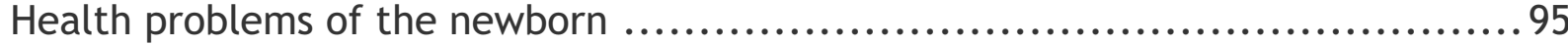

Care-seeking behavior for problems ......................................... 98

IX. Mortality ............................................................. 103

\section{Appendices}

Appendix I. Site Selection.................................................................. 108

Appendix 2. District Profile ............................................................... 110

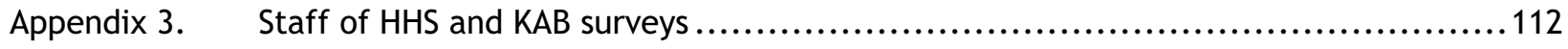

Appendix 4. Sampling errors and design effects ............................................ 117 


\section{Figures}

Figure 1.1: $\quad$ Research Design for the SMART Project.............................................

Figure 3.1: Percentage of households with electricity and telephone $\quad$........................... 16

Figure 3.2: $\quad$ Distribution of households according to language spoken at home .................... 18

Figure 4.1: $\quad$ Singulate mean age at marriage (SMAM) and total fertility rates ..................... 21

Figure 4.1: $\quad$ Percentage of women with full decision making power.............................. 25

Figure 4.2: $\quad$ Percentage of women with full control over finances............................... 25

Figure 4.3: $\quad$ Percentage of women with full freedom of mobility.............................. 26

Figure 5.1: Knowledge, ever use and current use of contraception............................. 28

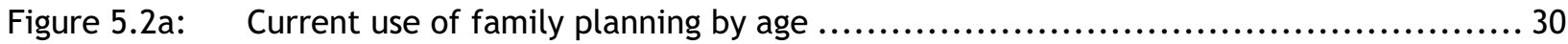

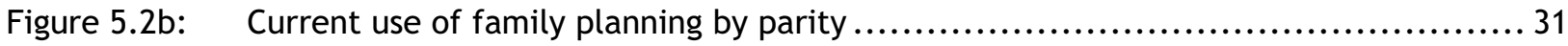

Figure 5.2c: Current use of family planning by education ....................................... 31

Figure 5.2d: Current use of family planning by language....................................... 32

Figure 5.2e: $\quad$ Current use of family planning by wealth quintile ................................. 32

Figure 6.1: $\quad$ Percentage difference between knowledge increases of pregnancy danger

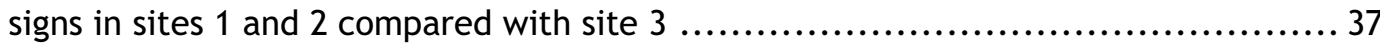

Figure 6.2: $\quad$ Percentage difference between knowledge increases of delivery danger

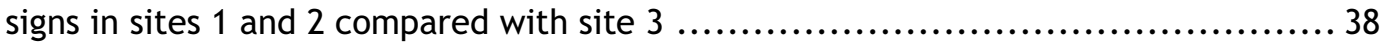

Figure 6.3: Percentage difference between knowledge increases of postpartum danger

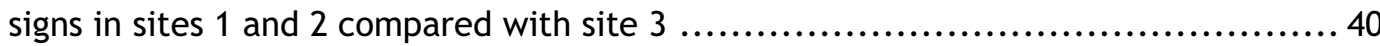

Figure 6.4: Percentage difference between knowledge increases of newborn danger

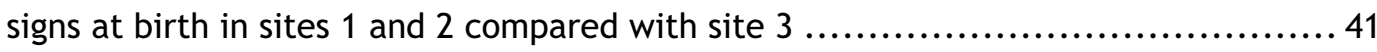

Figure 6.5: Difference between knowledge increases of newborn danger signs (first

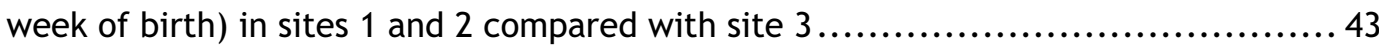

Figure 6.6: Percentage of women in site 1 who attended women's support group meetings ..................................................................... 45

Figure 6.7: $\quad$ Proportion of women in site 1 who know at least 3 danger signs of pregnancy, delivery, postpartum period and newborns by number of support group meetings attended

Figure 6.8: Women who know 3+ danger signs of childbearing period by support group

and IEEC material .............................................................. 49

Figure 6.9: Percent of women visited by LHW during previous 2 months ....................... 50

Figure 6.10: Proportion of women who know at least 3 danger signs of pregnancy,

delivery, postpartum period and newborns by LHW visitation in past 2

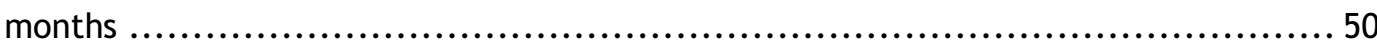

Figure 6.11: Percentage of women who know danger signs of pregnancy, delivery, postpartum and in newborn by decision-making power, KAB round $3 \ldots \ldots \ldots \ldots \ldots \ldots \ldots . \ldots 1$ 
Figure 6.12: Percentage of women who know danger signs of pregnancy, delivery, postpartum and newborns by their control over finances, KAB round $3 \ldots \ldots \ldots \ldots \ldots \ldots . .52$

Figure 6.13: Percentage of women who know danger signs of pregnancy, delivery,

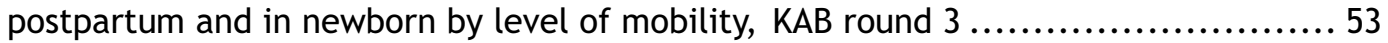

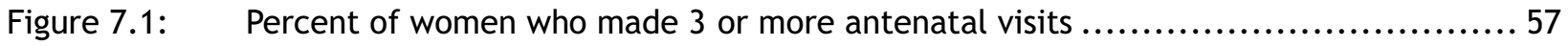

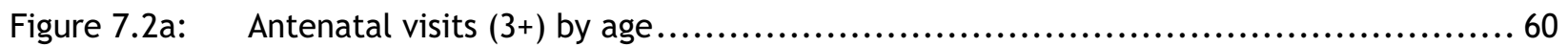

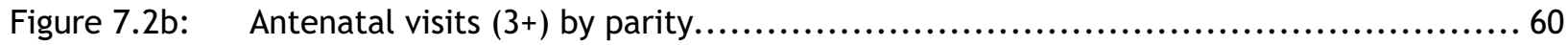

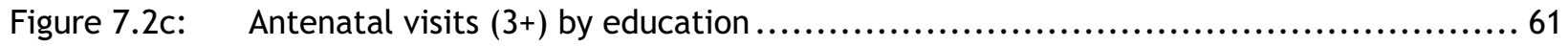

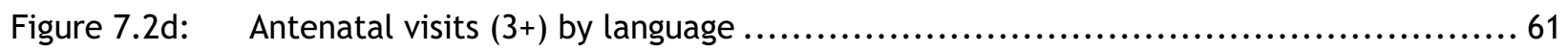

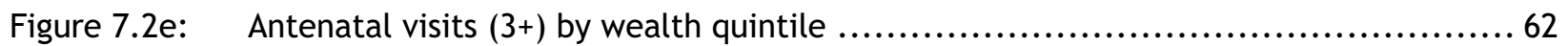

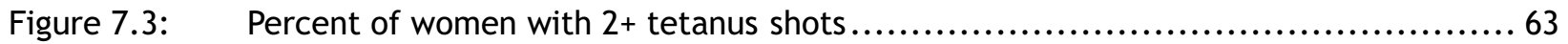

Figure 7.4: Percent of women with one or more TT shot according to number of ANC visits, by site, HHS endline ................................................. 63

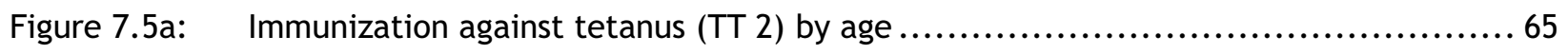

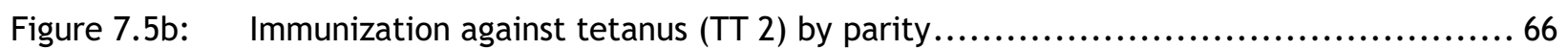

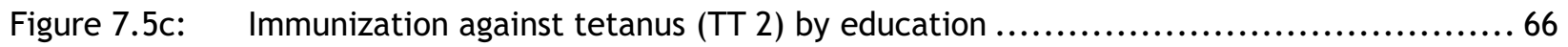

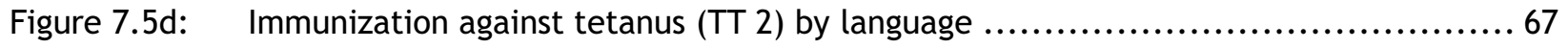

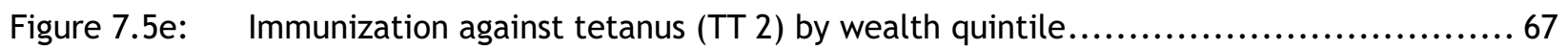

Figure 7.6: $\quad$ Percent of women receiving iron tablets ........................................ 68

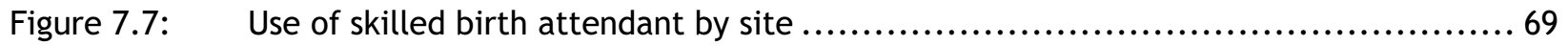

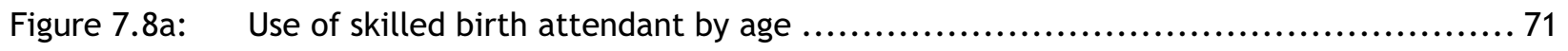

Figure 7.8b: Use of skilled birth attendant by parity ......................................... 72

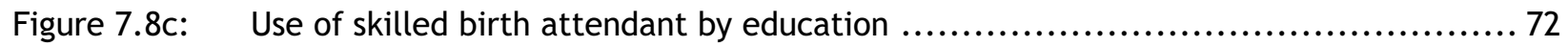

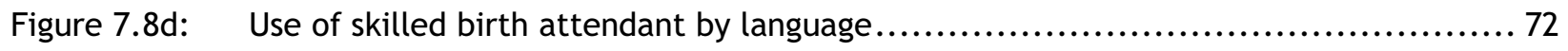

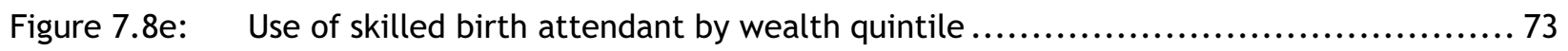

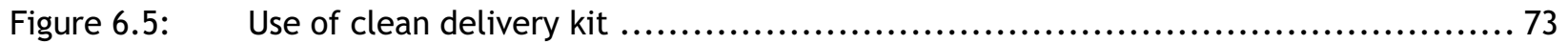

Figure 7.10: Percent change in newborns given breast milk with 4 hours of birth ................. 77

Figure 7.11: Percent change in newborns given colostrum ................................... 78

Figure 7.12: Percent change in newborns put with their mothers immediately after birth .......... 79

Figure 7.13: Percent change in newborns wrapped immediately after birth ...................... 80

Figure 7.14: Percent change in newborns whose first bath was delayed until day after birth .......... 81

Figure 7.15: $\quad$ Percent of women who received antenatal care (3+visits), took iron tablets and used skilled birth attendant by number of support group meetings

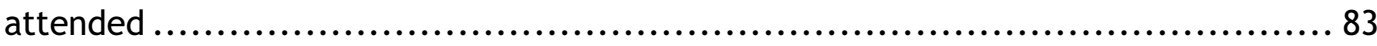

Figure 7.16: Percent of women who received antenatal care (3+ visits), took iron tablets, used skilled birth attendant and received TT shots by IEEC items received. 
Figure 7.17: $\quad$ Percent of women who received antenatal care (3+ visits), took iron tablets, used skilled birth attendant and received TT shots, by LHW visitation

Figure 7.18: $\quad$ Percentage of women who received ANC, TT shots $(2+)$, iron tablets and use of skilled birth attendant by decision-making power by district.

Figure 7.19: $\quad$ Percentage of women who received ANC, TT shots $(2+)$, iron tablets and use of skilled birth attendant by control over finances by district...

Figure 7.20: Percentage of women who received ANC, TT shots $(2+)$, iron tablets and use of skilled birth attendant by level of mobility by district.

Figure 8.1: $\quad$ Percentage of women reporting at least one serious complication of pregnancy, spontane ous or probed... 91

Figure 8.2: $\quad$ Percentage of women reporting at least one serious complication of delivery, spontane ous or probed

Figure 8.3: $\quad$ Percentage of women reporting at least one serious complication of postpartum period, spontaneous or probed.

Figure 8.4: Percentage of newborns who suffered from at least one complication at

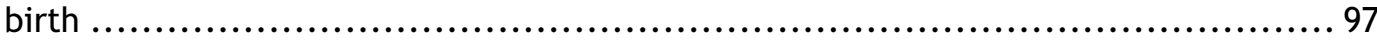

Figure 9.1: Perinatal, stillbirth, and early neonatal mortality rates by arm.....................105

Figure 9.2: $\quad$ Perinatal mortality rate by area ................................................ 106

\section{Tables}

Table 2.1: $\quad$ Numbers of households, currently married women of reproductive age, and live births, by study site and HHS round... 10

Table 2.2: $\quad$ Numbers of women interviewed and of live births in previous 6 months, by

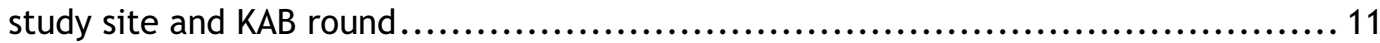

Table 3.1: $\quad$ Selected household characteristics and facilities, by site and HHS round .............. 14

Table 3.2: $\quad$ Household assets and agricultural land ownership by site and HHS round .............. 17

Table 4.1: Demographic characteristics of married women of reproductive age, by site

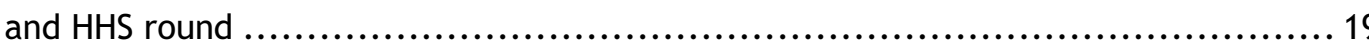

Table 4.2: $\quad$ Socio-economic characteristics of married women of reproductive age and husbands, by site and HHS round ................................................ 22

Table 4.3: $\quad$ Proportion of women with no, some or full autonomy according to topic by $\mathrm{KAB}$ round, all sites combined...................................................... 24

Table 5.1: Knowledge, ever use, and current use of family planning methods, by site

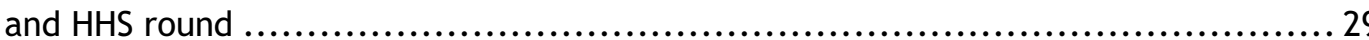

Table 5.2: $\quad$ Current use of contraception according to direct exposure to SMART project inputs in site $1, \mathrm{KAB}$ round 3 
Table 6.1: $\quad$ Spontaneous knowledge of danger signs and symptoms of pregnancy by site

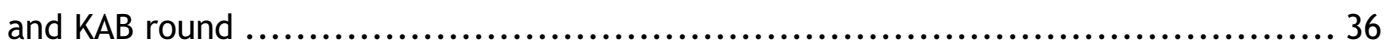

Table 6.2: Spontaneous knowledge of danger signs and symptoms of delivery by site

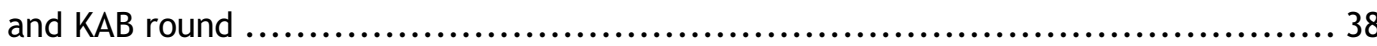

Table 6.3: Spontaneous knowledge of danger signs and symptoms postpartum by site

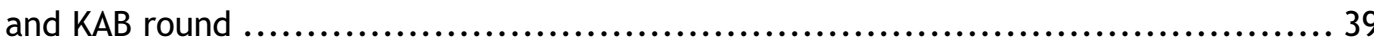

Table 6.4: Spontaneous knowledge of danger signs and symptoms in newborns at birth

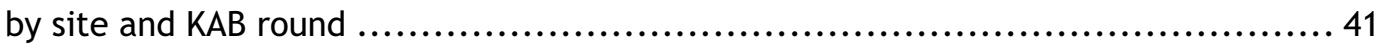

Table 6.5: $\quad$ Spontaneous knowledge of danger signs and symptoms in newborns within 7

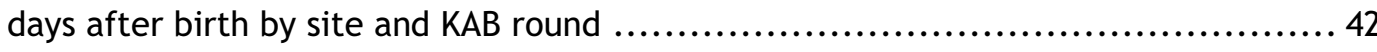

Table 6.6: Women's exposure to women support groups, IEEC materials, LHWs and PC trained dais in site $1, \mathrm{KAB}$ round 3 ............................................ 44

Table 6.7: $\quad$ Percentage of women who received or saw IEEC materials in site 1 by

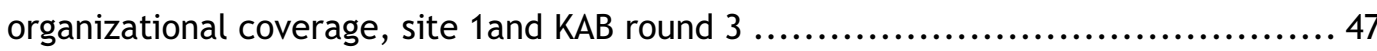

Table 6.8: $\quad$ Percent distribution of women according to number of materials received

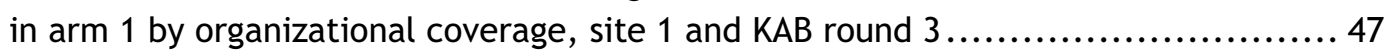

Table 6.9: Percentage of women who have seen/received IEEC materials according to

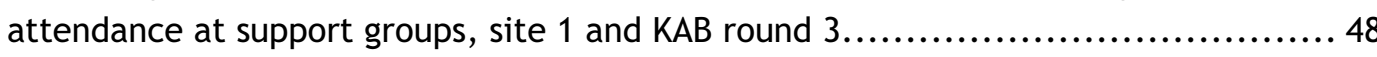

Table 6.10: $\quad$ Percentage of women pregnant during previous year who received antenatal care card, by organizational coverage, site 1 and $\mathrm{KAB}$ round $3 \ldots \ldots \ldots \ldots . . . .48$

Table 7.1: $\quad$ Outcome of last pregnancy during previous 12 months, by site and HHS

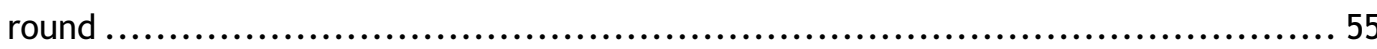

Table 7.2: $\quad$ Percentage of women receiving routine antenatal care during pregnancy, by site and HHS round ......................................................... 57

Table 7.3: $\quad$ Percent distribution of women by number of TT shots and source, by site

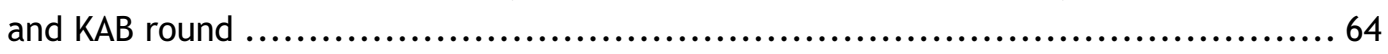

Table 7.4: Delivery care according to location and attendant, by site and HHS round ............. 70

Table 7.5: Distribution of delivery cost and median costs according to place of delivery and type of attendant, by site and HHS round........................... 75

Table 7.6: $\quad$ Timing of initiating breastfeeding, by site and KAB round ........................... 76

Table 7.7: $\quad$ Placement of newborn immediately after birth, by site and KAB round ............... 79

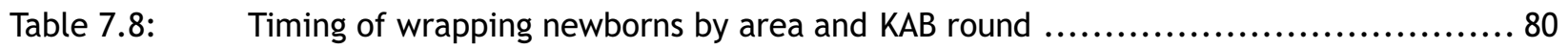

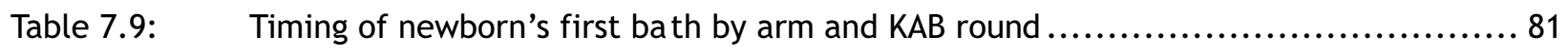

Table 7.10: Maternal health practices by exposure to SMART activities, site 1, KAB

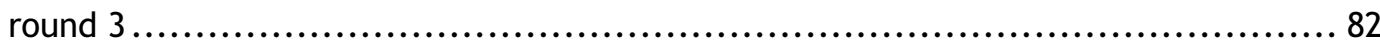

Table 8.1: $\quad$ Percentage of women reporting severe complications of pregnancy, by site

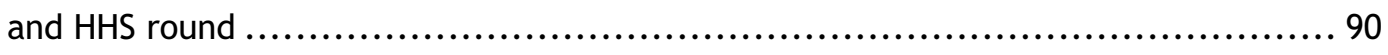

Table 8.2: $\quad$ Percentage of women reporting severe complications of delivery, by site and HHS round. 
Table 8.3: $\quad$ Percentage of women reporting severe complications in the postpartum period, by site and HHS round ................................................ 94

Table 8.4: Percentage of newborns who experienced health problems at birth, by

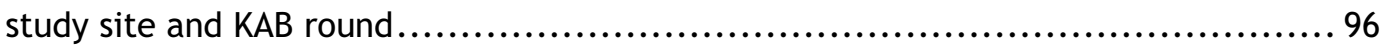

Table 8.5: $\quad$ Percentage of newborns who experienced health problems within 7 days

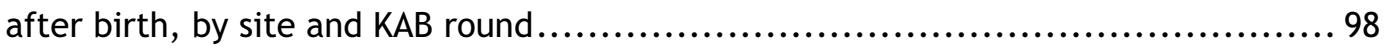

Table 8.6: Percentage of women who sought treatment from skilled health care providers for pregnancy complications, by site and HHS round...................... 99

Table 8.7: $\quad$ Percentage of women who sought treatment from skilled health care providers for delivery complications, by site and HHS round ....................... 100

Table 8.8: $\quad$ Percentage of women who sought treatment from skilled health care provider for postpartum complications, by site and HHS round .......................101

Table 8.9: $\quad$ Sources of treatment for newborn complications experienced at birth and within 7 days after birth ...................................................... 102

Table 9.1: Vital events recorded by the SMART project household survey in the previous 12 months at baseline and endline, by study arm .104

Table 9.2: Vital rates and selected $95 \%$ confidence intervals at baseline and endline, by study arm .104 


\section{Abbreviations}

\begin{tabular}{|c|c|}
\hline LHV & Lady Health Visitor \\
\hline MCH Center & Maternal and Child Health Center \\
\hline MDG & Millennium Development Goals \\
\hline $\mathrm{MNH}$ & Maternal and Neonatal Health \\
\hline M. Sterilization & Male Sterilization \\
\hline MMR & Maternal Mortality Ratio \\
\hline $\mathrm{MO}$ & Medical Officer \\
\hline MT & Medical Technician \\
\hline MWRA & Married Women of Reproductive Age \\
\hline NRSP & National Rural Support Program \\
\hline NMR & Neonatal Mortality Rate \\
\hline OTT & Operation Theatre Technician \\
\hline PAIMAN & Pakistan Initiative for Mothers and Newborns \\
\hline PC & Population Council \\
\hline PHC & Primary Health Care \\
\hline PHF & Primary Health Facility (BHU/ RHC) \\
\hline PIMS & Pakistan Institute of Medical Sciences \\
\hline PNMR & Perinatal Mortality Rate \\
\hline PSLMS & Pakistan Social and Living Standard Measurement Survey \\
\hline PWD & Population Welfare Department \\
\hline RHC & Rural Health Center \\
\hline RHSC A & Reproductive Health Services Center - A \\
\hline SES & Socioeconomic Status \\
\hline SMART & Safe Motherhood Applied Research and Training \\
\hline SAHR & Salutation Assess Help Reassure \\
\hline SMAM & Singulate Mean Age at Marriage \\
\hline TBA & Traditional Birth Attendant \\
\hline TCL & Training at Community Level \\
\hline TFR & Total Fertility Rate \\
\hline THQ & Tehsil Headquarter Hospital \\
\hline TOT & Training of Trainers \\
\hline UNFPA & United Nations Fund for Population Activities \\
\hline VBFPW & Village Based Family Planning Worker \\
\hline $\mathrm{VC}$ & Village Committee \\
\hline $\mathrm{VHC}$ & Village Health Committee \\
\hline WMO & Woman Medical Officer \\
\hline
\end{tabular}




\begin{tabular}{|c|c|}
\hline LHV & Lady Health Visitor \\
\hline MCH Center & Maternal and Child Health Center \\
\hline MDG & Millennium Development Goals \\
\hline $\mathrm{MNH}$ & Maternal and Neonatal Health \\
\hline M. Sterilization & Male Sterilization \\
\hline MMR & Maternal Mortality Ratio \\
\hline $\mathrm{MO}$ & Medical Officer \\
\hline MT & Medical Technician \\
\hline MWRA & Married Women of Reproductive Age \\
\hline NRSP & National Rural Support Program \\
\hline NMR & Neonatal Mortality Rate \\
\hline OTT & Operation Theatre Technician \\
\hline PAIMAN & Pakistan Initiative for Mothers and Newborns \\
\hline PC & Population Council \\
\hline PHC & Primary Health Care \\
\hline PHF & Primary Health Facility (BHU/ RHC) \\
\hline PIMS & Pakistan Institute of Medical Sciences \\
\hline PNMR & Perinatal Mortality Rate \\
\hline PSLMS & Pakistan Social and Living Standard Measurement Survey \\
\hline PWD & Population Welfare Department \\
\hline RHC & Rural Health Center \\
\hline RHSC A & Reproductive Health Services Center - A \\
\hline SES & Socioeconomic Status \\
\hline SMART & Safe Motherhood Applied Research and Training \\
\hline SAHR & Salutation Assess Help Reassure \\
\hline SMAM & Singulate Mean Age at Marriage \\
\hline TBA & Traditional Birth Attendant \\
\hline TCL & Training at Community Level \\
\hline TFR & Total Fertility Rate \\
\hline THQ & Tehsil Headquarter Hospital \\
\hline TOT & Training of Trainers \\
\hline UNFPA & United Nations Fund for Population Activities \\
\hline VBFPW & Village Based Family Planning Worker \\
\hline $\mathrm{VC}$ & Village Committee \\
\hline VHC & Village Health Committee \\
\hline WMO & Woman Medical Officer \\
\hline
\end{tabular}





\section{Executive Summary}

The Safe Motherhood Applied Research and Training Project was conceived as an operations research project designed to test the effectiveness of two different strategies for improving maternal and neonatal health in Pakistan. To evaluate the results of this test, several types of evaluative research were conducted, including qualitative studies of various types, health systems assessments, evaluations of specific components, and household surveys. It is these household surveys that are the subject matter of this report. They are of two types: a large-scale, before-after household survey (HHS) intended to measure mortality change as well as some other socio-economic, demographic, and health variables; and a smaller knowledge, attitude and behavior (KAB) survey conducted at baseline, midproject and endline and intended to obtain details on behavior and on exposure to SMART project activities.

\section{Methodology}

The primary outcome variable of interest for the operations research was the perinatal mortality rate (PNMR). The project hypothesized that PNMR would be greatest in site 1 , which had the most intense intervention, intermediate in site 2, which had a less intense intervention, and least in site 3 , the control site. The survey sample size was intended to detect a decline in PNMR of 30 percent as statistically significant at the .05 level. This requirement resulted in sample sizes large enough for detailed analysis of a range of variables studied in the HHS. The KAB, on the other hand, was intended for detail in subject matter rather than statistical power, so for some topics of interest sample sizes are rather small.

Each of the three sites consisted of 60 communities with an average of roughly 5,000 persons each. One hundred twenty rural communities in DG Khan were randomly allocated to site 1 or site 2, whereas the 60 rural communities of site 3 were a random selection of communities from a neighboring district, Layyah. For both surveys, probability samples were drawn from each of the 60 communities in each site. In the HHS, between about 7,000 and 8,500 married women of reproductive age were interviewed in each site, while in the KAB, sample sizes ranged from about 600 to 1000 MWRA per site. 


\section{Household Characteristics}

Data from sites 1 and 2 in DG Khan, which were randomly allocated by treatment, indicated no differences in a variety of household characteristics that could significantly affect study outcomes; in other words, the randomization was effective.

On the other hand, there were some differences between DG Khan (sites 1 and 2) and Layyah (site 3). DG Khan generally had larger households, with higher proportions receiving government water supplies, electricity and telephones (including land and cell phone connections) and fewer having washing machines, in-house toilet facilities, pucca houses and agricultural land compared to Layyah, the control area.

The increase between rounds in availability of several important development indicators across all three arms, including government water supply, toilet facilities, access to electricity, telephone connection, ownership of television, etc., indicates overall development of the area. Such improvements could affect health independently of the SMART project, and at the same time might suggest the possibility that direct improvements in health could have been occurring during the project period independently of the project.

Sites 1 and 2 consist of Saraiki and Balochi speakers whereas site 3 consists of Saraiki and Punjabi speakers. This may have a bearing on the ability of the respective districts to respond to health initiatives.

\section{Characteristics of Married Women of Reproductive Age}

There were no important differences between sites 1 and 2 in DG Khan. However, in some important ways, women living in the intervention area are somewhat different from the control area. Some of the differences are demographic: women in the control area are older, marry later, and have fewer children, indicating that they are further along in the demographic transition. There are also differences among social indicators. For example, women in the control area are more educated and less involved in generating household income, and have better educated husbands. However, the occupational profile is similar for both men and women. Changes between baseline and endline are modest. 


\section{Family Planning}

Knowledge and use of family planning is consistent with what might be expected in underserved rural areas of Pakistan. Nearly all women know of at least one method, but use rates are low. There were slight increases in use between baseline and endline. Use rates were slightly higher in the control area (Layyah), consistent with the lower fertility there; increases in use between rounds were most apparent there as well. Women exposed to SMART program interventions in the "HSI plus CBI" area were more likely to use family planning than those not exposed, but whether this is due to the project is unclear.

\section{Knowledge of Maternal and Neonatal Health}

Proportions of women who could spontaneously name three danger signs of pregnancy, delivery, the postpartum period, newborns at birth, and newborns during the first week increased substantially in all three sites; we believe the increases are partly a result of better interviewing technique at endline. Even at endline, proportions knowing three danger signs, as well as many important individual signs, are quite low. The increases, however, were substantially greater for site 1 than for the other sites, indicating the possibility that the education and motivation activities of the SMART project were effective in increasing women's knowledge.

This inference is supported by analysis of knowledge in site 1 according to exposure to SMART project activities. Knowledge of danger signs was substantially greater among women who attended support groups, especially more than once, than among those who had not. Similarly, knowledge was higher among those exposed to IEEC materials than those not exposed.

Lady Health Workers in all sites were more likely to have visited the respondent in the previous two months at endline than at baseline. This is likely due to the recruitment of substantial numbers of new LHWs during the project period, an activity not related to the SMART project. However, the increase in visitation appeared to be greatest in site 1, which could have been in response to SMART project training. Among various measures of women's autonomy, relationship with knowledge was most noticeable for mobility. Women with greater mobility, particularly those who could go alone to health facilities, could name more danger signs than women with less independent mobility. 


\section{Routine Maternal and Neonatal Health Practices}

Proportions of women who seek routine antenatal care (ANC), receive tetanus injections and iron supplements, and deliver in health facilities and with skilled birth attendants (SBA) are all comparable to those in Pakistan generally. Use of ANC, institutionalized delivery, and SBA increased somewhat over the two-year period between survey rounds in all sites; there was no consistent variation in change by site. In general, use of MNH services is greater among younger, better-educated and more prosperous women. Use of modern health care in DG Khan is less among Balochi women than Seraiki women, while in Layyah it is greater among Punjabi women than Seraiki women.

Several important neonatal care practices showed improvement in all sites between baseline and endline, including initiation of breastfeeding within four hours of birth, not discarding initial colostrum, immediate placement of the newborn with the mother, immediate wrapping of the newborn, and delaying bathing. These improvements were generally greater in the intervention sites than in the control site, but were not always greater in site 1 than in site 2.

Health care practices in site 1 were generally better among women who attended support groups and were exposed to educational materials. In several (but not all) important areas, delivery and neonatal care was better for women delivered by PC-trained dais than other home deliveries. Use of antenatal care was substantially better for women who had been recently visited by LHWs than other women, but there were no differences regarding tetanus immunization, use of iron tablets, or use of SBAs.

Costs associated with delivery were much higher for women delivered in facilities than for those delivered at home, in part because delivery in facilities was likely to be due to complications. From various qualitative studies, it appears likely that the high cost to clients is a substantial barrier to having obstetric and pediatric emergencies treated.

\section{Maternal and Newborn Emergencies}

At baseline, reporting of problems during pregnancy, delivery, the postpartum period, and for newborns was quite high. These levels decreased substantially between rounds for all sites, although they remained substantial. These differences between rounds were more pronounced after probing than for spontaneous reporting. It is unlikely that, in general, such reporting differences represent actual declines in experience of complications. Rather, it appears more likely that interviewers, with more experience, were more selective in the complications they recorded. The declines are not consistently related to site.

xviii 
Conversely, the proportions of women seeking medical care for potentially serious complications increased, presumably because the problems reported were more serious at endline than at baseline. Proportions seeking care for potentially life-threatening complications was often quite substantial, but even for potentially serious complications large proportions of women did not seek treatment. Because of difficulties in obtaining medically useful information in surveys of this type, it is difficult to say how often proper care was or was not sought for genuine emergencies, or whether there was change during the project period.

\section{Mortality}

At baseline, infant and perinatal mortality rates were comparable to levels for Pakistan generally; given the nature of the project area, this suggests somewhat lower than expected mortality. Aggregate maternal mortality from all three sites, from low numbers of deaths (13) was 236 per 100,000 live births, lower than expected on the basis of admittedly inconclusive national data. This rate declined between baseline and endline in all three sites, but the numbers involved are much too small for statistical inference.

During the project period, perinatal mortality declined by 23 percent in site 1 , but remained stationary in the other two sites. The decline in site 1 involved declines in both stillbirths and early neonatal deaths. Since some of the mortality, and most of the pregnancies, occurred prior to project implementation, it is likely that the observed decline understates the actual decline, but since the observation period was truncated it is not possible to be sure. Even so, the decline in site 1 is statistically significant, and represents a substantial achievement.

\section{General observations}

While results from these surveys are clear in several areas, in others the ability to draw firm conclusions is hampered by methodological difficulties. The Population Council has considerable experience in conducting household surveys involving demography, socioeconomic topics, and family planning, and in these areas the data are generally internally consistent and changes between survey rounds are quite plausible. Standard techniques were used, interviewers were well trained and supervised, and in general the data quality seems quite good. However, in some important areas such as knowledge of $\mathrm{MNH}$ complications, reporting of $\mathrm{MNH}$ problems, and health care seeking behavior, there seem to be substantial data problems. Our indicators and data collection approaches are standard in 
the literature. It therefore seems to us that, at least in Pakistan, substantial methodological inquiry is needed to work out consistent and reliable survey indicators for maternal and neonatal health.

Even for topics where there is no reason to question the data, the evaluation of the different aspects of the project presents a mixed picture. In general, there is little evidence of any change in the "HSI only" are in behavior or mortality. There is no reason from the survey data to believe that one-time, in-service training of health providers made a change in maternal and neonatal health sufficient to be measurable with our survey methods. In part, this may be because of the limitations of training by itself to change even provider behavior, let alone the overall functioning of a health system. But it may also be because most of the $\mathrm{MNH}$ care in DG Khan is provided by the private sector, which was not the target of our intervention.

On the other hand, some effects of the CBI interventions are clearly visible in the surveys. There appears to be a substantial increase in knowledge of the danger signs of the childbearing process, which is at least partly traceable to the support groups and IEEC materials. On the other hand, while there seems to have been some improvement in key MNH care-seeking behaviors, this does not seem to be particularly greater in site 1 than elsewhere, and the data do not allow us to trace an effect of the CBI interventions on emergency care-seeking behavior. Whether moderate improvements in knowledge and routine care are sufficient to result in significant mortality decline cannot be determined.

It is possible that dai training could have had a substantial effect on mortality. Mothers whose delivery was conducted by PC-trained dais seem to have been better cared for in some important ways than mothers delivered in the home by others. These survey data are not in themselves conclusive. However, preliminary data from a more rigorous and detailed comparative operations research study on PC-trained dais and a control group (including client interviews) suggest that PC-trained dais have substantially better routine knowledge and practice than untrained dais, that their clients are more likely to be referred for emergency care, and that those referrals may be for more appropriate reasons. Given the proportion of deliveries conducted by dais, this intervention alone could have led to a decline in perinatal mortality, which would have been limited to the CBI site.

The household survey measured a statistically significant decline in perinatal mortality in the CBI site from 81.4 to 63.0 per 1000 births, or 23 percent, with no decline in the other two sites. With the evidence of other effects in the CBI site, a strong case can be made that a 
package of community-based interventions caused a substantial decline in perinatal mortality.

Apart from its value in evaluating the SMART project, these household surveys have obtained a considerable amount of information about maternal and neonatal health in a rural area of southern Punjab, as well as of community responses to impetus for change. It is to be hoped that these data, analyzed in more detail, can be of considerable use to others in understanding the situation regarding maternal and neonatal health in Pakistan, and in devising means to improve the health of mothers and children in Pakistan. 



\section{Introduction}

The Safe Motherhood Applied Research and Training (SMART) is an operations research project designed to develop and test interventions to reduce maternal and neonatal mortality in a predominantly rural district, Dera Ghazi Khan, in southern Punjab, Pakistan.

\section{Rationale}

High maternal morbidity and mortality, along with high perinatal mortality are serious health problems in South Asia. In Pakistan, every year an estimated 30,000 maternal deaths occur; in other words one woman dies every 20 minutes. Many more suffer from temporary or permanent disabilities. The maternal mortality ratio (MMR) is believed to be around 300500 per 100,000 live births; neonatal mortality is about 50 per 1,000 live births; and perinatal mortality from a multi-centric hospital-based study is 92 per 1,000 births ${ }^{1}$. An integrated approach aimed at improving reproductive health services -- a policy adopted by Government of Pakistan -- and a number of intervention programs and projects are currently being implemented. However, there is a need for developing and conducting community-based and health systems research.

\section{Objectives}

The goal of this project is to develop, implement, and evaluate community-based intervention strategies to help increase the utilization of existing reproductive health services, with the intent of reducing maternal mortality and morbidity in the project sites. Specific objectives are:

- To empower women to take decisions and make choices regarding their own reproductive health and to provide knowledge on safe motherhood issues including nutrition, prenatal care, obstetric danger signs, safe delivery practices and family planning.

- To mobilize and organize community resources to facilitate better utilization of existing reproductive health services, particularly emergency obstetric care.

- To improve the quality, availability, and accessibility of reproductive health services

\footnotetext{
${ }^{1}$ Zaidi, S., The Role of the Obstetrician in Reducing Perinatal Mortality, in Zaidi S., (Ed.), Maternal and Perinatal Health, 1992. Karachi, TWEL Publishers, 115-20.
} 
- To introduce a behavioral change in the manner providers assess the needs of their clients and through a process of enforced information exchange meet their identified needs.

\section{Study design}

The strategy used was to test two sets of interventions (one at the community level and another at the health facility level) and test it against a comparison site. The operations research design is to test two separate intervention packages in D.G. Khan with district Layyah as the comparable, nearby control site. The first package includes a combination of community-based interventions (CBI) and health services interventions (HSI), while the second includes only the HSI.

Figure 1 illustrates the overall study design. In site 1 both health services and communitybased interventions were implemented; only health services interventions were implemented in site 2 .

Figure 1.1: $\quad$ Research Design for the SMART Project

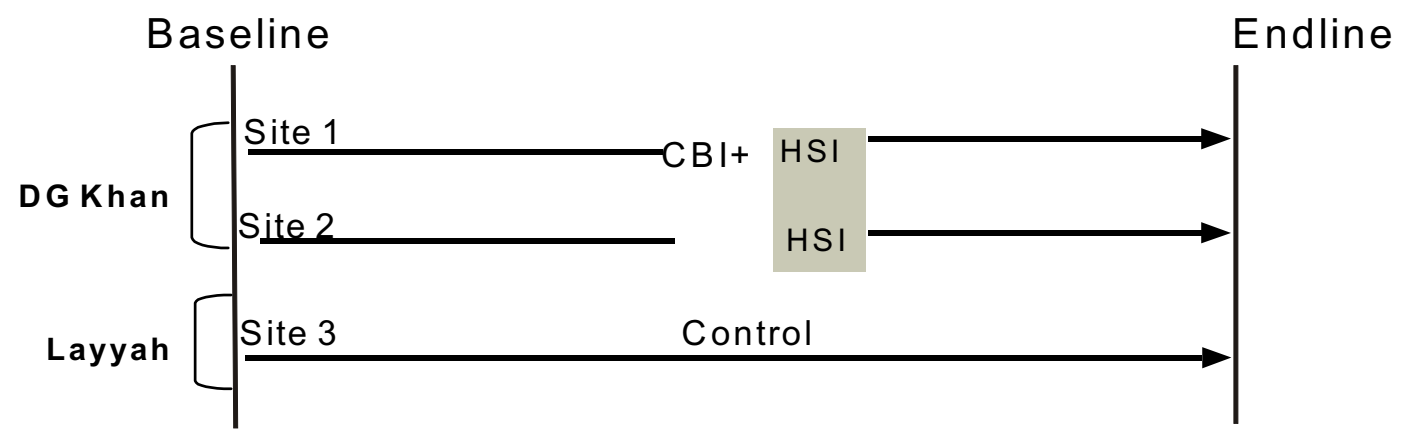

\section{Site selection}

Dera Ghazi Khan was selected as the intervention area and Layyah as the control area after many discussions and site visits and through factor analysis of available data. The aim was to select an average district of Pakistan, which was predominantly rural and had an adjacent district having similar indicators. After excluding the predominantly urban districts, the total number of districts included in the factor analysis was 94 . The factor analysis was carried out on SPSS using the principal components method (see Appendix 1 for detail). The 
Principal Investigator and other senior staff from Population Council then visited the districts that fell in the median band.

Ultimately, Dera Ghazi Khan and Layyah were selected as intervention and control districts respectively (See Appendix 2 for a brief description of these districts). In DG Khan, 120 clusters (mauzas), each having an average population of 5300 (about 590 households), were randomly selected from both DG Khan and Taunsa tehsils, but not the de-excluded area (tribal area); similarly 60 clusters were randomly selected in Layyah. Sixty of the 120 clusters in DG Khan selected at random were designated as 'site 1 ' where the 'HSI plus CBI' packages were implemented, while the other 60 clusters were designated as 'site 2', where the 'HSI only' package was implemented. The 60 clusters of Layyah constituted 'site 3', the control site.

\section{Evaluation design}

The design for evaluating the effectiveness of the interventions consisted of several components, which are described in SMART Report 1. Project Overview. These included a series of formative research studies conducted prior to baselines (see SMART Report 6. Formative Research on Maternal and Neonatal Health); baseline and endline health assessments of the MNH components of the public health system (see SMART Report 4: Knowledge and Behavior of Service Providers); evaluations of particular project components (see SMART Report 2. The Interventions); a verbal autopsy study to investigate the medical and social causes of infant and maternal death (see SMART Report 5. Verbal Autopsies of Infant and Maternal Deaths); and a series of household surveys, which is the subject of the present report.

Baseline and Endline Household Surveys (HHS), with large sample sizes sufficient to measure perinatal mortality, were conducted in all sites. The Baseline Survey was conducted from February to June 2004 in DG Khan and from June to August 2004 in Layyah district. The Endline Survey was carried out from January to May 2006 in both districts. Subsamples of the samples for these surveys were studied in a series of Knowldege, Attitude and Behavior (KAB) Surveys in order to study details of knowledge and behavior in relation to project activities. These were conducted in all three sites at baseline and endline, and for the HSI only and CBI plus HSI areas during program implementation.

Since the 120 clusters in the intervention communities of DG Khan were allocated at random to sites 1 and 2, it may be inferred that, barring measurement error, differences between sites may be ascribed to project interventions. Since Layyah is a different district with 
similar but not completely identical characteristics, and was subject to a different history during the project period, difference between the control area and the intervention sites cannot be strictly inferred to be the result of project activities; they may, however, be taken to indicate how events unfolded during the project period in the absence of the SMART project. 


\section{Survey Methodology}

The HHS was conducted in all three SMART Project arms before and after implementation of the SMART project. Baseline information was collected between February and June 2004, prior to the beginning of any significant implementation activities, which began in July 2004. The endline survey was conducted between February and April 2006, whereas project implementation activities had been substantially completed by June 2005, so that most but not all women who delivered in the six months prior to the endline survey would have become pregnant after implementation in their communities. The KAB was conducted at baseline and endline in all three sites, but the second round of the KAB was conducted in March and April 2005, at a time when most but not all implementation activities had been completed; it covered only the HSI only and HSI plus CBI areas. This second round was essentially a tracking survey, and because its interpretation in relation to project implementation is problematic, most results in this report will include only the baseline and endline results.

\section{Sample design}

For the selection of clusters for each type of intervention (HSI only and CBI plus HSI) in D.G. Khan, the district was divided into two regions, DG Khan Tehsil and Taunsa Tehsil, on the basis of availability of a government hospital (District Headquarters Hospital or Tehsil Headquarters Hospital). Each region was divided into circles by taking one of these hospitals as the center. The first circle was within a 5 kilometer radius from the hospital, the next circle at a 10 kilometer radius, then 15 kilometers and so on. Each circle was divided further into eight parts.

The District Census Report (1998) was used for the selection of clusters. The lowest level at which information was available in the District Census Report (DCR), was the mauza/deh/village; therefore, mauzas, which are rural enumeration units averaging roughly 5,0000 persons each, were defined as clusters for this project. (It should be noted, however, that a mauza is not a unified "community" in either a political or a sociological sense.) In total, 120 clusters were selected from both regions (DG Khan and Taunsa) and at least one cluster was selected from each sub-circle.

These selected clusters were marked on the map, starting from the north end of Taunsa tehsil to the south end of DG Khan tehsil. The clusters were randomly assigned to each 
intervention site (i.e., CBI+HSI site and HSI only site). Each intervention site had 60 clusters. The area where community-plus-facility-based interventions were launched is termed 'site 1 ', whereas the area with only facility-based interventions is termed 'site 2 '. Sixty clusters were randomly selected from rural district Layyah as the control area ('site 3').

Independent samples for the HHS were drawn at baseline and endline; that is, about one in six women who were interviewed in the baseline survey were also interviewed by chance at the endline. For the KAB, with 10 percent independent subsamples, there was also a chance that the same household could have been randomly chosen in two or even three rounds.

\section{Sample size}

\section{Household survey}

The main objective of the SMART project was to reduce the maternal mortality ratio (MMR). To measure MMR, a survey of more than 100,000 households would have been required, but it was not possible to conduct such a large survey within available resources. It was therefore proposed to have a proxy indicator for the MMR; we decided on the perinatal mortality rate (PNMR) for this purpose. On the basis of an estimated existing perinatal mortality rate of 85 per 1000 and a requirement of detecting a 30 percent reduction with 95 percent confidence and 80 percent power, a sample size of 7,000 married women of reproductive age (MWRA) for each area was proposed.

The parameters used in the sample design were thus as follows:

- Initial perinatal mortality rate: 85 stillbirths plus early neonatal deaths per 1000 live births plus stillbirths

- minimum measurable difference (d): $30 \%$;

- required confidence level (1-?): 95\%

- power (1-?): $80 \%$

- $\quad$ estimated design effect: 2.0 .

\section{KAB survey}

For all rounds of the KAB survey, the 10 percent subsample of the HHS sample was designed to yield about 700 MWRA per site. It was felt that this would be sufficient to yield useful indicators of a variety of tracking variables, albeit with greater sampling errors than the HHS. 


\section{Sampling methodology}

\section{Household survey}

A two-stage cluster sampling technique was applied; clusters (mauzas) were selected and households were drawn from each selected cluster. For the selection of the clusters at the first stage and of households at the second stage, different sampling methodologies were applied in the two districts. These differences, described below, did not affect the probability of a household's selection for the survey.

Intervention area (DG Khan). At the first stage the clusters were selected using simple random sampling (SRS), and at the second stage equal proportions (20 percent) of households were sampled from each selected cluster by using systematic random sampling. All married women of reproductive age from the selected households were eligible for inclusion in the study.

Control area (Layyah). In the control area, clusters were selected with probability proportional to size (PPS) at the first stage and equal numbers of households (120) were selected using systematic random sampling at the second stage. All married women of reproductive age from selected households were eligible for inclusion in the study.

\section{KAB survey}

The KAB subsamples were drawn at random from the HHS samples, with HHS round 1 used for KAB 1 and $K A B 2$, and HHS round 3 used for KAB 3. Between rounds these samples were independent; that is, if by chance an individual were chosen in more than one $\mathrm{KAB}$ round, the interview was accepted.

\section{Household listing}

After the selection of clusters both in DG Khan and Layyah, household lists were prepared by visiting each house in the selected clusters. These household listings were used as the frame to select households from clusters.

\section{Questionnaires}

Questionnaires differed substantially between the HHS and the KAB. The HHS questionnaire consisted of three parts. The first part collected information about households, 
including size, each member by age, marital status, and employment history, ownership of durable goods, source of drinking water, type of latrine etc. The second part collected information from all currently married women aged less than 50 years on sociodemographic characteristics of the women and family planning knowledge and use. Part three gathered information on the last pregnancy within one year prior to the survey, including information about last pregnancy such as outcome, type of birth attendant, and history of complications during pregnancy, delivery and/or within 40 days after delivery.

The KAB questionnaire collected information from married women aged less than 50 on women's knowledge of danger signs of pregnancy, delivery, the post-partum period and the newborn. It also collects information about women's exposure to and participation in SMART project activities, and on various dimensions of women's autonomy.

\section{Training and fieldwork}

\section{Household survey}

Six teams (consisting of 5 female interviewers, a female supervisor and a male for logistics) for the baseline survey and eight teams for the endline survey were recruited locally and trained for four weeks in DG Khan. Training of the interviewers was held during January 2004 for the baseline survey and during January 2006 for the endline survey. Fieldwork was conducted from February to June 2004 for the baseline survey and from February to April 2006 for the endline survey.

\section{KAB survey}

A team of five female interviewers for DG Khan and three female interviewers for Layyah were trained to collect $\mathrm{KAB}$ information. Training of the interviewers was held during June 2004 for KAB-1, in June-July 2005 for KAB-2, and in January 2006 for KAB-3. Fieldwork was conducted from June to July 2004 for KAB-1 survey, March to April for KAB-2 and January to April 2006 for KAB-3.

\section{Quality control}

Initially, qualified female interviewers (with at least graduation) were recruited from each district. Six experienced and qualified female supervisors were recruited and were involved from the beginning of the study. These six supervisors had been involved in conducting indepth interviews and focus group discussions (FGDs) to learn about the terminology, 
perceptions and existing behavior patterns regarding maternal and newborn health. This information was used to refine the draft questionnaire. Then the same supervisors were used for the field-testing of the draft questionnaire in local languages. These supervisors assisted in training and spent considerable time with each female interviewer during training sessions, role-plays and group discussions. These supervisors led their respective teams in the field.

During the fieldwork, these supervisors observed the female interviewers during the interview process with the respondents and identified areas for improvement, such as interviewing techniques. Supervisors were responsible for checking the questionnaires. If they found any missing or incorrect information, the interviewer was sent back to the household to complete or correct the information. Completed questionnaires were then sent to the SMART project office and were checked, edited and coded by a well-trained team of female editors. If these editors found any mistake or unclear information, then these questionnaires were sent back to the field for correction.

After editing, questionnaires were sent for data entry at project headquarters in DG Khan. Range checks, rule checks, etc., were made using the PC Edit software to identify those mistakes which were overlooked by editors. These mistakes were immediately reported to editors and then to field teams.

\section{Sample coverage}

\section{Household survey}

A list of all households in the selected clusters in both DG Khan and Layyah was prepared. According to these lists, there were 35,507 households in Arm 1, 34,529 households in Arm 2 and 18,702 in Arm 3. It was initially estimated that one in five households would be enough to obtain the required number of married women of reproductive age (MWRA), assuming on average one MWRA per household. However, during initial days of fieldwork for the baseline household survey in DG Khan, a ratio of 1.45 MWRA per household was found; therefore, the principal investigator decided to change the requirement to one in six of the listed households.

Teams visited selected households and interviewed all married women of reproductive age in each selected household. The household was replaced with the next household in the list if: 
- The household was locked and no household member was available during the team's stay in the community.

- The household was listed twice

- The household had shifted to other areas or could not be located

In case of refusal, interviewers did not replace the household. In total, 149 households $(0.8 \%)$ declined to give information in the baseline survey and 104 households $(0.5 \%)$ in the endline survey.

The number of households, currently married women of reproductive age actually interviewed, and births in the previous 12 months by round and study site, are shown in table 2.1.

Table 2.1: Numbers of households, currently married women of reproductive age, and live births, by study site and HHS round

\begin{tabular}{lrrrrrr}
\hline \multirow{2}{*}{ Sample } & \multicolumn{2}{c}{ Site 1 } & \multicolumn{2}{c}{ Site 2 } & \multicolumn{2}{c}{ Site 3 } \\
\cline { 2 - 7 } & Baseline & Endline & Baseline & Endline & Baseline & Endline \\
\hline Households & 5,945 & 6,052 & 5,784 & 5,952 & 7,004 & 7,089 \\
$\begin{array}{l}\text { Married women of } \\
\text { reproductive age }\end{array}$ & 8,348 & 8,707 & 8,026 & 8,666 & 7,039 & 7,296 \\
Live births in past year & 2,001 & 1,946 & 1,969 & 1,955 & 1,531 & 1,542 \\
\hline
\end{tabular}




\section{KAB survey}

Numbers of women interviewed and births in the previous 6 months are shown in table 2.2.

Table 2.2: Numbers of women interviewed and of live births in previous 6 months, by study site and KAB round

\begin{tabular}{llrr}
\hline Arm & Round & No. women interviewed & Births (during last 6 months) \\
\hline Site 1 & KAB 1 & 672 & 65 \\
& KAB 2 & 990 & 102 \\
& KAB 3 & 655 & 93 \\
Site 2 & KAB 1 & 769 & 83 \\
& KAB 2 & 816 & 88 \\
& KAB 3 & 602 & 105 \\
Site 3 & KAB 1 & 627 & 105 \\
& KAB 3 & 611 & 97 \\
\hline
\end{tabular}

\section{A note on sampling errors and statistical significance}

In general, tests of significance for data from household surveys should be calculated from estimates of variance based on the actual sample design used. For a typical stratified cluster survey design, actual standard errors of means, proportions, and other statistics are greater than they would be if the data had been collected with simple random sampling. A measure of the degree of the standard error increase is the "design effect", sometimes called "deft", which is the ratio of the standard error calculated from the actual sample design to the standard error calculated as if from a simple random sample.

To make such calculations, specialized software is available in various statistical packages. As of the writing of this report, we had only begun to apply this software. Initial applications focused on the mortality variables - specifically the perinatal mortality rate since this was the subject of the explicit hypothesis on which the study design was based, and for which the mathematics of hypothesis testing can be properly applied. Confidence intervals for mortality variables are therefore presented in the text of Chapter 9.

For other topics elsewhere in the text, we have not had time to test for significance of differences, and indeed such tests are not strictly appropriate, since they do not reflect $a$ priori hypotheses. A reader who chooses to apply ordinary proportion tests to these data should be warned that $\mathrm{p}$-values computed from such tests will generally be substantially 
smaller than those properly calculated on the basis of the sample design. Appendix 4 gives sample statistics on some selected key variables, which may provide guidance on the magnitude of design effects for this survey. Since the SMART household survey involves fairly large numbers of respondents per cluster, design effects are often substantial. 


\section{Household Characteristics}

There are two basic purposes of collecting information about household characteristics in baseline and endline surveys. First, this information will be used to construct a proxy indicator for the socio-economic status of the household. Second, it helps in understanding how similar or dissimilar baseline and end-line sample populations are.

Under this heading, information is collected about household size, structure of the house, source of drinking water, type of latrine available, access to other facilities such as electricity, telephone etc., household durables, and ownership of agricultural land. Some of these characteristics could also be directly related to the project objectives. For example, availability of safe drinking water and proper latrines can directly contribute to the health of the mother and newborn. Ownership of a television can be a source of information related to maternal and child health.

In general, findings of the surveys reported in chapters 3 and 4 of this report show three overall tendencies. First, households in site 1 and site 2 are generally similar, i.e., that the randomization process was effective. Second, DG Khan (site 1 and site 2) differs from Layyah (site 3) in various ways, some of which have implications for maternal and neonatal health. Third, there is a tendency towards modest positive change in a variety of general development indicators in all three arms between baseline and endline surveys, which are not related to project activities, and are broadly consistent with national changes occurring during this period.

\section{General characteristics and facilities}

Table 3.1 shows a range of household characteristics and facilities by study arm and survey round.

\section{Size}

On average, households in the intervention areas are larger (9.0 persons) than households in the control area (7.6 persons). 


\section{Structure of house}

At baseline, more than half of the houses in both areas (intervention and control) were made of mud (kutcha). There were dissimilarities between areas regarding structure of the house. There were more pucca houses in Layyah (24 percent) than in DG Khan (see table 3.1). At the time of the endline survey, the pattern was similar, but with slightly more households in each area of pucca construction.

\section{Source of drinking water}

Availability of safe drinking water helps in improving the health of household members in general, including maternal and newborn health.

Hand-pump water was the main source of drinking water for the vast majority of households in both areas. However, government water supply was available to some households in the intervention areas (see table 3.1).

Table 3.1: Selected household characteri stics and facilities, by site and HHS round

\begin{tabular}{lrrrrrr}
\hline & \multicolumn{2}{c}{ Site 1 } & \multicolumn{2}{c}{ Site 2 } & \multicolumn{2}{c}{ Site 3 } \\
\cline { 2 - 7 } Characteristic & Baseline & Endline & Baseline & Endline & Baseline & Endline \\
\hline Household size & 9.2 & 9.2 & 9.0 & 9.4 & 7.6 & 7.9 \\
Structure of house & & & & & & \\
$\quad$ Pucca & 18.4 & 21.7 & 15.4 & 17.5 & 23.9 & 26.4 \\
Semi Pucca & 25.0 & 21.0 & 23.9 & 24.9 & 24.2 & 32.4 \\
$\quad$ Kutcha & 56.6 & 57.4 & 60.7 & 57.5 & 51.9 & 41.2 \\
Source of drinking water & & & & & & \\
$\quad$ Govt water supply & 9.1 & 12.7 & 15.9 & 21.5 & 2.1 & 0.7 \\
$\quad$ Hand-pump & 83.7 & 81.7 & 78.2 & 72.6 & 97.8 & 99.1 \\
$\quad$ Other & 7.2 & 5.6 & 5.9 & 5.9 & 0.0 & 0.2 \\
Type of latrine & & & & & & \\
$\quad$ Flush connected to septic tank & 22.2 & 28.7 & 19.1 & 24.6 & 30.8 & 38.2 \\
$\quad$ Flush pit latrine & 8.5 & 5.7 & 7.7 & 7.3 & 5.2 & 2.2 \\
$\quad$ Other & 0.1 & 0.6 & 1.2 & 0.6 & 0.1 & 0.3 \\
$\quad$ No latrine in house & 69.2 & 65.0 & 72.0 & 67.5 & 63.9 & 59.4 \\
Electricity connection & 71.5 & 78.0 & 69.1 & 75.5 & 59.4 & 64.7 \\
Telephone: land line & 5.6 & 7.4 & 4.6 & 6.1 & 3.9 & 7.2 \\
$\quad$ Mobile phone & 4.1 & 19.3 & 3.6 & 15.4 & 0.3 & 12.8 \\
No. of households & 5,945 & 6,052 & 5,784 & 5,951 & 7,002 & 7,089 \\
\hline
\end{tabular}


Though patterns of drinking water by site were basically the same during the endline survey, slightly more households reported availability of government water supply in the intervention areas, indicating some improvement in DG Khan but not in Layyah.

\section{Toilet facilities}

Along with the source of drinking water, toilet facilities are a major indicator of a household's socio-economic status as well as the level of hygiene, sanitation, and comfort available to an expectant or new mother. The type of toilet facility in a household directly affects morbidity and mortality. Households lacking hygienic toilet facilities run a higher risk of disease and infection, which in turn puts the health of newborn children as well as their mothers at risk.

A majority of households in the intervention and control areas lacked access to a proper toilet facility inside the house (table 3.1). This situation improved slightly between rounds in each site.

\section{Electricity}

Most households in rural DG Khan and Layyah had an electricity connection, with the proportion somewhat higher in DG Khan (table 3.1 and figure 3.1). Availability of electricity connections increased during the project period by about 6 percent in each site.

\section{Telephone connections}

Telephone connections (either land line or cellular) are considered status symbols in rural Pakistan, but are also very useful communication tools. From a safe motherhood point of view a telephone can be used to call emergency transport, seek advice, or arrange for referral. During the last couple of years, access to telephone connections, particularly mobile ones, has increased tremendously in Pakistan due to a rapid expansion of mobile networks in rural areas along with reduced connection and call charges. This is reflected in all three sites (table 3.1 and figure 3.1). The availability of these telephones could have a significant effect on maternal and newborn deaths through improving communication between service providers and patients as well as with potential transporters. 
Figure 3.1: Percentage of households with electricity and telephone

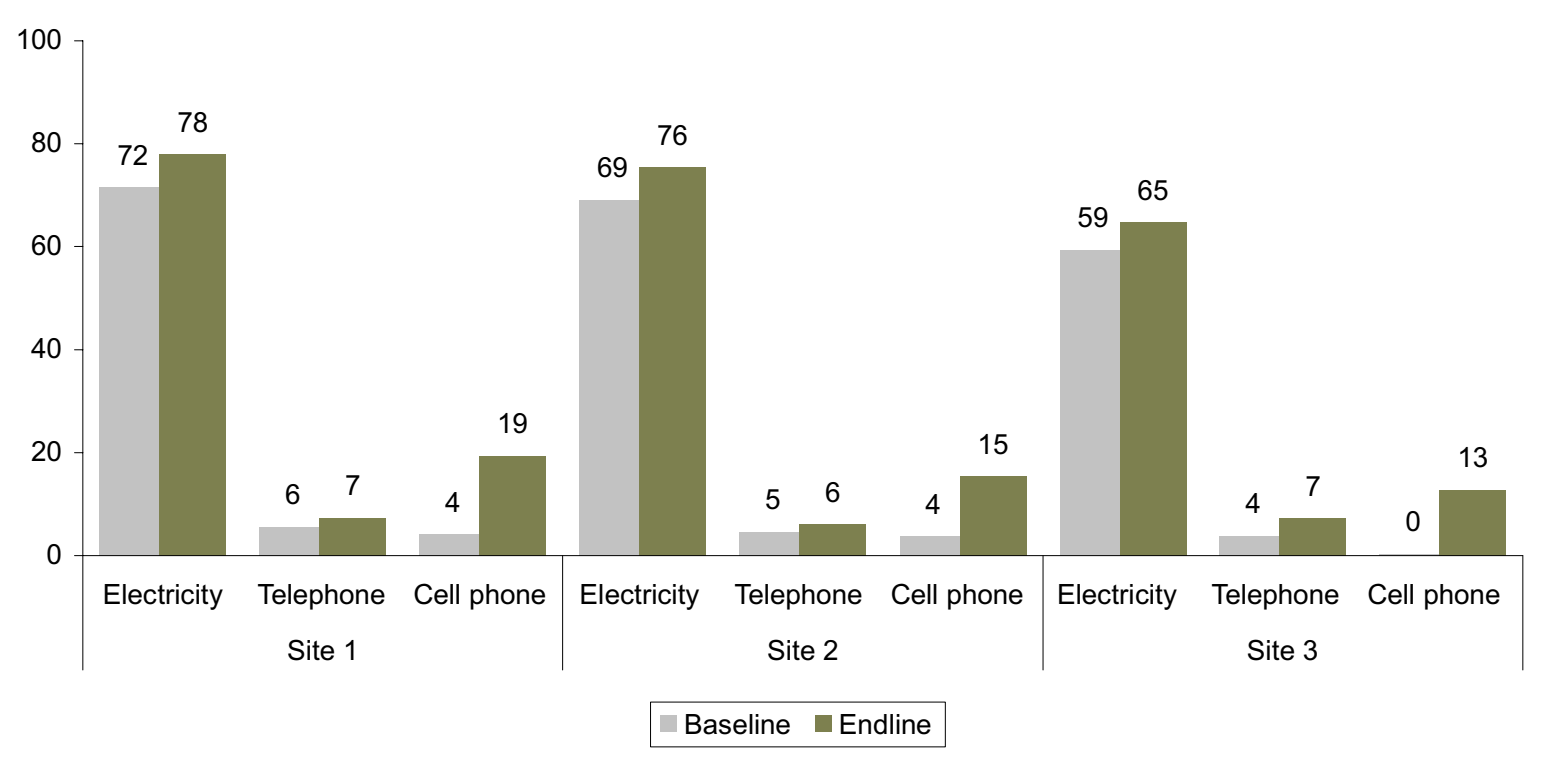

\section{Household assets}

\section{Consumer durables}

Table 3.2 shows data on household assets and land ownership. Household assets are used to determine the socio-economic status (SES) of the household. Often it is easier to obtain information on household possessions than on household income, which respondents may be less willing to provide. In addition, certain goods may have a direct bearing on health, such as televisions (for information) and refrigerators (for preservation of food)

All three sites had similar asset levels, indicating similar socio-economic status. There were some slight differences between DG Khan and Layyah in ownership of some assets, but these differences do not consistently favor either district, site 3 reporting higher ownership of agricultural land and sewing machines, and site 1 reporting greater ownership of washing machines. For other assets, there was a similar degree of ownership in all sites.

At the time of the endline survey, somewhat more households reported having certain significant household assets such as televisions, sewing machines, and motorcycles. These increases are generally modest. Part of this increase is probably genuine, but part could be due to improved trust between the interviewers and the communities. Some of these 
increases may also be due to increased availability of electricity. For other items ownership remained about the same or (as with radio and audio cassette) declined.

\section{Table 3.2: Household assets and agricult ural land ownership by site and HHS} round

\begin{tabular}{lrrrrrr}
\hline \multirow{2}{*}{ Household asset } & \multicolumn{2}{c}{ Site 1 } & \multicolumn{2}{c}{ Site 2 } & \multicolumn{2}{c}{ Site 3 } \\
\cline { 2 - 7 } & Baseline & Endline & Baseline & Endline & Baseline & Endline \\
\hline Household asset & & & & & & \\
Radio & 25.2 & 22.6 & 22.1 & 17.7 & 18.2 & 13.4 \\
Television & 18.7 & 25.9 & 15.8 & 20.5 & 17.7 & 25.2 \\
Cassette player & 27.1 & 25.7 & 22.2 & 20.0 & 23.1 & 21.1 \\
Sewing machine & 32.1 & 35.7 & 30.7 & 32.7 & 43.6 & 50.5 \\
Fridge & 12.9 & 13.3 & 11.1 & 10.8 & 12.5 & 12.8 \\
Desert cooler & 7.7 & 8.8 & 7.2 & 6.9 & 7.2 & 5.6 \\
Washing machine & 15.0 & 16.9 & 13.1 & 15.3 & 11.4 & 12.3 \\
Tractor & 5.8 & 5.6 & 5.7 & 5.0 & 5.8 & 6.4 \\
Motorcycle & 11.2 & 17.6 & 10.8 & 15.2 & 8.3 & 10.4 \\
Bicycle & 46.6 & 46.7 & 46.1 & 44.7 & 45.1 & 46.5 \\
Car/jeep & 3.2 & 2.8 & 2.8 & 2.0 & 2.0 & 2.0 \\
Own agricultural land & 46.2 & 44.9 & 47.1 & 43.4 & 56.7 & 56.4 \\
Agricultural land size & & & & & & \\
No land & 53.8 & 55.1 & 52.9 & 56.6 & 43.3 & 43.6 \\
1-5 acres & 30.1 & 30.5 & 29.7 & 29.0 & 33.1 & 34.7 \\
6-12 acres & 8.3 & 8.0 & 7.5 & 7.8 & 12.5 & 12.5 \\
13-25 acres & 3.1 & 3.0 & 3.1 & 2.8 & 6.0 & 5.7 \\
26 + acres & 1.7 & 1.3 & 2.0 & 1.4 & 2.0 & 2.5 \\
Do not know & 3.0 & 2.1 & 4.8 & 2.4 & 3.1 & 1.1 \\
Total & 100.0 & 100.0 & 100.0 & 100.0 & 100.0 & 100.0 \\
No. of households & 5,945 & 6,052 & 5,784 & 5,951 & 7,004 & 7,089 \\
\hline
\end{tabular}

\section{Agricultural land}

Fewer than half the households in D G Khan and more than half in Layyah reported owning agricultural land, most commonly fewer than 5 acres. In DG Khan, there was a small but significant decline; somewhat fewer households from sites 1 and 2 reported ownership of agricultural land at endline than at baseline. 


\section{Ethnicity}

Ethnicity can have strong effects on health-seeking behavior. Using language as a marker for ethnicity, both in DG Khan and Layyah Saraiki speakers are a substantial majority. In DG Khan Balochi speakers, who have lived in the district for generations, tend to be an impoverished minority. In Layyah the Punjabi minority has immigrated into the district during the last generation or two and tends to be upwardly mobile.

Figure 3.2: Distribution of households according to language spoken at home

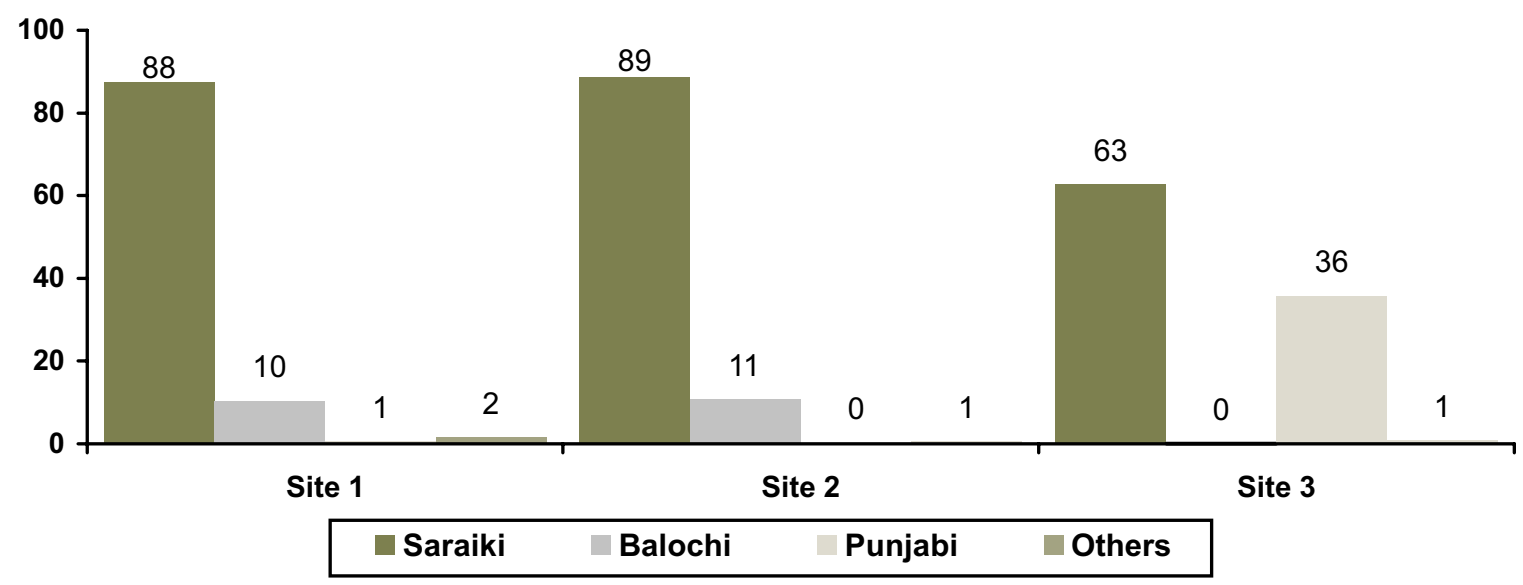

A wealth score was calculated based on the ownership of household assets, and this score was divided into approximate quintiles. Balochi household are poorer and Punjabi are richer, and Seraiki households fall in between. For example 60 percent of Balochi households, 52 percent of Seraiki, and 33 percent of Punjabi households lie in the first two quintiles. These differences can be important factors in maternal and neonatal health. 


\section{IV: Demographic and Social Characteristics of Married Women of Reproductive Age}

\section{Demographic characteristics}

Socio-demographic characteristics of the married women of reproductive age (MWRA) in the sample are presented in table 4.1. In all sites, demographic characteristics are similar at baseline and endline.

\section{Age}

Women in Dera Ghazi Khan have a distinct pattern of lower age at marriage and higher fertility than those in Layyah. On average respondents in DG Khan were almost three years younger than women in district Layyah. At the time of the baseline survey, almost one-fifth of women from the intervention area were under 20 years of age compared with only 9 percent in the control area. Pregnancy rates are higher among younger married women, whose chances of facing maternal health complications are higher compared to women in their 20s and 30s. Therefore, more women in the intervention area are at greater risk of developing complications due to young age.

\section{Table 4.1: Demographic characteristics of married women of reproductive} age, by site and HHS round

\begin{tabular}{lrrrrrrr}
\hline & \multicolumn{3}{c}{ Site 1 } & \multicolumn{2}{c}{ Site 2 } & \multicolumn{2}{c}{ Site 3 } \\
\cline { 3 - 7 } Characteristic & Baseline & Endline & Baseline & Endline & Baseline & Endline \\
\hline Age & & & & & & \\
& Less than 20 & 19.9 & 17.7 & 19.2 & 18.5 & 8.9 & 7.8 \\
& $20-24$ & 21.9 & 21.5 & 21.2 & 20.2 & 17.4 & 17.3 \\
$25-29$ & 19.0 & 19.1 & 19.4 & 18.8 & 19.4 & 20.6 \\
$30-34$ & 14.4 & 14.8 & 15.6 & 16.3 & 19.6 & 19.9 \\
$35-39$ & 11.5 & 11.5 & 11.9 & 11.7 & 16.2 & 15.7 \\
$40-44$ & 8.8 & 9.2 & 8.2 & 8.7 & 11.5 & 12.0 \\
& $45-49$ & 4.4 & 6.0 & 4.7 & 5.7 & 7.0 & 6.6 \\
& Mean (years) & 27.8 & 28.5 & 28.0 & 28.5 & 30.9 & 31.0
\end{tabular}




\begin{tabular}{lrrrrrr}
\hline & \multicolumn{2}{c}{ Site 1 } & \multicolumn{2}{c}{ Site 2 } & \multicolumn{2}{c}{ Site 3 } \\
\cline { 2 - 7 } Characteristic & Baseline & Endline & Baseline & Endline & Baseline & Endline \\
\hline Age at first marriage & & & & & & \\
Less than 15 & 57.6 & 54.0 & 56.6 & 53.7 & 21.1 & 17.7 \\
15-19 & 37.9 & 41.1 & 38.7 & 41.7 & 56.9 & 58.2 \\
$20-24$ & 3.8 & 4.1 & 4.1 & 3.7 & 17.9 & 19.2 \\
25 and more & 0.7 & 0.7 & 0.6 & 0.9 & 4.0 & 5.0 \\
Mean age at marriage (years) & 14.6 & 14.8 & 14.7 & 14.8 & 17.2 & 17.5 \\
Number of living children & & & & & & \\
0 & 14.7 & 13.0 & 14.8 & 13.4 & 12.9 & 11.2 \\
1-2 & 26.2 & 25.2 & 25.3 & 25.7 & 23.3 & 25.1 \\
3-4 & 22.8 & 24.4 & 23.7 & 23.4 & 24.5 & 25.8 \\
5-6 & 18.6 & 18.8 & 18.7 & 19.3 & 21.3 & 21.6 \\
$7+$ & 17.7 & 18.5 & 17.5 & 18.3 & 18.0 & 17.3 \\
Mean number of living children & 3.65 & 3.78 & 3.66 & 3.76 & 3.84 & 3.84 \\
No. of respondents & 8,331 & 8,693 & 8,014 & 8,652 & 6,897 & 7,287 \\
\hline
\end{tabular}

\section{Age at first marriage}

The mean age at first marriage of survey respondents is low, and did not change between rounds. However, age at marriage is significantly higher in Layyah than in DG Khan -- one of several indicators that the fertility transition is further along in Layyah than in D.G. Khan. In DG Khan, more than half of respondents reported first marriage before age 15. However, it should be noted that these data are from women already married at the time of the survey; thus, for example, married women 15-19 at the time of the survey must have married before age 19. Hence, the mean age at marriage from a sample of currently married women of reproductive age substantially underestimates the average age at which women marry.

For this reason, we calculate 'singulate mean age at marriage' (SMAM), which estimates the average number of years lived in the single state in the population. As an estimate of current age at first marriage, it assumes that age at marriage has remained constant during the previous generation. In fact, age at marriage has gradually been increasing in Pakistan for several decades, so the SMAM in this case probably slightly underestimates current age at marriage. Data presented in figure 4.1 show that women in the intervention area get married much earlier than women in the control area. Singulate mean age at marriage has slightly increased during the project period in all three sites, from 18.3 to 18.8 years in the two intervention sites combined, and from 25.2 to 25.8 years in the control site. 
Figure 4.1: Singulate mean age at marriage (SMAM) and total fertility rates

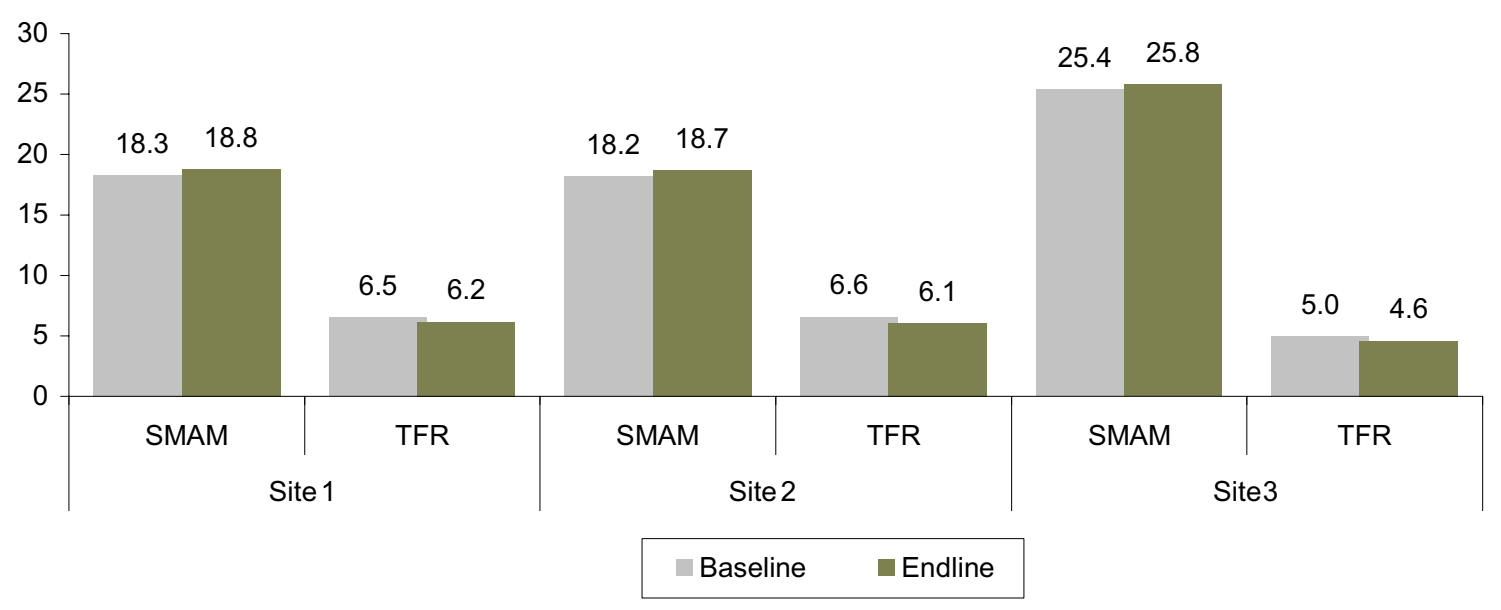

\section{Number of living children}

Despite women marrying at younger ages in DG Khan, the average number of children is about the same as in Layyah; currently married women in the baseline survey reported having 3.7 living children in all three arms. Mean numbers of living children remained the same at the endline survey.

\section{Fertility}

If women of younger ages in DG Khan have the same number of children as those in Layyah, the implication is that their fertility must be higher. Indeed, the total fertility rate (TFR) in the intervention area is higher than in the control area (figure 4.1), by about one and one-half children. The TFR declined in both areas by nearly half a child per woman between the baseline and the endline.

\section{Social characteristics of women and their husbands}

\section{Maternal education}

As expected, the educational level of women in these areas was very low. Data from baseline survey presented in table 4.2 show that a large majority of women had never been to school (88 percent in the intervention areas and 80 percent in the control area). However, a small proportion ( 6 percent) of women had completed primary schooling, more in the control than in the intervention area. There was little difference between baseline and endline in educational attainment. 
Table 4.2: Socio-economic characterist ics of married women of reproductive age and husbands, by site and HHS round

\begin{tabular}{|c|c|c|c|c|c|c|}
\hline \multirow[b]{2}{*}{ Characteristic } & \multicolumn{2}{|c|}{ Site 1} & \multicolumn{2}{|c|}{ Site 2} & \multicolumn{2}{|c|}{ Site 3} \\
\hline & Baseline & Endline & Baseline & Endline & Baseline & Endline \\
\hline \multicolumn{7}{|l|}{ Education } \\
\hline No schooling & 87.5 & 85.7 & 87.7 & 87.6 & 79.6 & 77.6 \\
\hline Less than primary & 4.1 & 4.2 & 3.9 & 4.1 & 3.9 & 4.8 \\
\hline Primary & 3.8 & 4.1 & 3.7 & 3.3 & 8.7 & 9.5 \\
\hline More than primary & 4.6 & 6.1 & 4.7 & 5.0 & 8.0 & 8.1 \\
\hline Literate & 12.2 & 13.9 & 11.6 & 12.6 & 19.8 & 21.3 \\
\hline Working for income & 53.9 & 50.2 & 54.6 & 51.3 & 40.4 & 46.2 \\
\hline \multicolumn{7}{|l|}{ Type of work* } \\
\hline Agriculture related & 71.8 & 64.5 & 67.7 & 65.1 & 71.5 & 77.0 \\
\hline Raising livestock & 7.3 & 6.1 & 2.9 & 5.7 & 9.6 & 16.5 \\
\hline Stitching/ embroidery & 24.9 & 30.6 & 31.8 & 33.6 & 11.6 & 9.5 \\
\hline Carpet-weaving & 3.4 & 3.5 & 2.1 & 2.2 & 3.1 & 3.5 \\
\hline \multicolumn{7}{|l|}{ Husband's education } \\
\hline No schooling & 52.9 & 52.7 & 54.7 & 52.8 & 44.7 & 42.5 \\
\hline Up to primary & 16.7 & 15.4 & 16.3 & 17.6 & 18.6 & 20.7 \\
\hline Middle & 11.1 & 11.0 & 10.2 & 10.6 & 13.4 & 13.6 \\
\hline Secondary & 19.4 & 20.9 & 18.7 & 19.1 & 23.3 & 23.2 \\
\hline \multicolumn{7}{|l|}{ Husband's occupation } \\
\hline Agriculture & 38.3 & 38.0 & 40.8 & 36.7 & 39.2 & 38.1 \\
\hline Government services & 6.7 & 6.2 & 6.9 & 6.8 & 7.1 & 6.7 \\
\hline Private services & 2.0 & 2.3 & 2.0 & 2.3 & 2.4 & 2.3 \\
\hline Self-employed & 9.6 & 8.9 & 9.3 & 7.7 & 10.2 & 10.3 \\
\hline Laborer & 34.9 & 37.2 & 32.9 & 37.6 & 36.5 & 36.6 \\
\hline Unemployed & 6.3 & 5.9 & 5.8 & 7.1 & 3.7 & 3.6 \\
\hline Others & 2.2 & 1.6 & 2.3 & 1.8 & 0.5 & 1.2 \\
\hline No. of respondents & 8,331 & 8,693 & 8,014 & 8,652 & 6,897 & 7,287 \\
\hline
\end{tabular}

* More than one type of work per woman is possible

\section{Women's employment}

More women are working for income in the intervention area (54 percent) than in the control area (40 percent; see table 4.2). There was a decline in the proportion of working women in the intervention area and an increase in the control area between baseline and endline. Most working women are involved in agriculture-related activities, followed by stitching and embroidery. 
The decline in proportion of women working for income in DG Khan and the increase in Layyah could be due to the timing of the survey. For the endline survey in DG Khan, those clusters where most households are involved in harvesting and it is difficult to find women at home during the daytime, were covered before the start of harvesting season. In Layyah, the baseline was conducted in June to September 2004 and the endline survey was carried out from January to April 2004, which is harvest time; the increase in the proportion of working women could therefore have been due to the timing of the survey.

\section{Women's autonomy}

Women's autonomy plays an important role in improving women's care seeking behavior. Women with higher levels of autonomy are more likely to seek treatment for maternal and newborn health problems. Data on women's autonomy were obtained only in the KAB questionnaires; therefore sample sizes are smaller than for other social indicators.

For this report, women's autonomy is measured in three areas: level of participation in decision-making, control over finances, and level of mobility. A composite index was developed based on a battery of questions for each area of autonomy. The index for decision-making consists of five questions: Who makes the decision for treatment when respondent is sick? Who makes the decision to get treatment during pregnancy? Who makes the decision about place of treatment? Who makes the decision for treatment when your husband is sick? Who makes the decision for treatment of your sick children?

The index for control over finances comprises three questions as follows: Can you spend money for the treatment of your husband's sickness? Can you spend money for the treatment of your sickness? Can you spend money for the treatment of your child's sickness?

The index of mobility contains five questions: Can you go alone to the nearest field? Can you go to a market alone? Can you go the next village alone? Can you go to the nearest BHU/RHC alone? Can you go to the THQ/DHQ hospital alone? For each index, women's autonomy was classified as "none" if all questions were answered in the negative, "full" if all questions were positive, and "some" for responses in between.

Table 4.3 shows responses to the three indexes, for the three study sites combined, in KAB rounds 1 and 3 . According to the criteria of our indices, women at baseline reported more autonomy in household finances than in decision-making or mobility. By endline, women reported somewhat less autonomy in household decision-making, but substantially more 
control over finances and freedom of movement. These changes were greater in DG Khan than in Layyah. Responses to question such as these typically combine actual individual characteristics with normative standards of behavior, and are sensitive to the nature of the questions asked, to the level of comfort between the interviewer and the respondent, and to respondent expectations. For example, it is possible that the SMART project, coupled with repetition of the interview process, led to changes in response patterns on these questions which may have been more normative than behavioral in nature.

Table 4.3: Proportion of women with no, some or full autonomy according to topic by KAB round, all sites combined

\begin{tabular}{|c|c|c|c|c|c|c|c|c|}
\hline \multirow{3}{*}{ Topic } & \multicolumn{8}{|c|}{ Degree of autonomy } \\
\hline & \multicolumn{2}{|c|}{ None } & \multicolumn{2}{|c|}{ Some } & \multicolumn{2}{|c|}{ Full } & \multicolumn{2}{|c|}{ Total } \\
\hline & No. & Pct. & No. & Pct. & No. & Pct. & No. & Pct. \\
\hline \multicolumn{9}{|c|}{ Power in decision-making } \\
\hline Round 1 & 1514 & 73.3 & 289 & 14.0 & 263 & 12.7 & 2066 & 100.0 \\
\hline Round 3 & 1550 & 83.1 & 126 & 6.8 & 189 & 10.1 & 1865 & 100.0 \\
\hline \multicolumn{9}{|l|}{ Control over finances } \\
\hline Round 1 & 1013 & 49.0 & 609 & 29.5 & 444 & 21.5 & 2066 & 100.0 \\
\hline Round 3 & 508 & 27.3 & 541 & 29.0 & 815 & 43.7 & 1864 & 100.0 \\
\hline \multicolumn{9}{|c|}{ Freedom of movement } \\
\hline Round 1 & 1581 & 76.6 & 387 & 18.7 & 97 & 4.7 & 2065 & 100.0 \\
\hline Round 3 & 991 & 53.1 & 484 & 26.0 & 390 & 20.9 & 1865 & 100.0 \\
\hline
\end{tabular}

\section{Women's involvement in decision-making}

Figure 4.1 shows changes in the proportions reporting full involvement in household decision-making processes. Over a period of time, women's involvement in decisionmaking process was reduced in site 1 but not in sites 2 or 3 . This may be the result of greater male involvement in $\mathrm{MNH}$ in site 1, which was one of the aims of the community mobilization component. 
Figure 4.1: Percentage of women with full decision making power

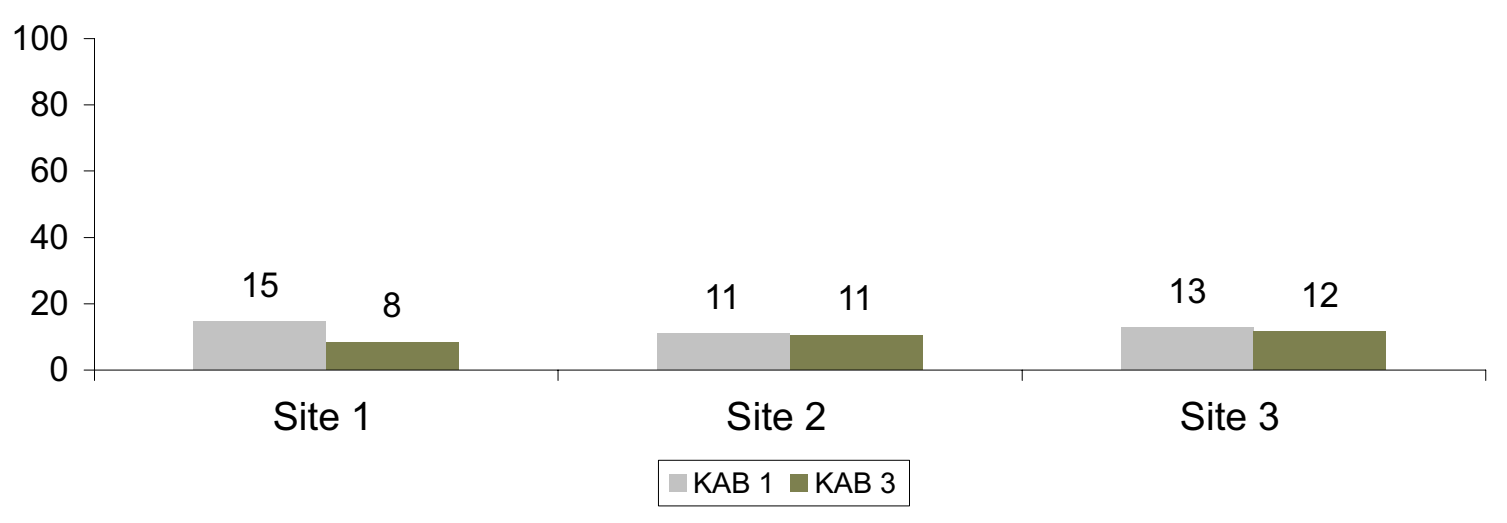

\section{Control over finances}

Women's control over finances increased in all three areas between rounds, especially in site 1. Given that the index deals with health expenditure, it may be that CBI activities had an effect on this, but the substantial increases in the other sites suggests other influences as well.

Figure 4.2: Percentage of women with full control over finances

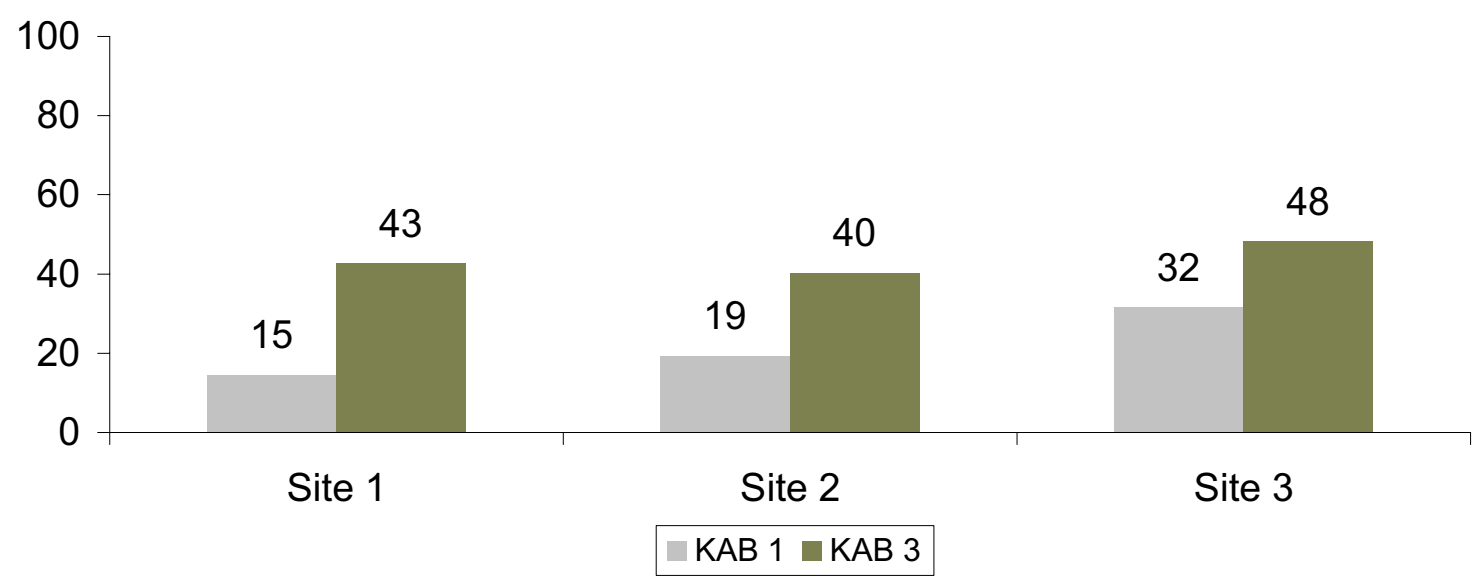

\section{Female mobility}

Full mobility for women in DG Khan increased from negligible to more than 20 percent, while it remained at intermediate levels in Layyah. The difference between "some mobility" and "full mobility" generally involved freedom to go alone to health facilities. It is possible 
that the change in responses in DG Khan represents a response to increased emphasis on health-seeking behavior.

Figure 4.3: Percentage of women with full freedom of mobility

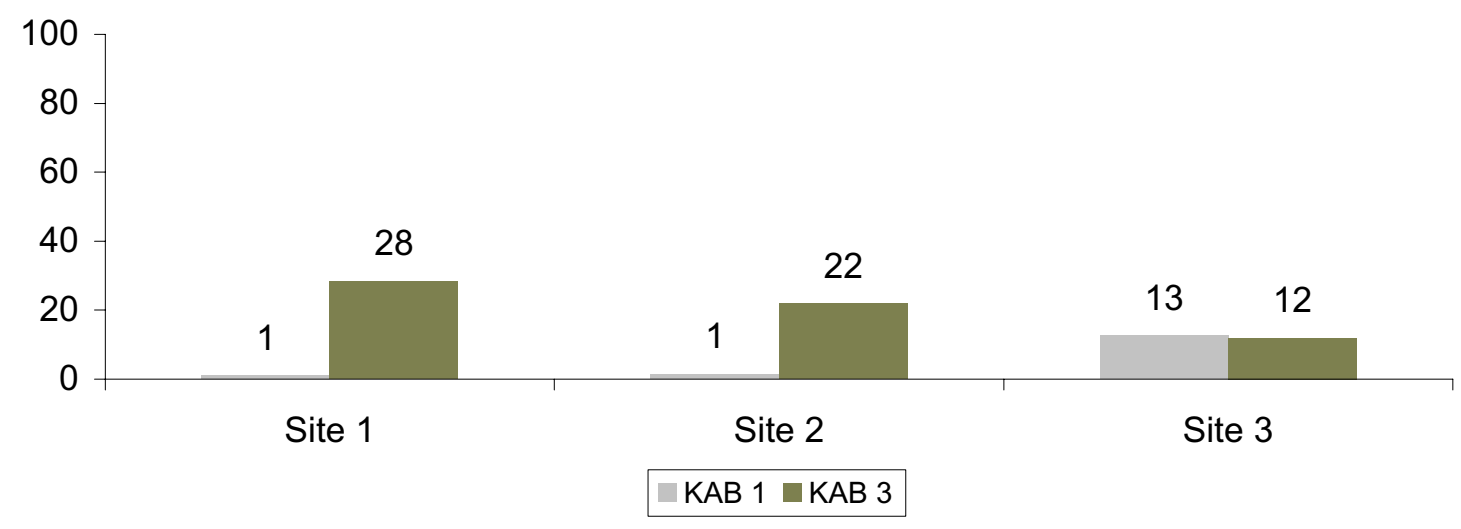

\section{Husbands' education and occupation}

More than half of respondents' husbands had never been to school in the intervention area compared with 44 percent in the control area (table 4.2). Fewer than one-fifth of husbands in the intervention area and more than one-fifth in control area had completed secondary school. Educational attainment of the husbands increased very slightly between survey rounds.

The main occupations for husbands are agriculture and labor. There is little difference in occupation between DG Khan and Layyah except for unemployment, i.e., the proportion of husbands who were unemployed was higher in DG Khan than in Layyah. In site 2, there was a modest shift between rounds from employment in agriculture to employment as laborers. 


\section{V: Family Planning}

Family planning plays an important role in saving women's lives. It helps prevent unwanted pregnancies that often put women at increased risk from pregnancy-related complications. This risk is further elevated because unwanted pregnancies often result in unsafe induced abortions.

Through its community education and mobilization efforts the SMART project sought to increase awareness of and interest in the benefits of family planning. Project staff provided information on family planning methods through IEEC materials.

\section{Knowledge}

Women's knowledge of family planning methods was widespread in the target communities as reported in both survey rounds. About 95 percent of MWRA knew of at least one method of family planning, with little difference among project sites (figure 5.1 and table 5.1). Women's knowledge of modern family planning methods was also high, but their knowledge about traditional family planning methods was substantially lower. Patterns regarding knowledge about modern and traditional methods were also similar by site.

Since family planning knowledge was already very high, there was little room for improvement in overall knowledge or knowledge of modern methods. However, there was an increase between rounds in knowledge of traditional methods in site 1, from 58 percent to 70 percent. 
Figure 5.1: Knowledge, ever use and current use of contraception

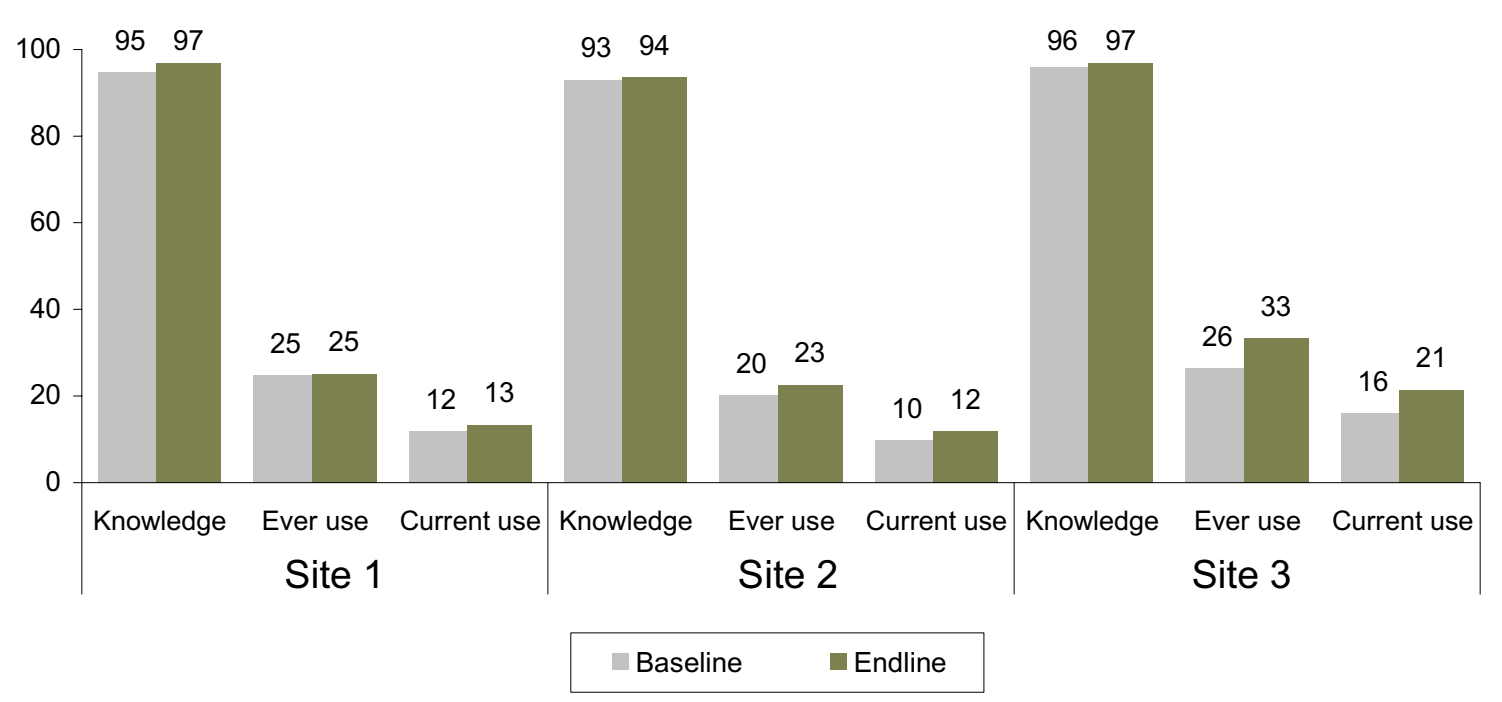

\section{Use}

\section{Ever use}

Ever use of family planning methods is low in all three arms, but is higher in Layyah (26 percent) than DG Khan (22 percent). There have been slight increases in family planning use between rounds, especially in site 3 .

\section{Current use}

Current use of family planning methods for fertility regulation was much lower than the national average of about 33 percent (table 5.1 and figure 5.1). Data presented in table 5.1 suggest that women are using family planning methods more for limiting than for spacing children, as long-term or permanent methods are more popular than temporary methods. For example, at the time of the baseline survey, 61 percent of current users were using female sterilization (41 percent) and IUD (20 percent). Among temporary methods, injectables and withdrawal (10 percent each) were most commonly used.

There was a 2 percentage point increase in current use of contraceptives in both project areas, and a 5 percentage point increase in Layyah. 
Table 5.1: Knowledge, ever use, and current use of family planning methods, by site and HHS round

\begin{tabular}{lrrrrrrr}
\hline \multirow{2}{*}{ Family planning topic } & \multicolumn{2}{c}{ Site 1 } & \multicolumn{2}{c}{ Site 2 } & \multicolumn{2}{c}{ Site 3 } \\
\cline { 2 - 7 } & Baseline & Endline & Baseline & Endline & Baseline & Endline \\
\hline Knowledge & & & & & & \\
Any method & 94.7 & 96.8 & 93.0 & 93.7 & 96.0 & 96.8 \\
Modern methods & 94.6 & 96.7 & 92.8 & 93.7 & 96.0 & 96.7 \\
$\quad$ Traditional methods & 57.6 & 70.4 & 56.5 & 56.8 & 60.5 & 58.7 \\
Ever use & & & & & & \\
Any method & 24.8 & 25.1 & 20.2 & 22.6 & 26.4 & 33.4 \\
Modern methods & 22.4 & 23.6 & 18.4 & 21.1 & 22.7 & 27.3 \\
Traditional methods & 5.8 & 3.4 & 4.0 & 3.5 & 6.9 & 11.1 \\
Current use & & & & & & \\
Any method & 11.8 & 13.4 & 9.8 & 11.9 & 16.1 & 21.4 \\
Modern methods & 10.1 & 12.0 & 8.5 & 10.5 & 13.1 & 16.1 \\
Condoms & 0.7 & 1.0 & 0.6 & 0.8 & 1.3 & 2.7 \\
Pills & 0.9 & 1.0 & 0.7 & 1.1 & 0.9 & 1.0 \\
Injectables & 1.1 & 1.4 & 1.1 & 1.3 & 1.3 & 2.1 \\
IUDs & 2.5 & 3.0 & 1.9 & 2.4 & 2.9 & 3.1 \\
F. Sterilization & 4.7 & 5.3 & 4.1 & 4.5 & 6.6 & 7.1 \\
M. Sterilization & 0.2 & 0.2 & 0.2 & 0.4 & 0.0 & 0.1 \\
Traditional methods & 1.7 & 1.4 & 1.2 & 1.4 & 2.9 & 5.2 \\
Withdrawal & 1.3 & 1.0 & 0.7 & 1.0 & 1.9 & 4.5 \\
Periodic abstinence & 0.1 & 0.0 & 0.2 & 0.1 & 0.6 & 0.3 \\
Others & 0.3 & 0.4 & 0.3 & 0.3 & 0.4 & 0.4 \\
No. of respondents & 8,348 & 8,707 & 8,026 & 8,666 & 7,037 & 7,296 \\
\hline
\end{tabular}

\section{Correlates of contraceptive use}

In this section, the associations between current use of contraception and selected characteristics of women (age, parity, education) and households (ethnicity and socioeconomic status) are explored.

Age. In general, contraceptive use increases with age of mother; figure 5.2a shows this in our sample, in all arms and both rounds. As is often the case, use declines slightly at higher ages as women no longer feel the need for using contraceptives.

Parity. As with age, current use of family planning shows a generally positive association with parity (figure $5 \mathrm{c}$ ). However, there is some decline in prevalence at higher parity. This may be an age effect, or perhaps it is evidence of a recent decline in family size preference among younger women. 
Education. Data presented in figure 5.2c, show that current use rate increases sharply as women's educational level increases, with women with secondary schooling approaching the national average. However, since a large majority of women had never been to school in these arms, there are only small numbers of women in each positive education category, which creates some anomalies in the pattern.

Ethnicity. Data presented in figure 5.2d illustrate that current use of family planning methods is higher among Saraiki-speaking women than Balochi-speaking women in DG Khan, while in Layyah, Punjabi women are more likely than Saraiki women to use contraception. This is consistent with the correlation between these groups and SES generally.

Wealth quintile. Current use of contraception is influenced by the socio-economic status of the household. Findings from baseline and endline surveys show increasing contraceptive use with higher socioeconomic status; this is true for all three sites (see figure 5.2e). This trend is relatively modest, however, especially in DG Khan.

Figure 5.2a: Current use of family planning by age

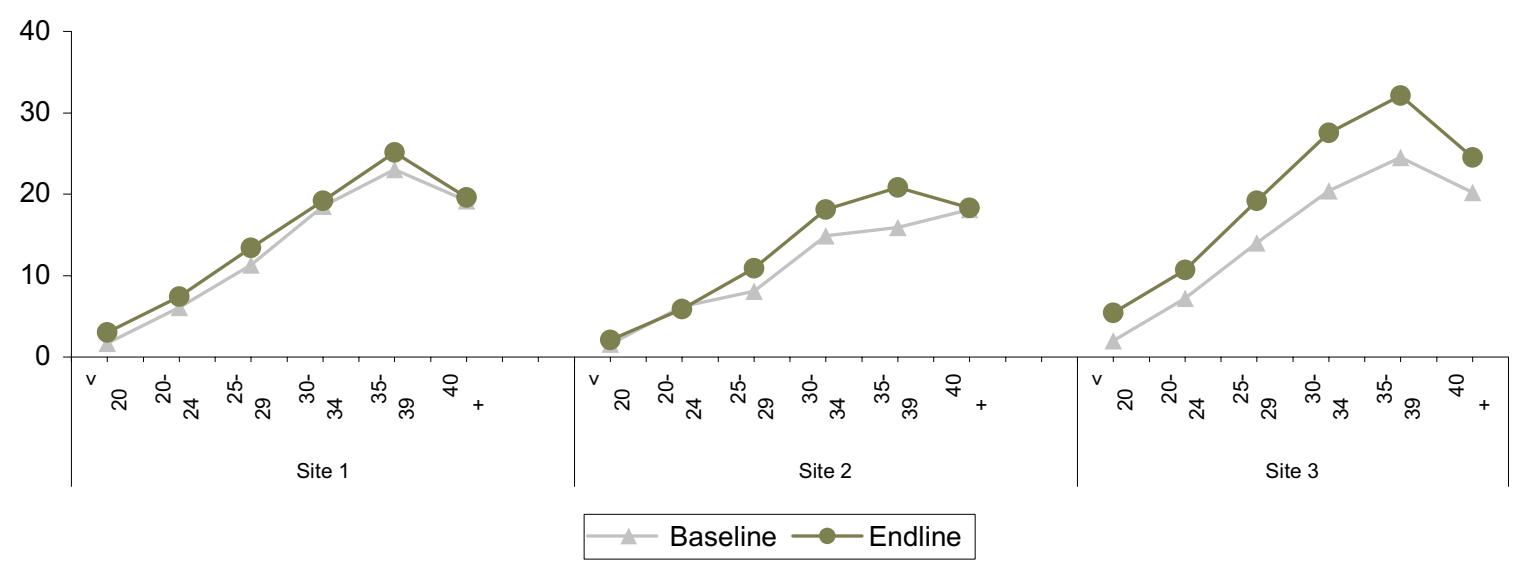


Figure $5.2 \mathrm{~b}$ : Current use of family planning by parity

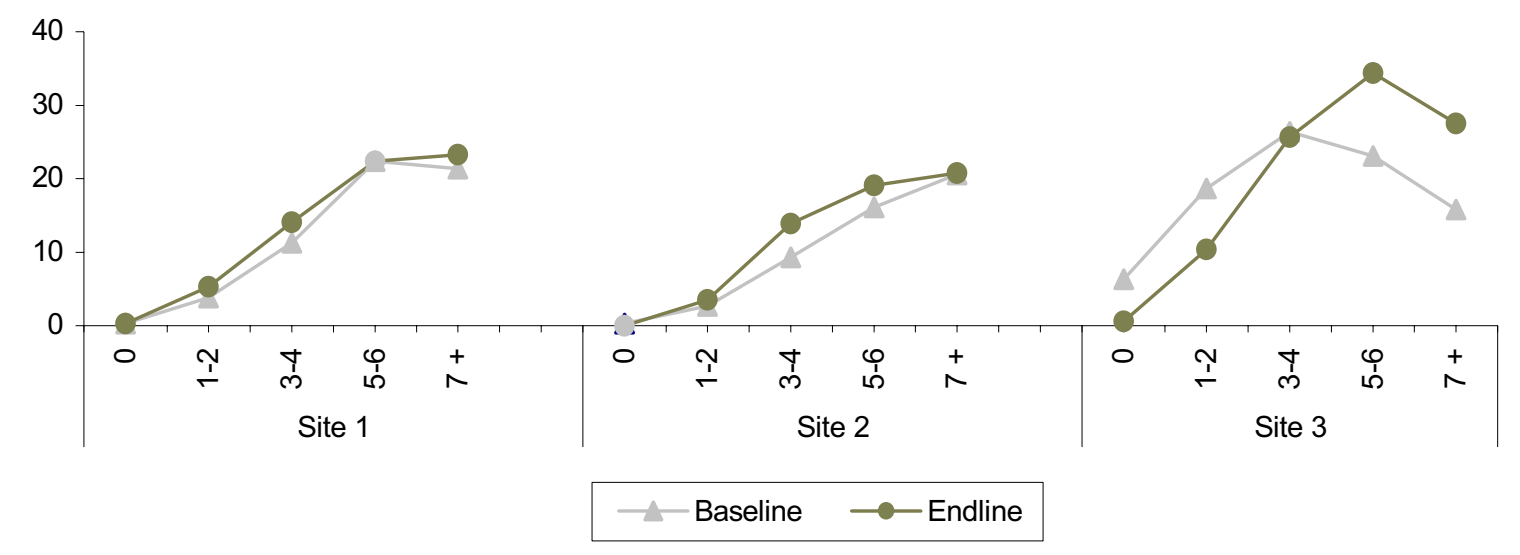

Figure 5.2c: Current use of family planning by education

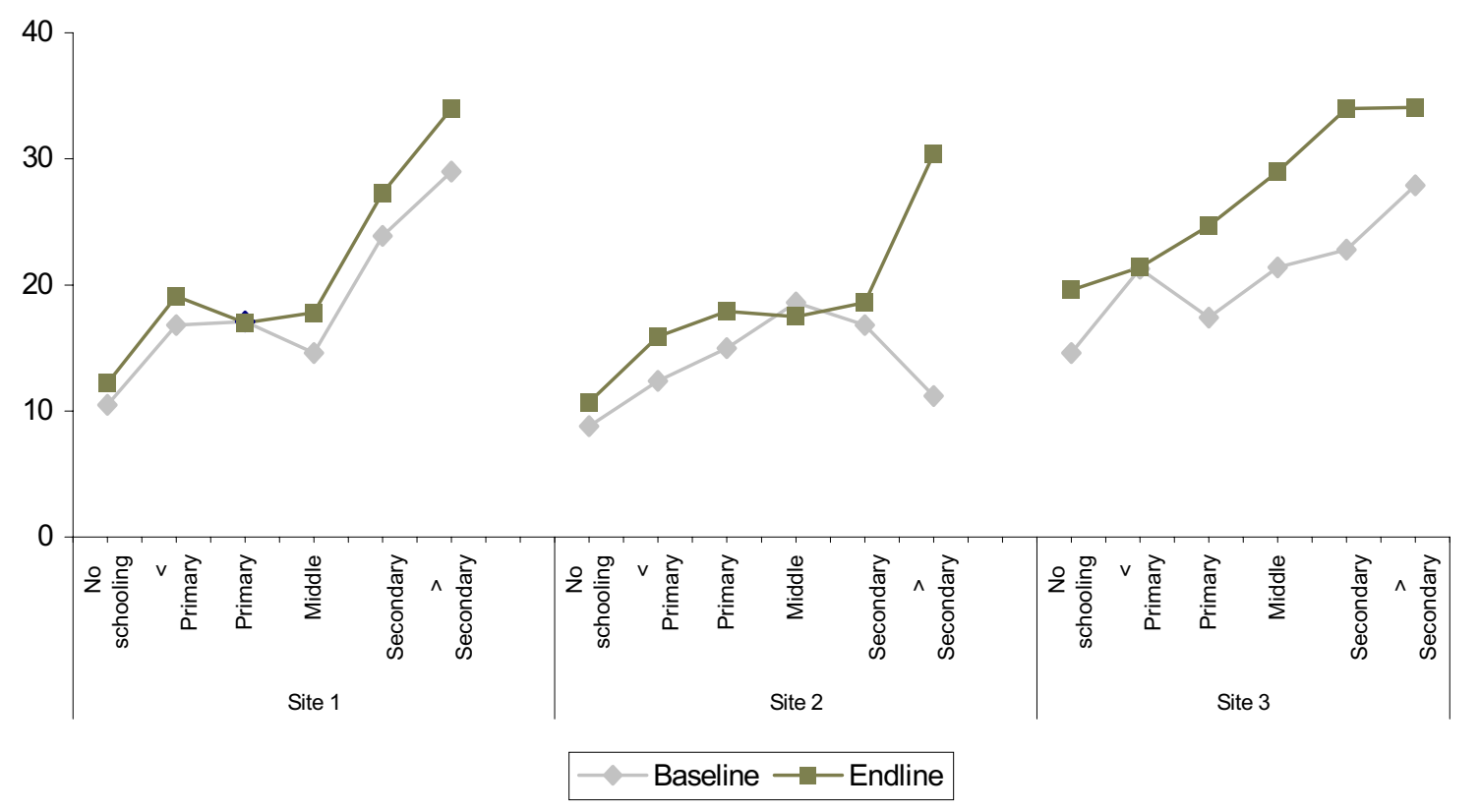


Figure 5.2d: Current use of family planning by language

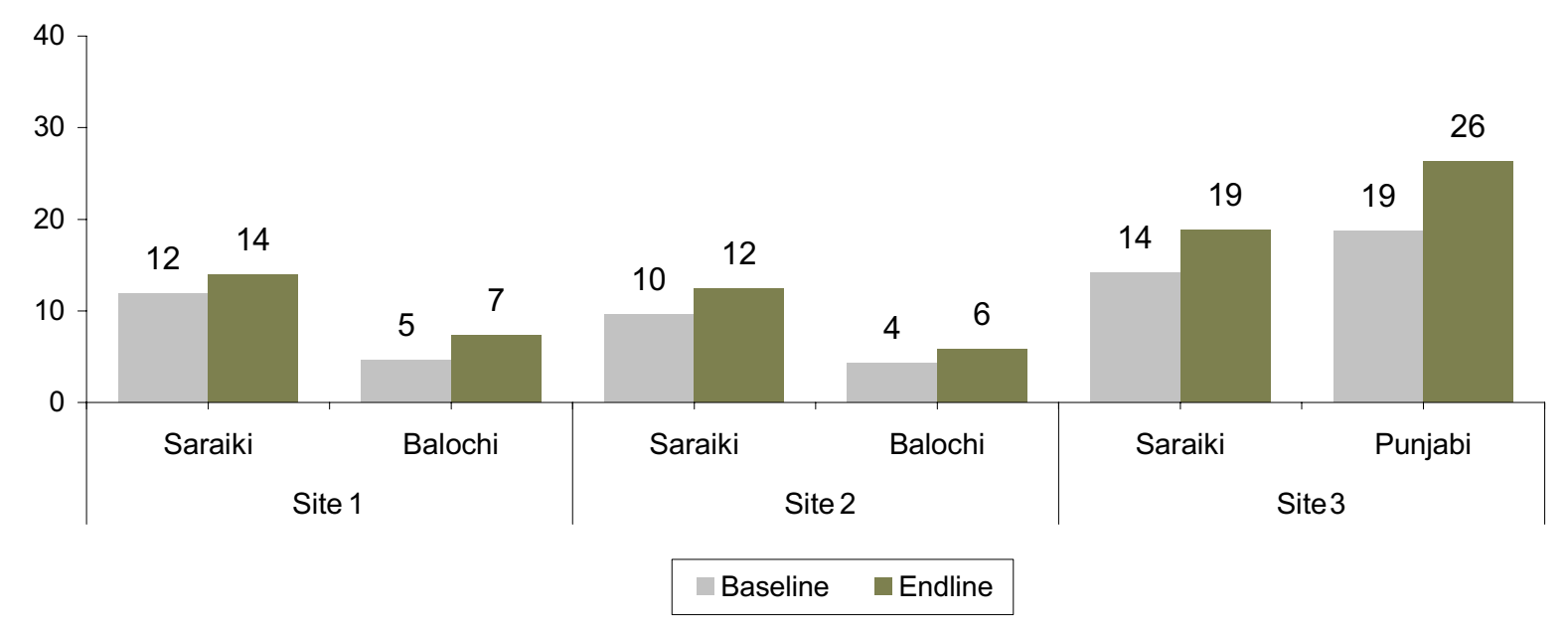

Figure 5.2e: Current use of family planning by wealth quintile

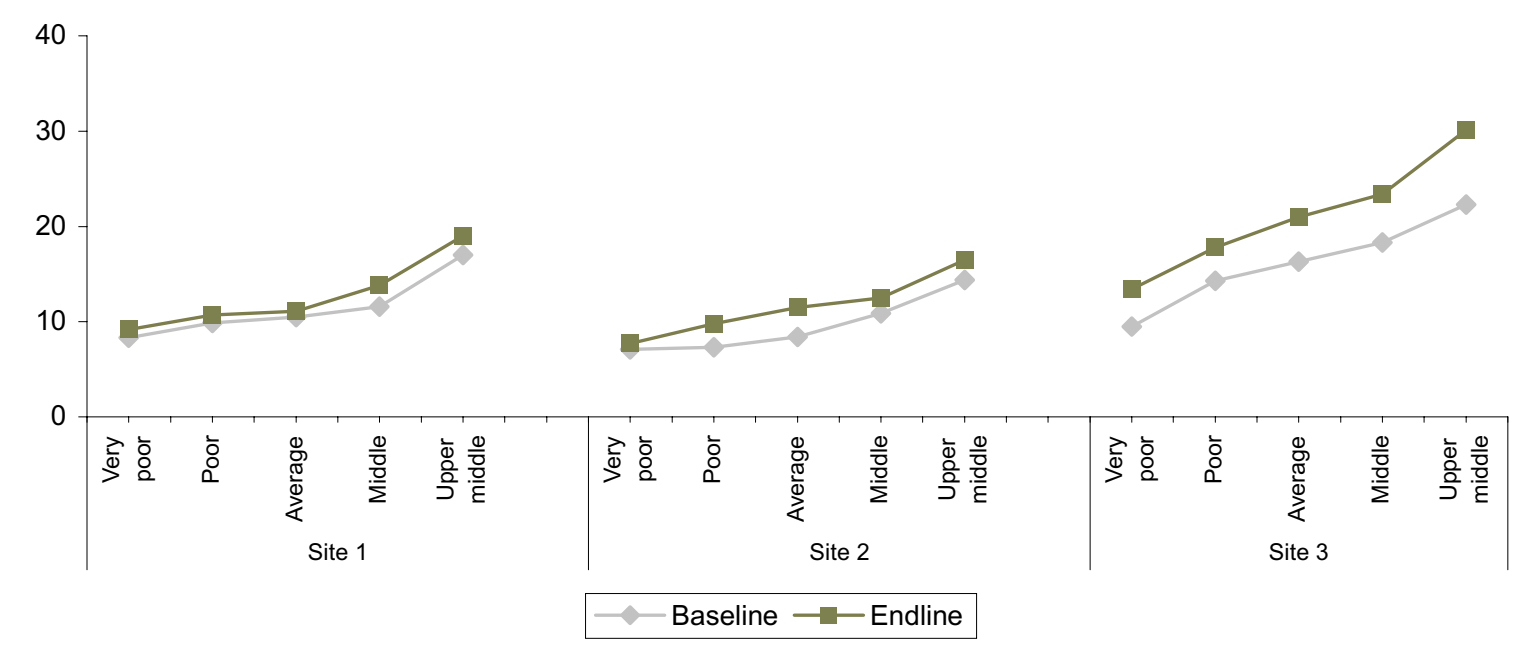

\section{Response to program inputs}

In site 1, the "HSI plus CBI" site, the SMART project undertook several activities that could have influenced the use of family planning. These included educational support groups, distribution of information, education, and empowerment for change (IEEC) materials, and training of Lady Health Workers (LHW). Family planning was a component, albeit not a central one, in each of these activities. On the other hand, the SMART project made no effort to increase the availability of contraceptives or family planning services. While the overall results from site 1 show only modest increases in family planning between baseline and 
endline, it is nevertheless possible that the project might have had some impact on those who were the direct beneficiaries of project activities.

Table 5.2 shows the relationship between current use of contraception and exposure to program interventions in site 1 . The overall contraceptive prevalence rate for the KAB subsample in round 3 was 17.3 percent, somewhat higher for the main sample in site 1 (13.8 percent). Women who had attended one or more support groups, or had a family member attend such groups, were noticeably more likely to be current users of contraception than women who did not attend. Those visited by an LHW during the previous two months were only slightly more likely to be using family planning than those not visited. Since attendance at support groups was self-selecting, we cannot say whether the higher use of family planning by attendees was a result of attending, or was an indicator of the type of woman who chose to attend such groups. Exposure to IEEC materials was strongly related to attendance at support groups.

\section{Table 5.2: Current use of contraception according to direct exposure to}

\section{SMART project inputs in site $1, \mathrm{KAB}$ round 3}

\begin{tabular}{lrr}
\hline Program intervention & No. & Pct. \\
\hline Support group & & \\
Attended & 54 & 22.1 \\
Did not attend & 60 & 14.4 \\
IEEC materials & & \\
Seen and/or received & 86 & 20.0 \\
Not seen/received & 26 & 12.8 \\
LHW visit during last 2 months & & \\
Yes & 58 & 18.4 \\
No & 40 & 14.5 \\
Current users & 114 & 17.3 \\
\hline
\end{tabular}

${ }^{*}$ Either respondent or someone in family attended. 



\section{VI: Knowledge of Maternal and Neonatal Health}

\section{Knowledge of potentially serious complications}

Knowledge about pregnancy-related dangers signs plays an important role in healthseeking behavior. If women are able to recognize danger signs then it is expected that they will be more likely to go for treatment in case they experience them. Data on knowledge of complications during the childbearing cycle were collected in the KAB subsample. Specifically, women were asked about the signs and symptoms that need immediate treatment or consultation with medically trained professional during each of those periods. They were first asked in general (spontaneous knowledge); then, after all spontaneous responses had been given, they were asked about knowledge of a specific set of danger signs (prompted knowledge). The aim of the project was to increase the proportion of married women of reproductive age who knew of at least three danger signs in each period. In all survey rounds, the great majority of respondents responded affirmatively to prompting on knowledge questions; the following analysis is therefore limited to spontaneous knowledge.

\section{Pregnancy}

The danger signs of pregnancy on which information was collected and analyzed are as follows: blurring of eyes; swelling of the face; spotting; heavy vaginal bleeding; fits or convulsions; periods of unconsciousness; and severe abdominal pain. When women were asked at baseline about the danger signs that could occur during pregnancy, only nine percent could identify three or more danger signs in all three sites. That is, at baseline all three sites showed equally low knowledge about danger signs of pregnancy. Table 6.1 shows that 
Table 6.1: Spontaneous knowledge of danger signs and symptoms of pregnancy by site and KAB round

\begin{tabular}{lrrrrrr}
\hline \multirow{2}{*}{ Knowledge topic } & \multicolumn{2}{c}{ Site 1 } & \multicolumn{2}{c}{ Site 2 } & \multicolumn{2}{c}{ Site 3 } \\
\cline { 2 - 7 } & Baseline & Endline & Baseline & Endline & Baseline & Endline \\
\hline Know at least 3 danger signs & 8.8 & 34.9 & 8.5 & 24.9 & 9.4 & 16.4 \\
Blurring of eyes & 6.1 & 7.6 & 9.5 & 5.1 & 5.1 & 5.8 \\
Swelling of the face & 4.3 & 17.0 & 3.1 & 8.1 & 2.6 & 5.4 \\
Spotting & 3.4 & 15.0 & 3.9 & 11.2 & 2.6 & 9.9 \\
Heavy vaginal bleeding & 8.6 & 37.8 & 10.0 & 36.0 & 6.2 & 19.0 \\
Fits or convulsions & 4.2 & 8.1 & 4.4 & 4.6 & 6.1 & 5.0 \\
Loss of Consciousness & 1.9 & 3.7 & 1.3 & 2.1 & 5.3 & 2.0 \\
Severe abdominal pain & 12.6 & 37.5 & 12.8 & 31.3 & 10.0 & 28.3 \\
No. of respondents & 672 & 655 & 769 & 602 & 627 & 611 \\
\hline
\end{tabular}

Table 6.1 shows that knowledge of danger signs increased overall and for nearly all signs in all three sites, with the effects in general greatest for site 1, intermediate for site 2 , and lowest but still substantial for site 3, the control area. As we shall see, similar patterns also hold for danger signs for delivery, the postpartum period, and for neonates, although the relative increases in site 2 are not consistent. We cannot account for the increase in the control area, and find the degree of increase in site 2 (the HSI only area) unlikely as a project effect. We have examined the following possible sources of bias in the survey:

- Excessive deviation of some individual interviewers from the norm

- Sensitization of households included (by chance) in both baseline and endline

- Variation over time, i.e., that knowledge increased during the fieldwork within each survey round

None of these investigations accounts for the findings presented here. It remains possible that by the time of the endline, interviewers were more experienced, more patient and better able to elicit real knowledge than they had been during the baseline. We cannot test this hypothesis. It is plausible, though, that the consistent differences between sites is real: site 1 represents an intense effort at community education, and site 2 , in addition to training of providers, may have spillover effects from LHW training and from "contamination" from nearby communities in site 1. (During the endline survey, some women were found to have booklets and cassettes, and others were aware of the education activities elsewhere.) Hence the following analysis in this and the following chapter will first present actual data in table form, and then display a "difference of differences" approach. For this, we will assume that the difference observed in the control area represents survey bias rather than actual change, 
and show the difference between the change in the experimental arms and the control area between baseline and endline.

Figure 6.1: Percentage difference between knowledge increases of pregnancy danger signs in sites 1 and 2 compared with site 3

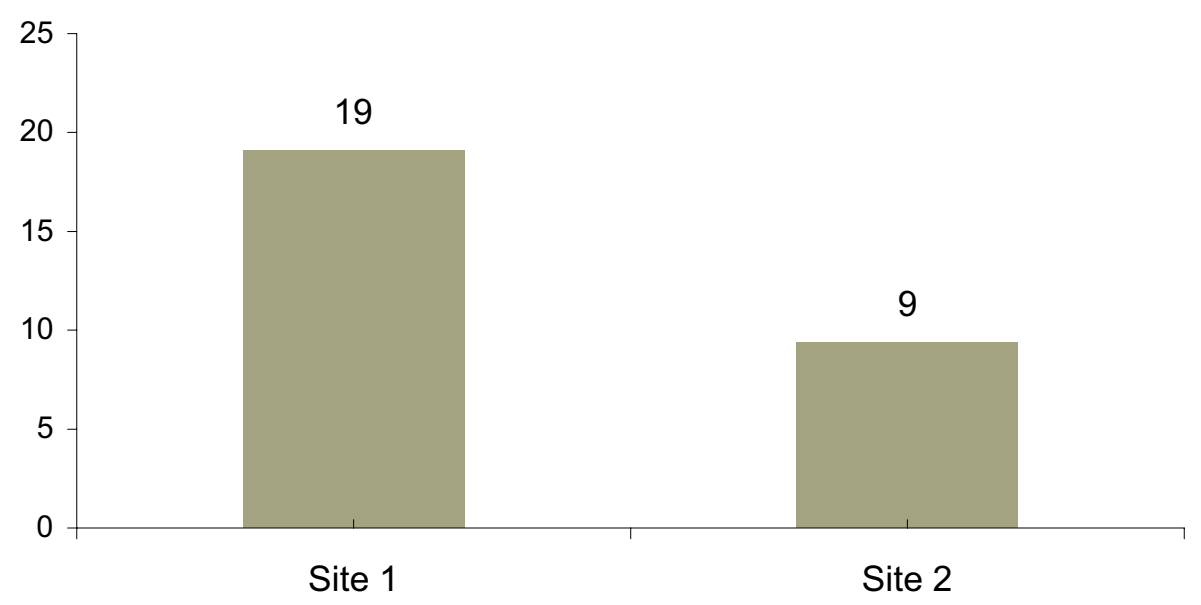

Data from baseline and endline surveys on knowledge about pregnancy danger signs are presented in this way in figure 6.1. With this assumption, knowledge of 3 danger signs has increased by 9 percent in site 2 and 18 percent in site 1, compared with the control area. Particularly noteworthy were increases in numbers spontaneously mentioning facial swelling, spotting/bleeding, and severe abdominal pain as danger signs.

\section{Delivery}

The dangers signs of delivery on which information was collected were: prolonged labor; bleeding before labor began; premature rupture of membranes; delayed or retained placenta; excessive bleeding; and breech delivery. Knowledge about delivery-related danger signs was minimal at the time of the baseline survey; in all three arms only six to seven percent of women could name three danger signs of delivery. 
Table 6.2: Spontaneous knowledge of danger signs and symptoms of delivery by site and $\mathrm{KAB}$ round

\begin{tabular}{lrrrrrr}
\hline \multirow{2}{*}{ Knowledge topic } & \multicolumn{2}{c}{ Site 1 } & \multicolumn{2}{c}{ Site 2 } & \multicolumn{2}{c}{ Site 3 } \\
\cline { 2 - 7 } & Baseline & Endline & Baseline & Endline & Baseline & Endline \\
\hline Know at least 3 danger signs & 6.8 & 18.3 & 6.3 & 11.2 & 7.0 & 13.5 \\
$\quad$ Prolonged labor (> 12 hours) & 10.0 & 27.3 & 13.5 & 18.3 & 6.7 & 19.6 \\
$\quad$ Bleeding before labor begins & 4.9 & 24.1 & 7.4 & 23.4 & 5.3 & 20.8 \\
$\quad$ Premature rupture of & 4.5 & 19.5 & 4.0 & 15.1 & 6.2 & 13.1 \\
$\quad$ membranes & & & & & & \\
$\quad$ Retained or delayed placenta & 9.2 & 36.5 & 7.3 & 23.4 & 11.3 & 11.7 \\
Excessive bleeding & 8.0 & 23.5 & 7.6 & 19.0 & 10.4 & 14.4 \\
$\quad$ Breech delivery & 6.5 & 12.5 & 4.0 & 8.8 & 8.5 & 9.8 \\
No. of respondents & 672 & 655 & 769 & 602 & 627 & 611 \\
\hline
\end{tabular}

As with the danger signs of pregnancy, knowledge of the danger signs at delivery increased in all three sites (table 6.2), with the greatest increase visible in site 1 both overall and for each individual sign. However, increase in knowledge in site 2 is slightly less than in site 3 . Figure 6.2 shows the "difference of differences" by study site.

Figure 6.2: Percentage difference between knowledge increases of delivery danger signs in sites 1 and 2 compared with site 3

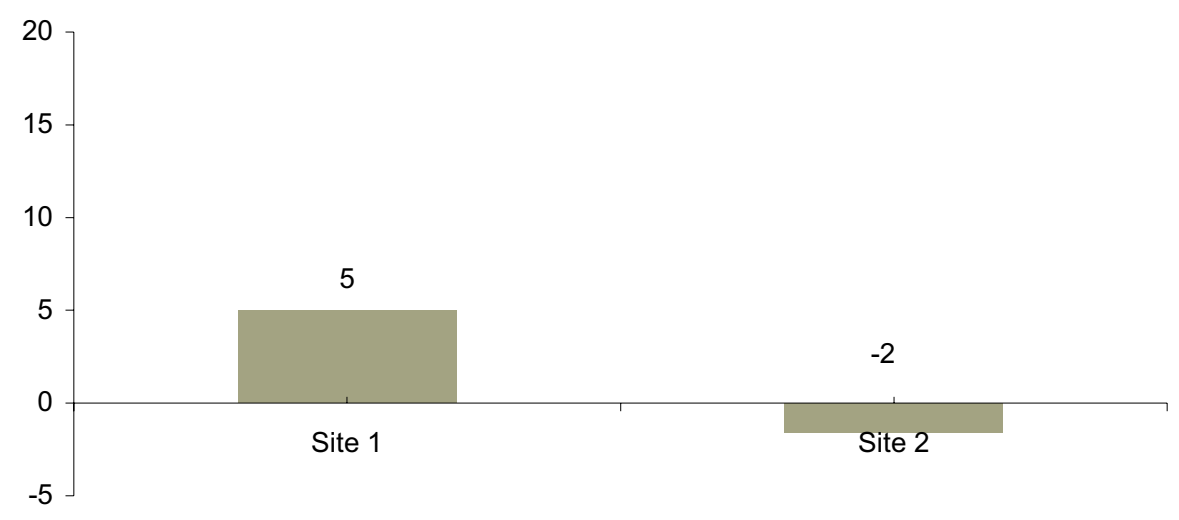

The increases for individual signs are strong and consistent in site 1, with only knowledge of breech delivery showing as little as a doubling of reported knowledge. At endline in site 1 , the signs most often reported were retained or delayed placenta, prolonged labor, bleeding prior to labor, and excessive bleeding. 


\section{Postpartum}

Women's knowledge about danger signs in the postpartum period was very low in all three sites at the time of the baseline survey (table 6.3). Only four percent of women knew at least three danger signs of the postpartum period in site 1 , three percent in site 2 and seven percent in site 3 at the time of the baseline survey. Of the five specific dangers signs probed, only "excessive vaginal bleeding" was spontaneously reported by more than 10 percent of women in any study arm.

Table 6.3: Spontaneous knowledge of danger signs and symptoms postpartum by site and $\mathrm{KAB}$ round

\begin{tabular}{lrrrrrr}
\hline \multirow{2}{*}{ Knowledge topic } & \multicolumn{2}{c}{ Site 1 } & \multicolumn{2}{c}{ Site 2 } & \multicolumn{2}{c}{ Site 3 } \\
\cline { 2 - 7 } & Baseline & Endline & Baseline & Endline & Baseline & Endline \\
\hline Know at least 3 danger signs & 4.3 & 10.4 & 2.6 & 5.2 & 6.9 & 12.7 \\
Excessive vaginal bleeding & 12.5 & 38.4 & 15.0 & 32.3 & 12.0 & 29.6 \\
Fits or convulsions & 6.4 & 8.9 & 5.9 & 6.0 & 4.3 & 20.9 \\
Loss of consciousness & 2.5 & 4.0 & 2.0 & 1.6 & 5.7 & 5.7 \\
Prolapsed uterus & 4.6 & 14.5 & 4.0 & 10.2 & 4.8 & 7.1 \\
High fever & 5.5 & 28.7 & 5.9 & 17.9 & 8.6 & 32.6 \\
No. of respondents & 672 & 655 & 769 & 602 & 627 & 611 \\
\hline
\end{tabular}

By the endline survey, knowledge had increased in all three sites. Increases were notable for most individual signs in all three sites, particularly for excessive vaginal bleeding and high fever. In this case, however, the increase was greater in the control area than in site 2 (at least in absolute terms). Figure 6.3 therefore shows a negative "difference of differences" for site 2 . In site 1 , the difference was only slightly greater than for the control area. 
Figure 6.3: Percentage difference between knowledge increases of postpartum danger signs in sites 1 and 2 compared with site 3

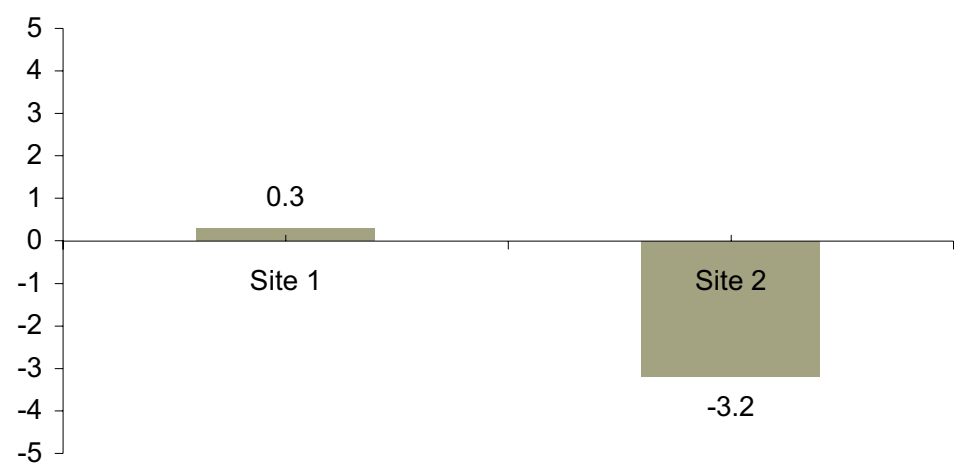

Excessive bleeding is a sign of postpartum hemorrhage, which is the most common cause of maternal death; however, formative research confirmed that postpartum bleeding is often welcomed as evidence of cleansing of the uterus. In these surveys, excessive bleeding is counted as a danger sign both for delivery and postpartum. The proportion of women reporting this sign for either delivery or the postpartum period rose from 15 percent to 45 percent in site 1 , from 17 percent to 42 percent in site 2, and from 12 percent to 36 percent in site 3 (data not shown). These increases, particularly in site 1, are greater than for other danger signs, and may indicate a welcome increase in the seriousness with which this event is viewed.

\section{Newborns (day of birth)}

The danger signs on which information was collected and analyzed are: no/weak cry; breathing problems; discolored skin (yellow or blue); cold/shivering body (hypothermia); skin lesion; fits; and red and swollen eyes. Women's knowledge about the danger signs in newborns at birth was low in all three sites at baseline; 13 to 15 percent of women could name at least three danger signs in newborns in all three sites at the time of baseline (table 6.4). Knowledge of danger signs increased overall and for nearly all signs in all sites, with the effects in general greatest for site 1, intermediate for site 2, and lowest for site 3 . Figure 6.4 presents this in terms of difference of differences; knowledge of danger signs was greater by 17 percent in site 1 than in site 3 . 
Table 6.4: Spontaneous knowledge of danger signs and symptoms in newborns at birth by site and KAB round

\begin{tabular}{lrrrrrr}
\hline \multirow{2}{*}{ Knowledge topic } & \multicolumn{2}{c}{ Site 1 } & \multicolumn{2}{c}{ Site 2 } & \multicolumn{2}{c}{ Site 3 } \\
\cline { 2 - 7 } & Baseline & Endline & Baseline & Endline & Baseline & Endline \\
\hline Know at least 3 danger signs & 12.9 & 35.6 & 15.6 & 27.3 & 13.6 & 19.3 \\
$\quad$ No or weak cry & 3.6 & 11.7 & 4.6 & 6.3 & 6.2 & 16.4 \\
$\quad$ No or difficult breathing & 4.3 & 15.3 & 6.4 & 13.7 & 3.7 & 15.4 \\
$\quad$ Difficult fast breathing & 5.4 & 3.8 & 5.7 & 3.8 & 4.9 & 9.3 \\
$\quad$ Yellow skin (jaundice) & 23.4 & 48.2 & 21.9 & 42.9 & 19.5 & 20.0 \\
$\quad$ Blue skin & 14.3 & 42.3 & 16.7 & 31.7 & 18.0 & 15.7 \\
$\quad$ Baby is very cold/shivering & 1.2 & 11.0 & 2.6 & 7.4 & 5.9 & 11.8 \\
$\quad$ (hypothermia) & & & & & & \\
$\quad$ Unable to suck or feeble & 2.1 & 4.3 & 1.8 & 3.8 & 2.4 & 5.5 \\
$\quad$ suck & 2.7 & 5.7 & 3.4 & 7.1 & 4.5 & 11.7 \\
$\quad$ Skin lesion or blister & 10.1 & 40.6 & 13.3 & 30.9 & 7.2 & 4.8 \\
$\quad$ Fits/ abnormal or jerky & & & & & & \\
$\quad$ movements & 1.9 & 2.4 & 2.0 & 2.5 & 5.4 & 6.0 \\
$\quad$ Red and swollen eyes & 672 & 655 & 769 & 602 & 627 & 611 \\
No. of respondents & & & & & &
\end{tabular}

The most commonly known danger signs at birth in the baseline were yellow skin (jaundice), blue skin, and fits. Few women in any site mentioned breathing problems, hypothermia, and sucking problems at baseline.

Figure 6.4: Percentage difference between knowledge increases of newborn danger signs at birth in sites 1 and 2 compared with site 3

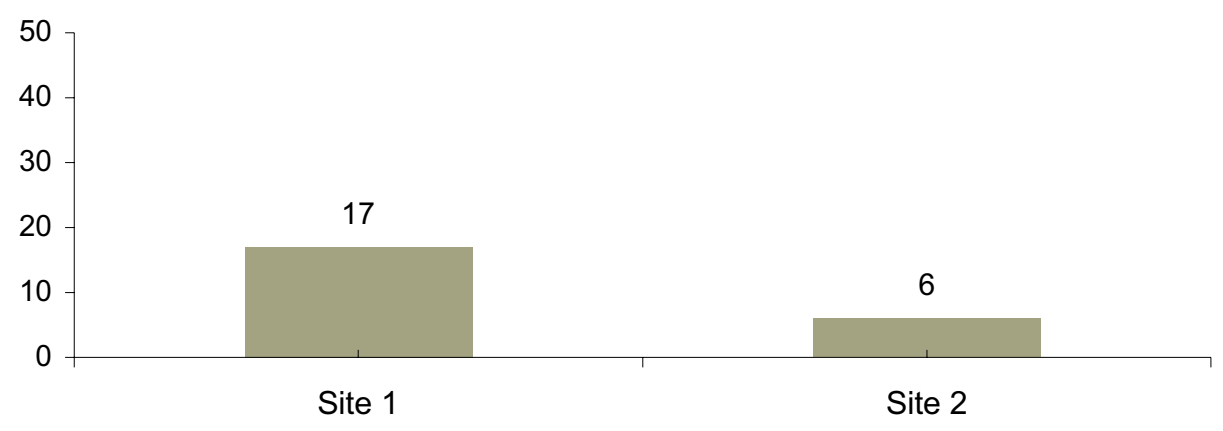

Women's knowledge about some danger signs in newborns shows a large increase for some signs and is nominal for others. For example, mention of 'weak cry or no cry at birth' as a danger sign increased from 4 percent at baseline to 12 percent at endline. Similarly, 
recognition that blue skin at birth is a danger sign tripled from baseline (14 percent) to endline (44 percent); and recognition of fits as a danger sign increased four times.

\section{Newborns (within 7 days)}

As with the danger signs at birth, knowledge of danger signs within 7 days after birth is the same at baseline and has increased in all three sites, with the greatest increase in site 1 visible overall and for each individual sign (table 6.5).

Table 6.5: Spontaneous knowledge of danger signs and symptoms in newborns within 7 days after birth by site and KAB round

\begin{tabular}{lrrrrrr}
\hline \multirow{2}{*}{ Knowledge topic } & \multicolumn{2}{c}{ Site 1 } & \multicolumn{2}{c}{ Site 2 } & \multicolumn{2}{c}{ Site 3 } \\
\cline { 2 - 7 } & Baseline & Endline & Baseline & Endline & Baseline & Endline \\
\hline Know at least 3 danger signs & 14.7 & 48.5 & 17.1 & 35.7 & 12.0 & 29.1 \\
$\quad$ Fast and difficult breathing & 4.9 & 9.0 & 6.0 & 8.1 & 3.2 & 7.8 \\
$\quad$ Yellow skin (jaundice) & 22.3 & 43.8 & 19.9 & 40.2 & 15.9 & 18.5 \\
$\quad$ Blue skin & 14.4 & 37.9 & 14.8 & 30.2 & 15.9 & 13.9 \\
$\quad$ Baby is very cold/shivering & 3.0 & 13.0 & 3.5 & 7.7 & 4.1 & 14.2 \\
$\quad$ (hypothermia) & & & & & & \\
$\quad$ Unable to suck or feeble & 1.9 & 7.3 & 3.9 & 4.1 & 3.0 & 7.8 \\
$\quad$ sucking & & & & & & \\
$\quad$ Skin lesion & 3.3 & 5.8 & 3.6 & 6.0 & 3.0 & 10.8 \\
$\quad$ Fits/ abnormal or jerky & 8.6 & 37.9 & 9.6 & 30.5 & 5.1 & 4.3 \\
$\quad$ movements & & & & & & \\
$\quad$ Red swollen eyes & 2.7 & 2.3 & 2.3 & 3.5 & 5.4 & 8.1 \\
$\quad$ Failure to pass urine & 6.0 & 8.0 & 7.9 & 8.5 & 5.9 & 14.1 \\
$\quad$ Frequent watery stools/or & 7.3 & 30.1 & 8.6 & 17.5 & 6.9 & 27.5 \\
$\quad$ stools with blood or mucus & & & & & & \\
$\quad$ Fever & 18.6 & 43.3 & 14.6 & 30.0 & 8.1 & 35.1 \\
No. of respondents & 672 & 655 & 769 & 602 & 627 & 611 \\
\hline
\end{tabular}

Levels of knowledge increase are similar to those for newborns. The percentage of women who know at least three danger signs within one week of birth increased by three times in site 1 , doubled in site 2 and was more than double in site 3 between the two rounds. 
Figure 6.5: Difference between knowledge increases of newborn danger signs (first week of birth) in sites 1 and 2 compared with site 3

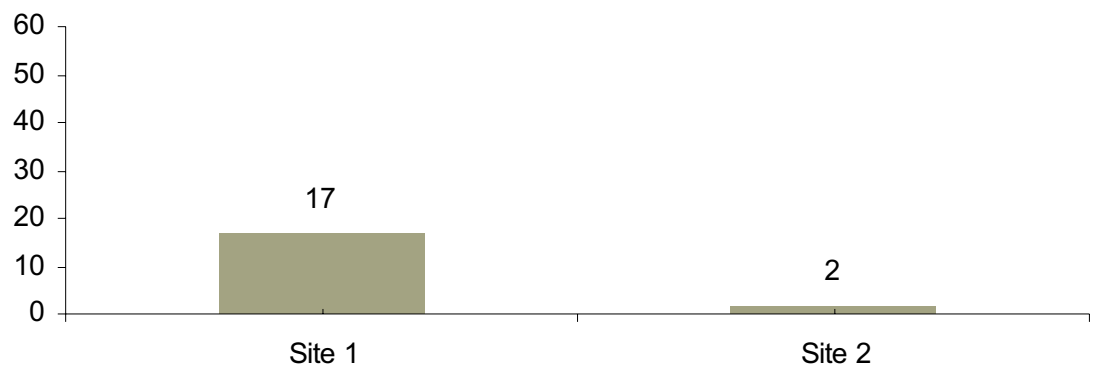

Figure 6.5 shows "difference of differences". Women's knowledge of danger signs in newborns in site 1 has increased 17 percentage points more than site 3 , but only 2 percentage points more for site 2 .

In summary, the ability of respondents to spontaneously name potentially serious complications at each period of the childbearing cycle was low at baseline and increased markedly by the endline in all three sites. It is likely that some of these differences represent some form of ascertainment bias between survey rounds. However, it appears that there has also been a real and substantial increase in knowledge of danger signs in project site 1, the area of intensive community education efforts. Differences between site 3, the control area, and site 2, the area of "HSI only" intervention are less consistent and less convincing.

\section{Knowledge response to program inputs in $\mathrm{CBI}$ communities}

In the 60 mauzas of the "HSI plus CBI" area, the Population Council conducted substantial community mobilization and education activities that might have been responsible for the observed increases in knowledge in those communities. These included support groups for both women and men that met up to six times to discuss matters relating to maternal and neonatal health; information, education, and empowerment for change (IEEC) materials that were used in the support groups and also distributed elsewhere in the communities; and the training of Lady Health Workers, which might have been a factor contributing to increased knowledge on the part of their clients. There was also training of local dais (traditional birth attendants), but while this training might have affected $\mathrm{MNH}$ care, it was unlikely to have affected knowledge in the community more generally. (For a full description of these activities, see SMART Report 2: The Interventions.) 
In the $\mathrm{KAB}$ survey, women were asked about their exposure to these activities; data from site 1 and $\mathrm{KAB}$ round 3 are presented (table 6.6), since only these are generally relevant. For about 38 percent of respondents, either the woman herself or a family member went to at least one support group meeting. Two-thirds had received or seen some form of IEEC material. The great majority had been visited by an LHW in the previous two months. (The SMART project trained all LHWs in place at the beginning of the project, but additional ones were added during the project; respondents did not always know if a LHW had been SMART-trained or not.) For women recently delivered at home attended by a dai, slightly more than half were delivered by a PC-trained dai. (The names of the dais were given and checked, and their training status was always correct.)

Table 6.6: Women's exposure to wome n support groups, IEEC materials, LHWs and PC trained dais in site 1, KAB round 3

\begin{tabular}{lrr}
\hline Project activity & No. & Percent \\
\hline Women's Support Groups & & \\
Number of times attended (respondent) & 446 & 68.1 \\
Never & 94 & 14.4 \\
Once & 115 & 17.6 \\
Twice or more & & \\
Attended by & 209 & 31.9 \\
Respondent & 37 & 5.6 \\
Family member only & 409 & 62.4 \\
None & & \\
IEEC material received/seen & 432 & 66.4 \\
Yes & 219 & 33.6 \\
No & & \\
Booklet & & 65.3 \\
Cassette & 428 & 63.5 \\
Antenatal card & 416 & 23.4 \\
Yes & 153 & 83.4 \\
No & & 16.6 \\
Pisited by LHW & 546 & 53.3 \\
Untrained dai & 109 & 46.7 \\
\hline
\end{tabular}


The Population Council carried out these community mobilization activities directly in 39 clusters through seven teams (each team comprised of two females and one male); while in 21 clusters the National Rural Support Program (NRSP), on a subcontract, worked through two regular teams (each team comprising of one male and one female) and their CBOs. By design, the Council's program was more labor-intensive than that of NRSP, but the nature of the interventions was the same.

\section{Women's support groups}

According to program records, about 41 percent of all married women of reproductive age in site 1 had attended one or more women's support groups. In the KAB sample, about onethird (32 percent) of respondents in the community-based intervention area reported participating at least once in support groups. Of those who did participate, slightly more than half participated in more than one session (table 6.6 and figure 6.6). An additional 6 percent did not attend a support group at all, but another family member did.

Respondents in PC intervention areas were more likely to have attended support groups than those in NRSP areas. Of those who did attend, those in the PC area were more likely to have attended more than once. The chance of a family member attending when the respondent did not was about equal in the two groups.

\section{Figure 6.6: Percentage of women in site 1 who attended women's support group meetings}

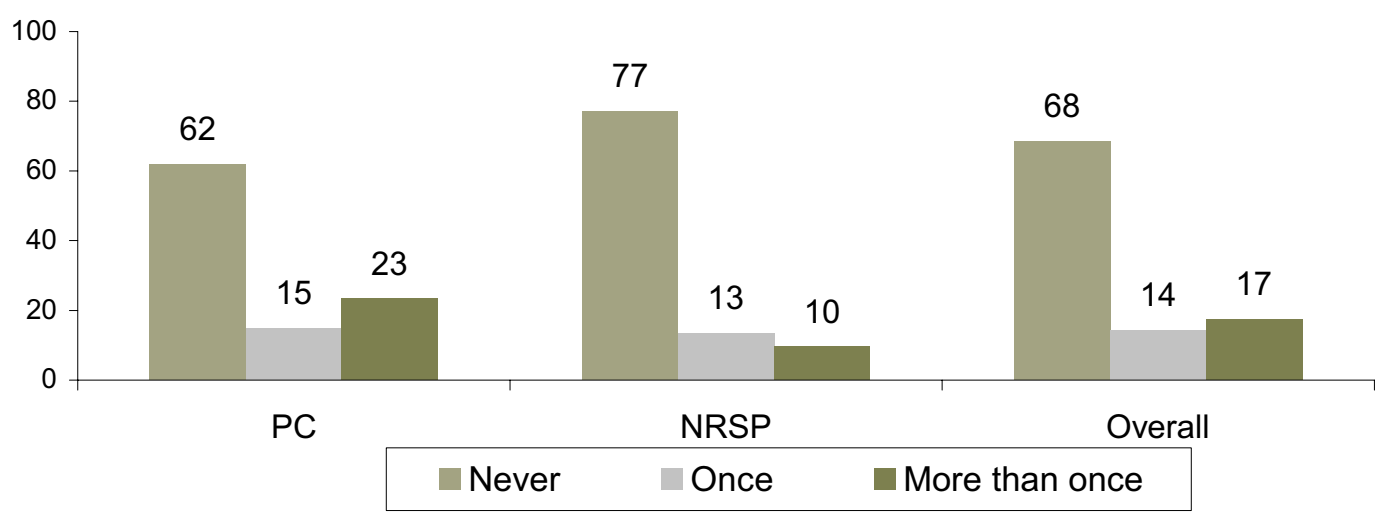

Figure 6.7 presents data on women's knowledge about danger signs during pregnancy, delivery and the postpartum period and in newborns by the number of meetings attended. Women who participated in women's support groups are more knowledgeable than those 
who did not, and women who attended group meetings more than once are more likely than those who attended only once to be knowledgeable. Apparently women's support groups were effective in improving women's knowledge of danger signs.

Figure 6.7: Proportion of women in site 1 who know at least 3 danger signs of pregnancy, delivery, postpartum period an $\mathrm{d}$ newborns by number of support group meetings attended

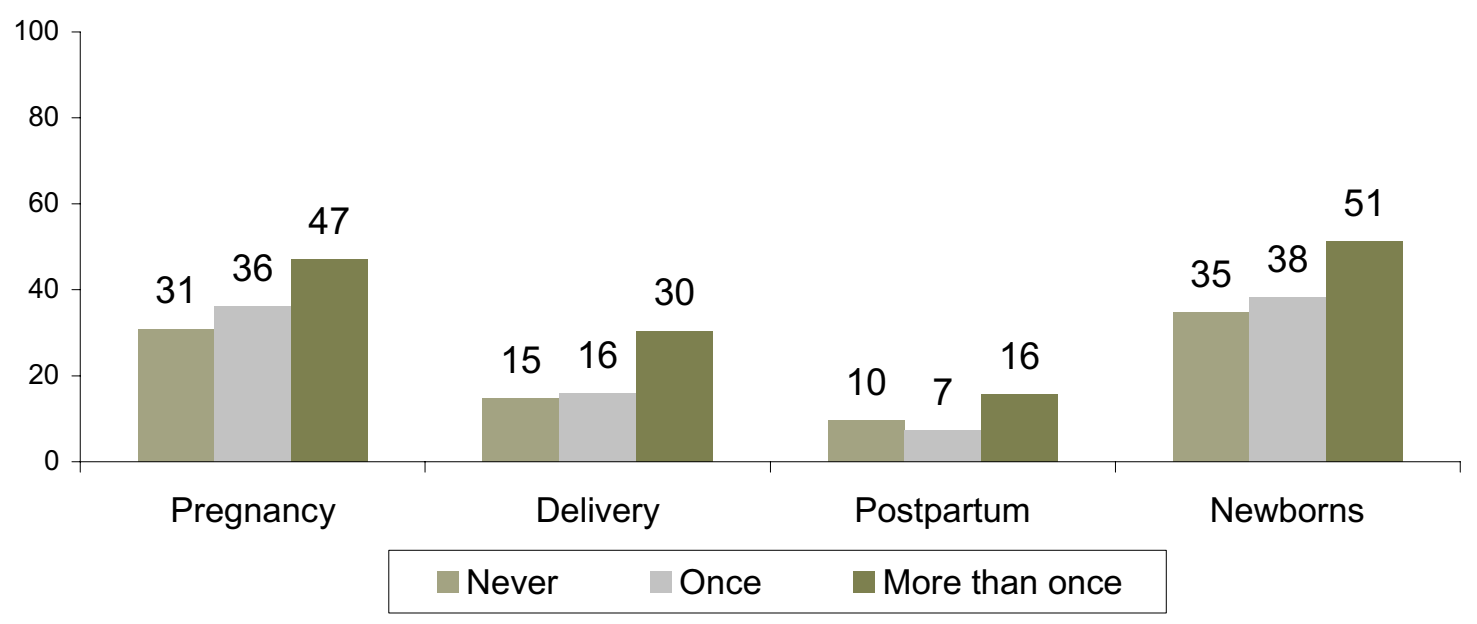

\section{Information, education, and empowerment for change (IEEC) material}

An important activity in site 1 was the distribution of pictorial booklets and audiocassettes to married women of reproductive age and antenatal cards to currently pregnant women.

Data presented in table 6.7 show that about two-thirds of women in the intervention area received or saw (in the following text, "received" means "received" or "saw/heard") booklets and almost same proportion heard audiocassettes. Less than one-quarter of women reported receiving antenatal cards. More women received these materials in the Population Council- served communities than the NRSP communities. 
Table 6.7: Percentage of women who received or saw IEEC materials in site 1 by organizational coverage, site 1 and $\mathrm{KAB}$ round 3

\begin{tabular}{lcrr}
\hline IEEC material & PC & NRSP & Overall \\
\hline Booklet & 73.8 & 53.2 & 65.0 \\
Cassette & 72.1 & 51.4 & 63.3 \\
Antenatal Card & 25.4 & 20.4 & 23.3 \\
No. of respondents & 378 & 280 & 658 \\
\hline
\end{tabular}

Three-fourths of women in PC areas and 54 percent in NRSP areas reported receiving at least one of the IEEC materials (table 6.8). Sixty-three percent of women received at least two IEEC items, higher in the PC areas (71 percent) than the NRSP areas (51 percent).

Table 6.8: Percent distribution of wo men according to number of materials received in arm 1 by organizational coverage, site 1 and KAB round 3

\begin{tabular}{crrr}
\hline Number of IEEC materials received & PC & NRSP & Total \\
\hline 0 & 25.4 & 46.4 & 34.3 \\
1 & 2.9 & 2.5 & 2.7 \\
2 & 46.8 & 30.7 & 40.0 \\
3 & 24.9 & 20.4 & 22.9 \\
No. of respondents & 378 & 280 & 658 \\
\hline
\end{tabular}

It is important to know how women were exposed to IEEC materials. Table 6.9 shows that women who attended women support groups always received booklets and cassettes; that if any other family member attended support group meetings, the respondent nearly always saw or received these materials; and that in more than 40 percent of cases where no one in the family attended, the respondent had seen or received the materials. For the antenatal cards, which were intended to be given to pregnant women, these were much less likely to have been received if no one in the family attended a support group. 
Table 6.9: Percentage of women who have seen/received IEEC materials according to attendance at support groups, site 1 and KAB round 3

\begin{tabular}{lrrr}
\hline IEEC material & Respondent attended & $\begin{array}{c}\text { Only other family } \\
\text { member attended }\end{array}$ & No one attended \\
\hline Booklet & 100.0 & 94.6 & 44.8 \\
Cassette & 100.0 & 89.2 & 42.5 \\
Antenatal Card & 44.7 & 45.9 & 10.4 \\
No. of observations & 208 & 37 & 412 \\
\hline
\end{tabular}

Overall, about one-fourth of women who delivered during the year prior to the survey received an ANC card (table 6.10); the proportion was similar in PC and NRSP areas. However, some women who delivered in the previous year might have delivered before project services reached their community.

Table 6.10: Percentage of women pregnant during previous year who received antenatal care card, by organizational coverage, site 1 and KAB round 3

\begin{tabular}{lrrr}
\hline Received antenatal card & PC & NRSP & Total \\
\hline Yes & 27.4 & 23.0 & 25.3 \\
No & 72.6 & 77.0 & 74.7 \\
Total & 100.0 & 100.0 & 100.0 \\
No. of respondents & 84 & 74 & 158 \\
\hline
\end{tabular}

Figure 6.8 presents data on the relationship between exposure to IEEC material and women's knowledge of danger signs. Women who had seen or received at least one item had greater knowledge than those who did not. While IEEC material seems effective in improving women's knowledge, it is also true that most such women also attended support groups, so the two effects need to be separated. Nearly all women who attended support groups received IEEC materials; however, 44 percent of women who received IEEC materials did not attend support groups. It appears from figure 6.8 that while knowledge is generally highest for those who received IEEC materials and also attended support groups, there was also some improved knowledge among those who had only received the materials. 
Figure 6.8: Women who know 3+ danger signs of childbearing period by support group and IEEC material

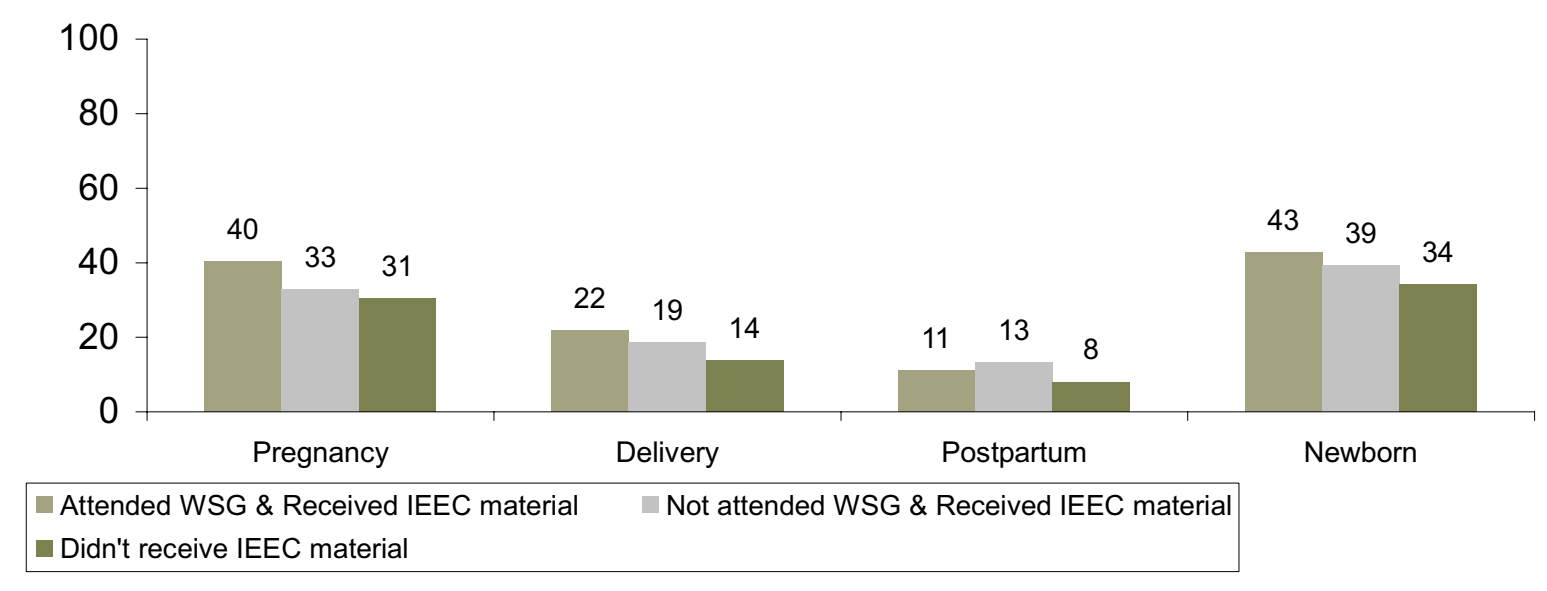

\section{Training of lady health workers (LHWs)}

The health care providers at the community level (dais and LHWs) were trained in order to improve the quality of care provided to mothers and neonates. The main objectives of training LHWs were to improve their clinical skills and to bring about a behavioral change in the manner with which they deal with their clients. Client Centered Approach training helps service providers improve their interpersonal communication skills when dealing with clients. Technical training was conducted to improve the technical skills of LHWs. In all, 154 LHWs and 13 Supervisors were trained in 11 batches (See SMART Report 4. Knowledge and Behavior of Service Providers). This training might have had an impact on their clients' knowledge. On the other hand, it was not anticipated that the dai training would have a measurable impact on clients' knowledge.

It was assumed that after the training of LHWs, there would be an improvement in the frequency and content of home visits by LHWs. The LHW is expected to visit every household once in two months. Data presented in figure 6.9 illustrate LHWs' home visitation pattern. There has been an improvement in visitation rate of LHWs over the project period in all three sites, perhaps due to placement of new LHWs in both districts during the project period. However, the improvement is greatest in site 1. Before the start of the SMART project, 35 percent of women in site 1 reported being visited by a LHW during the two months prior to the survey; by round 3, this had increased to 54 percent. Comparable proportions increased from 40 to 49 percent in site 2 and from 44 percent to 59 percent in site 3 . 
Figure 6.9: Percent of women visited by LHW during previous 2 months

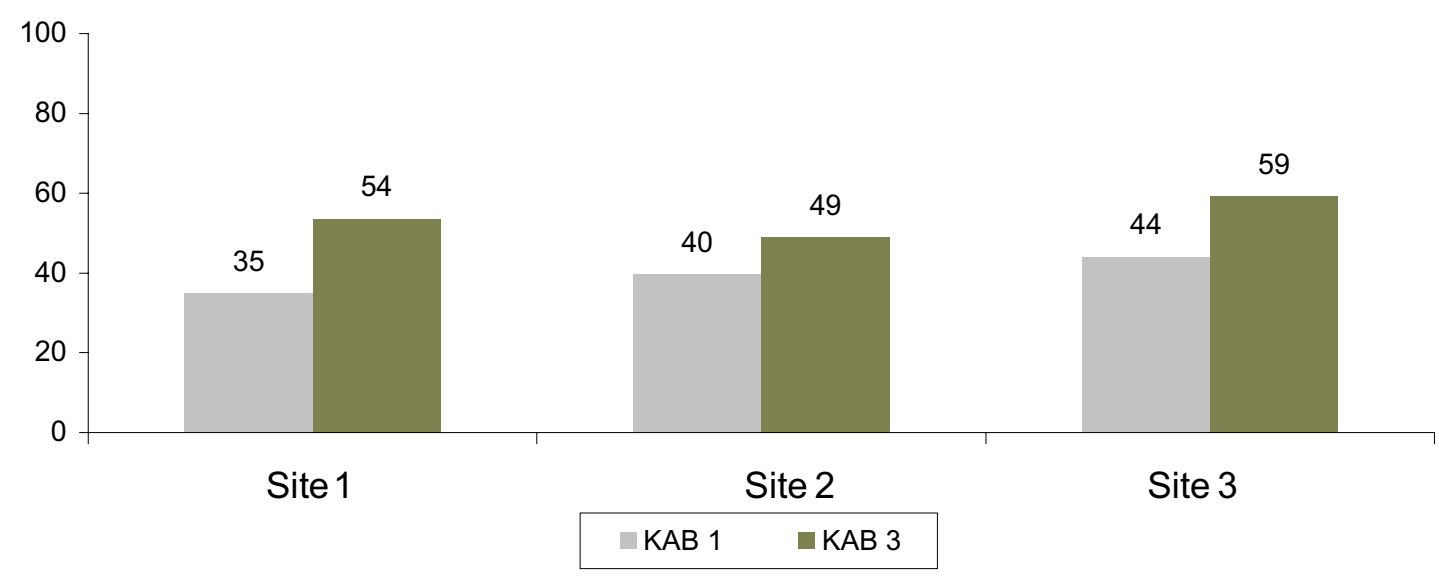

On the other hand, LHWs do not have a consistent impact on women's knowledge about danger signs in site 1 (figure 6.10). Women who have been visited by a LHW during the last 2 months have better knowledge about the danger signs of pregnancy and in newborns, but are less likely to know about delivery and postpartum danger signs.

Figure 6.10: Proportion of women who know at least 3 danger signs of pregnancy, delivery, postpartum period and newborns by LHW visitation in past 2 months

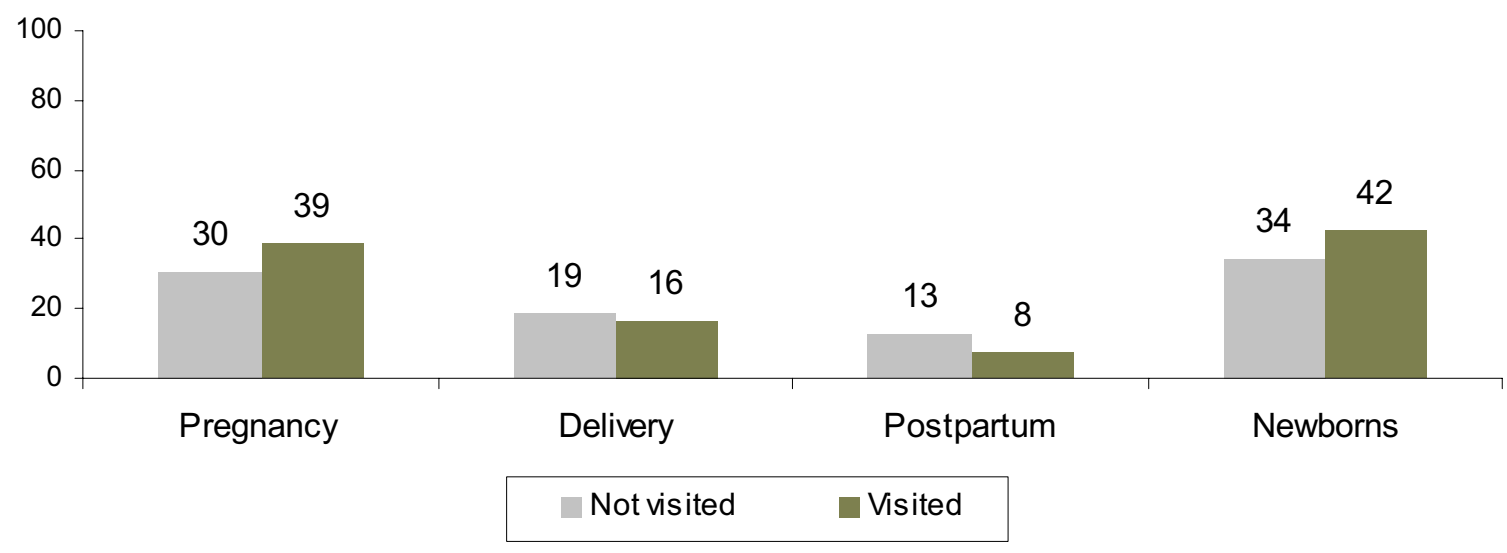

\section{Knowledge and women's autonomy}

Using data from the KAB survey, we looked at the relationship between the three dimensions of women's autonomy and knowledge of danger signs during the childbearing 
cycle. Since there were no substantial differences within DG Khan between arms 1 and 2, data are presented here only for DG Khan (combined arms) and Layyah.

Decision-making power. In DG Khan, the level of women's participation in decisionmaking is not associated with their knowledge of danger signs of pregnancy, delivery, postpartum, and in newborns (figure 6.11). On the other hand, in Layyah, women with a greater level of involvement in the decision-making process are more knowledgeable in all areas than those women who have no or some power.

Figure 6.11: Percentage of women who know danger signs of pregnancy, delivery, postpartum and in newborn by decision-making power, KAB round 3

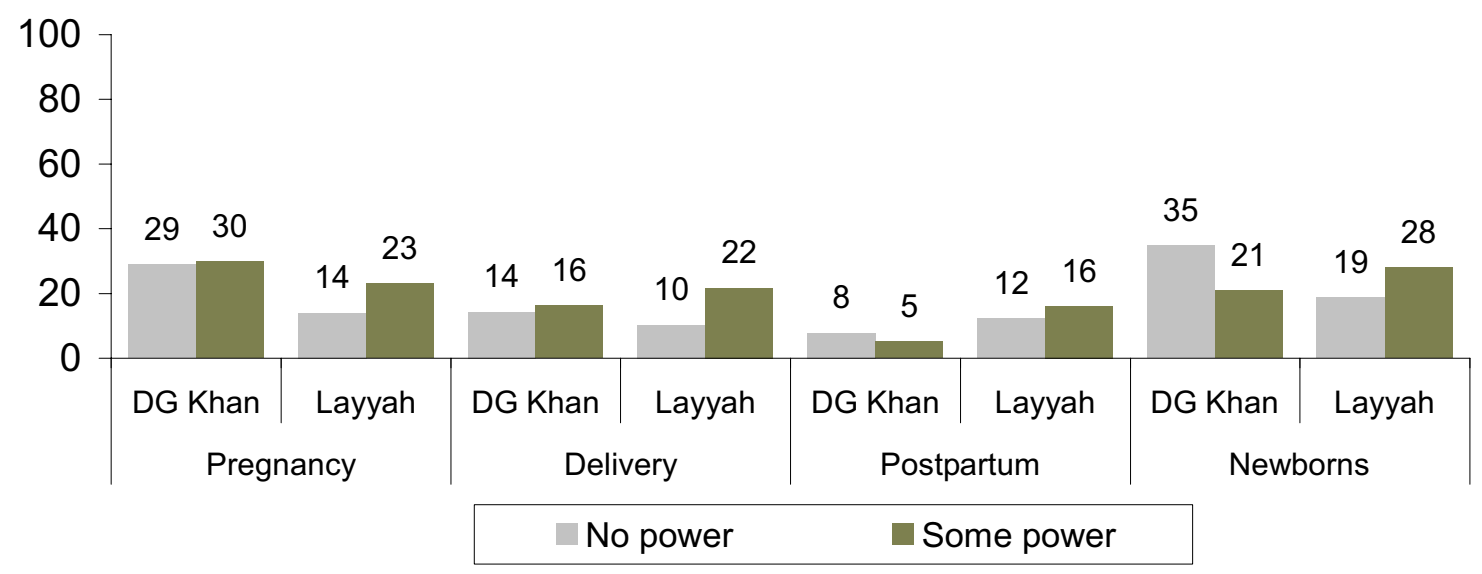

\section{Control over finances}

Women's control over finances shows little consis tent association with any facet of knowledge (figure 6.12), although women with full control over finances show somewhat greater levels of knowledge of the danger signs of pregnancy than women with no or some control (data not shown). 
Figure 6.12: Percentage of women who know danger signs of pregnancy, delivery, postpartum and newborns by their control over finances, KAB round 3

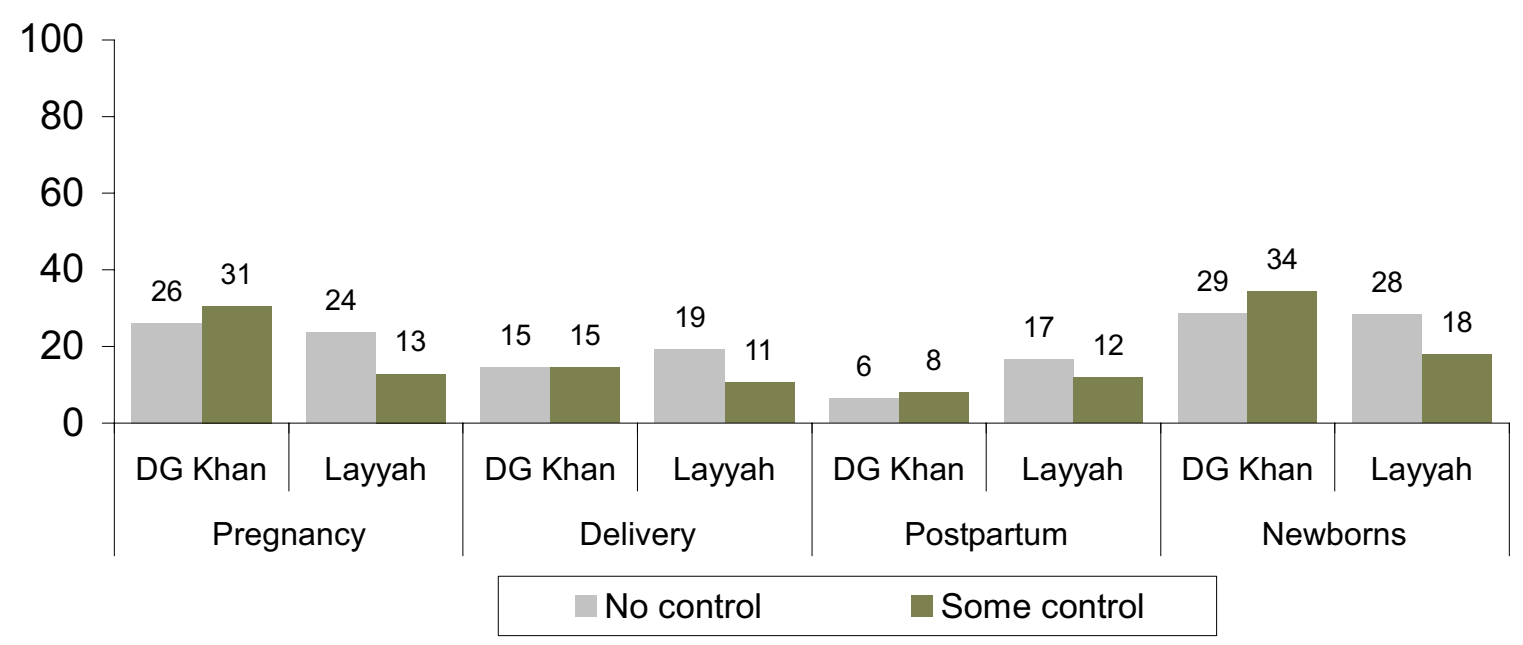

\section{Female mobility}

Female mobility has a stronger relationship with women's knowledge about danger signs in both districts (figure 6.13) than other measures of women's autonomy. Women with full freedom to move about are more knowledgeable than women with restricted mobility, in all knowledge areas and in both districts. For the most part, women with partial mobility have greater knowledge than women with no mobility.

Freedom of movement, as measured by our survey, is the most salient of the women's autonomy variables, as will also be shown below. This relationship appears to be largely independent of attendance at support group or socio-economic status, both of which are only weakly associated with mobility (data not shown). Usually, the difference between "full mobility" and "some mobility" is whether the woman can go to a health center or hospital alone. It appears that women who have this freedom are more knowledgeable about MNH than those who do not. 
Figure 6.13: Percentage of women who know danger signs of pregnancy, delivery, postpartum and in newborn by level of mobility, KAB round 3

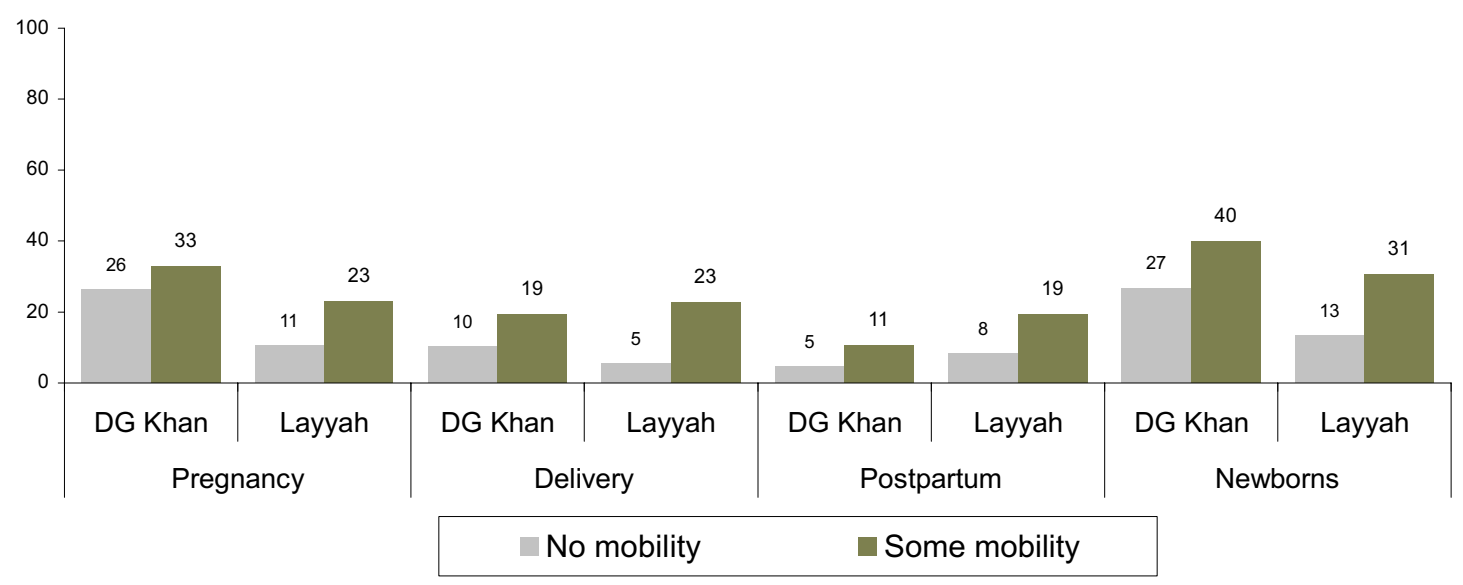





\section{Routine Maternal and Neonatal Health Practices}

In the HHS, respondents were asked how long ago they had their last pregnancy, and its result. Women who reported being pregnant during the year prior to the survey were asked about the care they received during pregnancy, delivery and the postpartum period. They were also asked about care of their newborn on the day of birth and within the first seven days. In the $\mathrm{KAB}$, the subsample respondents were asked about exposure to women's support groups and IEEC materials, and details regarding births taking place in the previous six months.

\section{Delivery outcome}

One of the objectives of the project was to improve pregnancy outcome by creating awareness among women about the care needed during pregnancy, e.g., advice on proper diet, avoiding heavy work, consultation with qualified health care providers, etc.

Eighty-seven percent of pregnancy outcomes reported in the baseline survey resulted in live births and about four percent in stillbirths. Fewer than 10 percent of pregnancies resulted in either spontaneous or induced abortion. There were differences in the stillbirth rates, ranging from about 3 percent in site 2 to 5 percent in site 3; rates were consistent within each site. Wastage of pregnancy due to spontaneous abortion was highest in site 1 and lowest in site 2 . There were no important changes in birth outcomes between rounds in any site.

Table 7.1: Outcome of last pregnancy during previous 12 months, by site and HHS round

\begin{tabular}{lrrrrrr}
\hline & \multicolumn{2}{c}{ Site 1 } & \multicolumn{2}{c}{ Site 2 } & \multicolumn{2}{c}{ Site 3 } \\
\cline { 2 - 7 } & Baseline & Endline & Baseline & Endline & Baseline & Endline \\
\hline Outcome & & & & & & \\
$\quad$ Live birth & 85.2 & 85.2 & 88.3 & 87.5 & 86.6 & 88.4 \\
Stillbirth & 3.8 & 3.4 & 2.8 & 2.9 & 4.9 & 5.1 \\
Spontaneous abortion & 10.2 & 10.6 & 8.2 & 9.1 & 7.7 & 5.8 \\
Induced abortion & 0.8 & 0.7 & 0.7 & 0.5 & 0.7 & 0.7 \\
$\quad$ Total & 100.0 & 100.0 & 100.0 & 100.0 & 100.0 & 100.0 \\
No. of observations & 2329 & 2290 & 2219 & 2241 & 1760 & 1749 \\
\hline
\end{tabular}




\begin{tabular}{lrrrrrr}
\hline & \multicolumn{2}{c}{ Site 1 } & \multicolumn{2}{c}{ Site 2 } & \multicolumn{2}{c}{ Site 3 } \\
\cline { 2 - 7 } & Baseline & Endline & Baseline & Endline & Baseline & Endline \\
\hline Type of delivery & & & & & & \\
$\quad$ Normal vaginal delivery & 84.4 & 84.6 & 85.6 & 86.4 & 84.8 & 84.1 \\
$\quad$ Assisted vaginal delivery & 3.5 & 2.4 & 4.0 & 2.6 & 4.3 & 5.7 \\
Caesarean section & 1.2 & 1.7 & 1.6 & 1.3 & 2.6 & 3.6 \\
Abortion (spontaneous & 10.9 & 11.3 & 8.8 & 9.6 & 8.3 & 6.5 \\
Induced) & & & & & & \\
$\quad$ Total & 100.0 & 100.0 & 100.0 & 100.0 & 100.0 & 100.0 \\
No. of observations & 2325 & 2288 & 2217 & 2237 & 1758 & 1747 \\
\hline
\end{tabular}

In the baseline survey, women reported that 85 percent of deliveries were normal vaginal deliveries. Fewer than two percent were delivered through caesarean section, well below the recommended level. (According to WHO, between 5 and 15 percent of deliveries need caesarian section.) The caesarean section rate is slightly higher in site 3 in both rounds than in DG Khan. No consequential change was seen between rounds.

\section{Use of maternal health care services}

The project aimed to increase utilization of maternal health care services. This included increase in antenatal visits, increase in immunization rate against tetanus, increased use of iron supplements, increased use of skilled birth attendants and increase in postpartum care.

In the following sections, data on pregnancies that resulted in either live births or stillbirths are analyzed because use of antenatal care and delivery care services are more relevant if the pregnancy is full-term.

\section{Antenatal care}

\section{Use of antenatal services}

Antenatal care helps in keeping pregnant women healthy and also in identifying pregnant women who may have early signs of a risk of complications that may require timely intervention.

An antenatal visit is defined as a visit to a qualified health provider, which can be a medical doctor, a nurse, an LHV or trained midwife (but not an LHW or dai), during pregnancy for a routine checkup. The Ministry of Health of Pakistan recommends that each pregnant 
woman should have at least three such antenatal visits. Table 7.2 and figure 7.1 show the percentage of women who visited a qualified care provider during their last pregnancy, and the source of that care.

\section{Table 7.2: Percentage of women rece iving routine antenatal care during} pregnancy, by site and HHS round

\begin{tabular}{|c|c|c|c|c|c|c|}
\hline \multirow[b]{2}{*}{ Pregnancy care } & \multicolumn{3}{|c|}{ Site 1} & \multicolumn{2}{|l|}{ Site 2} & \multirow{2}{*}{$\begin{array}{r}\text { Site } 3 \\
\text { Endline }\end{array}$} \\
\hline & Baseline & Endline & Baseline & Endline & Baseline & \\
\hline \multicolumn{7}{|l|}{ Antenatal visits } \\
\hline 0 & 49.0 & 41.8 & 51.0 & 46.9 & 58.6 & 44.2 \\
\hline 1 & 13.5 & 16.3 & 13.2 & 15.5 & 10.4 & 14.5 \\
\hline 2 & 22.1 & 21.5 & 20.7 & 20.3 & 18.6 & 18.9 \\
\hline 3 and more & 15.3 & 20.4 & 15.1 & 17.3 & 12.5 & 22.6 \\
\hline \multicolumn{7}{|c|}{ Source of antenatal care* } \\
\hline Basic Health Unit & 28.4 & 25.8 & 36.0 & 34.1 & 40.8 & 31.9 \\
\hline Rural Health Center & 9.5 & 16.5 & 7.9 & 11.8 & 12.3 & 10.1 \\
\hline DHQ/THQ hospital & 25.6 & 13.8 & 17.2 & 10.6 & 21.5 & 12.3 \\
\hline $\mathrm{MCH}$ center & 1.3 & 1.2 & 0.7 & 0.3 & 1.7 & 3.5 \\
\hline Private hospital & 33.2 & 40.1 & 34.9 & 41.9 & 20.8 & 40.3 \\
\hline Other & 2.0 & 2.6 & 3.3 & 1.3 & 2.9 & 1.9 \\
\hline No of respondents & 1740 & 1711 & 1588 & 1645 & 1334 & 1457 \\
\hline
\end{tabular}

*Percentages are based on numbers of visits rather than respondents

Figure 7.1: $\quad$ Percent of women who made 3 or more antenatal visits

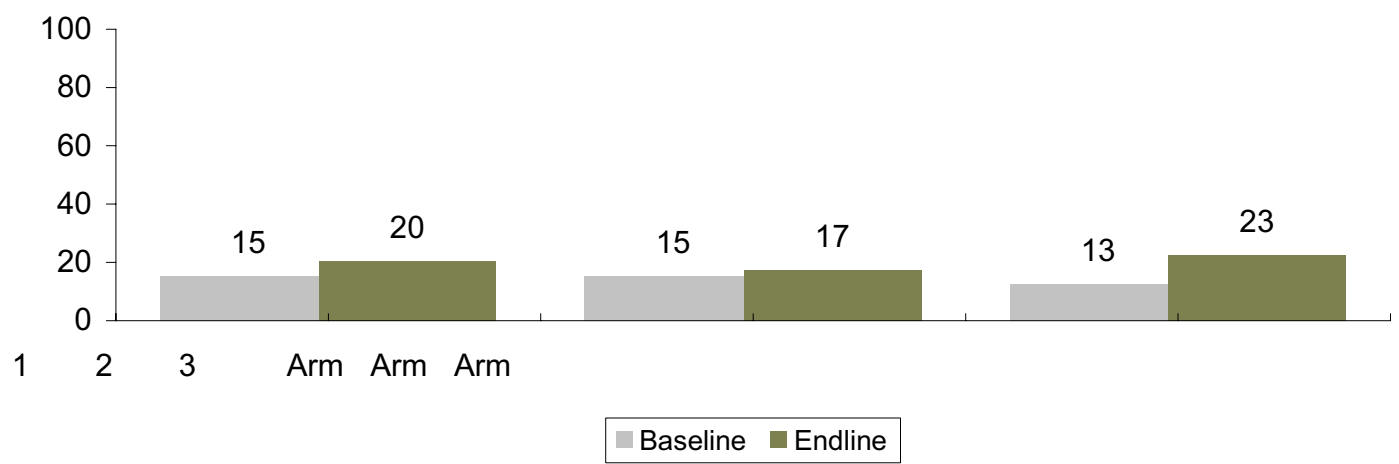

At baseline, approximately 15 percent of pregnant women in each site had at least 3 routine antenatal visits; about half of all women in the CBI and HSI areas, compared with 41 percent 
in Layyah, had gone for at least one visit. By comparison, the 2004-05 Pakistan Social and Living Standards Measurement Survey found that 54 percent of pregnant women in rural DG Khan and 45 percent in Layyah had visited a health facility at least once for pre-natal consultation.

In each site the proportion with three antenatal visits increased in the endline survey, with the increase greatest in Layyah, lowest in the HSI arm, and intermediate in the CBI arm. The higher increase in the control area suggests that factors other than the SMART project were involved.

\section{Source of antenatal care}

Women who went for three or more antenatal visits were asked about the source of their care. Data presented in table 7.2 show that women are going to both government and private health facilities for antenatal care. At baseline, about one-third of women in both project areas were going to private hospitals, compared with one-fifth in Layyah. In all three areas, substantial proportions of women went to BHUs, RHCs, and DHQ/THQ hospitals, all of which are government facilities.

In all three sites, the proportion seeking antenatal care at private facilities increased substantially at the time of the endline survey, with the greatest increase in Layyah. The proportion visiting DHQ or THQ hospitals was sharply reduced, especially in the CBI area.

\section{Correlates of antenatal care}

Some women are more likely to seek antenatal care than others, and analysis of which women are more likely to seek care can help providers target their services to those who most need them. Figures 7.3a through 7.3e show how antenatal care varies by several important demographic and socioeconomic variables.

Age. Younger women (less than 20 years of age) and older women (above 35) are at elevated risk of pregnancy complications, and it is particularly important that these women seek antenatal care. However, figure 7.2a shows that in all sites and survey periods, the proportion of women with three or more antenatal visits declines with increasing age.

Parity. The situation with parity is similar to age. Women giving birth for the first time and women with high parity are at greater risk than those in between, but the proportion seeking antenatal care in general declines monotonically with parity. We assume that this 
could be a confluence of two tendencies. First, younger and lower-parity women tend to be better educated and are more likely to heed "modern" advice. Second, older and higherparity women, having more personal experience with childbearing, may feel less in need of special care.

Education. The powerful effect of education on health behavior is well known. From figure $7.2 \mathrm{c}$ it is clear that, with some anomalies, the proportion of women seeking antenatal care visits (3+ visits) rises sharply with increasing education.

Ethnicity. Ethnicity can have strong effects on health seeking behavior. Figure 7.2d shows that in DG Khan Saraiki speakers are twice as likely to seek antenatal care as Balochi speakers, while in Layyah Saraiki speakers are less likely to seek such care than Punjabi speakers.

Wealth quintile. Women with higher economic status can be expected to be better educated, and also to have better access to transport and fewer concerns about the expense of care. Figure 7.2e shows, as expected, that the proportion of women with three or more antenatal visits rises with wealth quintiles. This tendency, however, is relatively weak compared with the effect of education.

These data in general show that antenatal care increases with socioeconomic status and decreases with age and parity. Multivariate analysis might help to show which of these effects remain important after controlling for other correlates.

In all three sites, the overall increase in the proportion with three or more antenatal visits is consistent across levels of explanatory variables; that is, the increase is not limited to certain subgroups. (There are a few exceptions to this statement that we assume, in the absence of logic or evidence to the contrary, are non-systematic data anomalies.) In Layyah, the control area, it appears that the associations are generally more pronounced at the endline than at the baseline; that is, the tendency for younger and lower-parity women and women with higher socio-economic status to be more likely to receive antenatal care seems to be greater at the endline than at baseline. 
Figure 7.2a: Antenatal visits (3+) by age

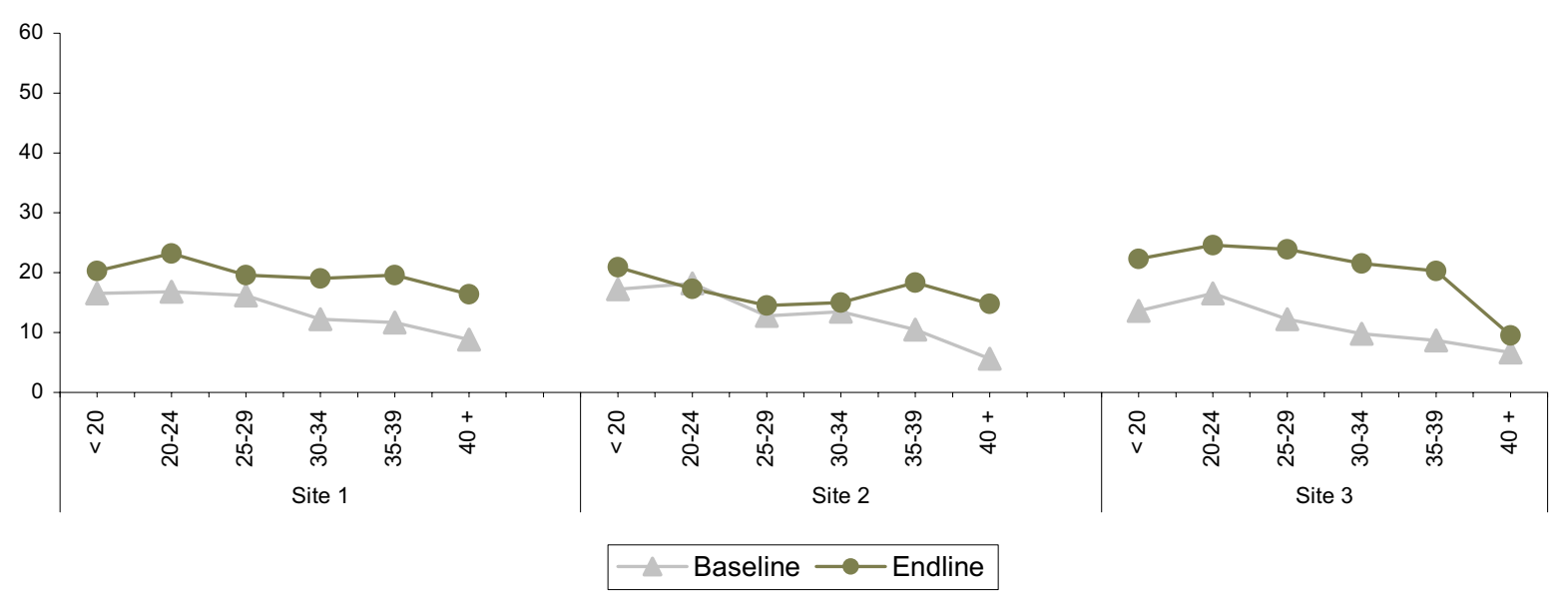

Figure 7.2b: Antenatal visits $(3+)$ by parity

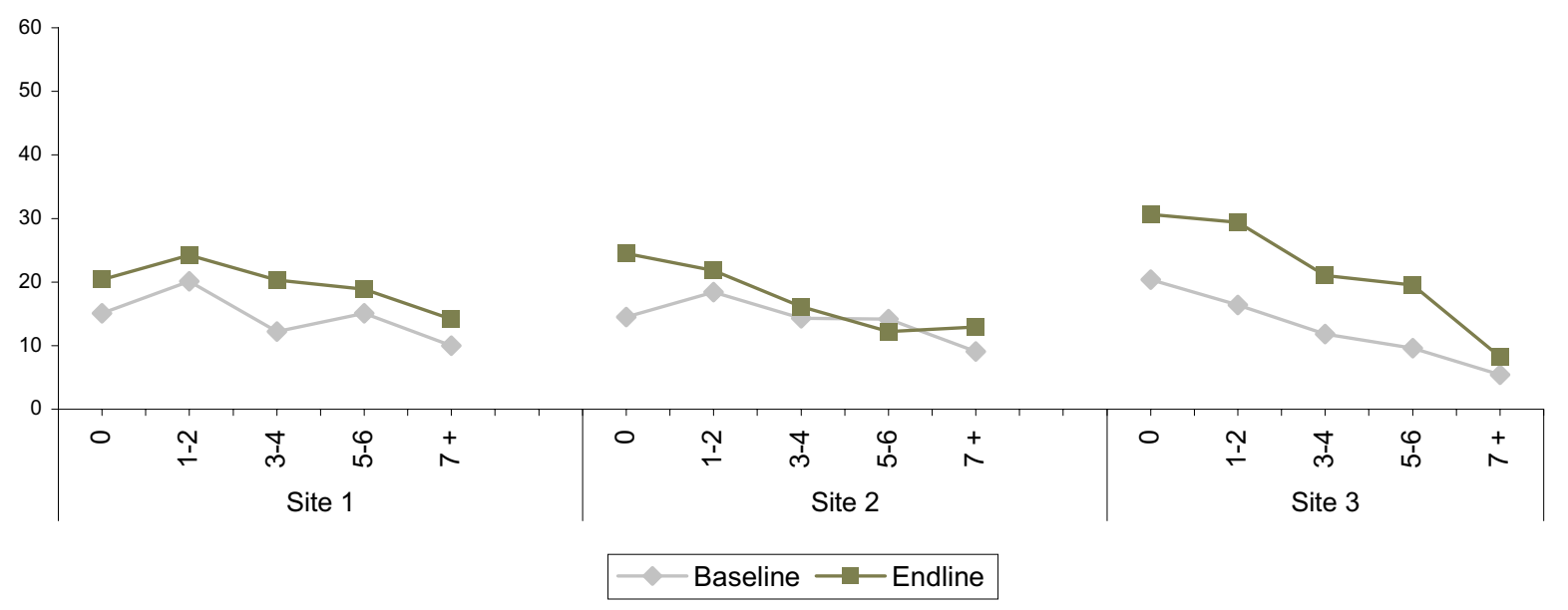


Figure 7.2c: Antenatal visits $(3+)$ by education

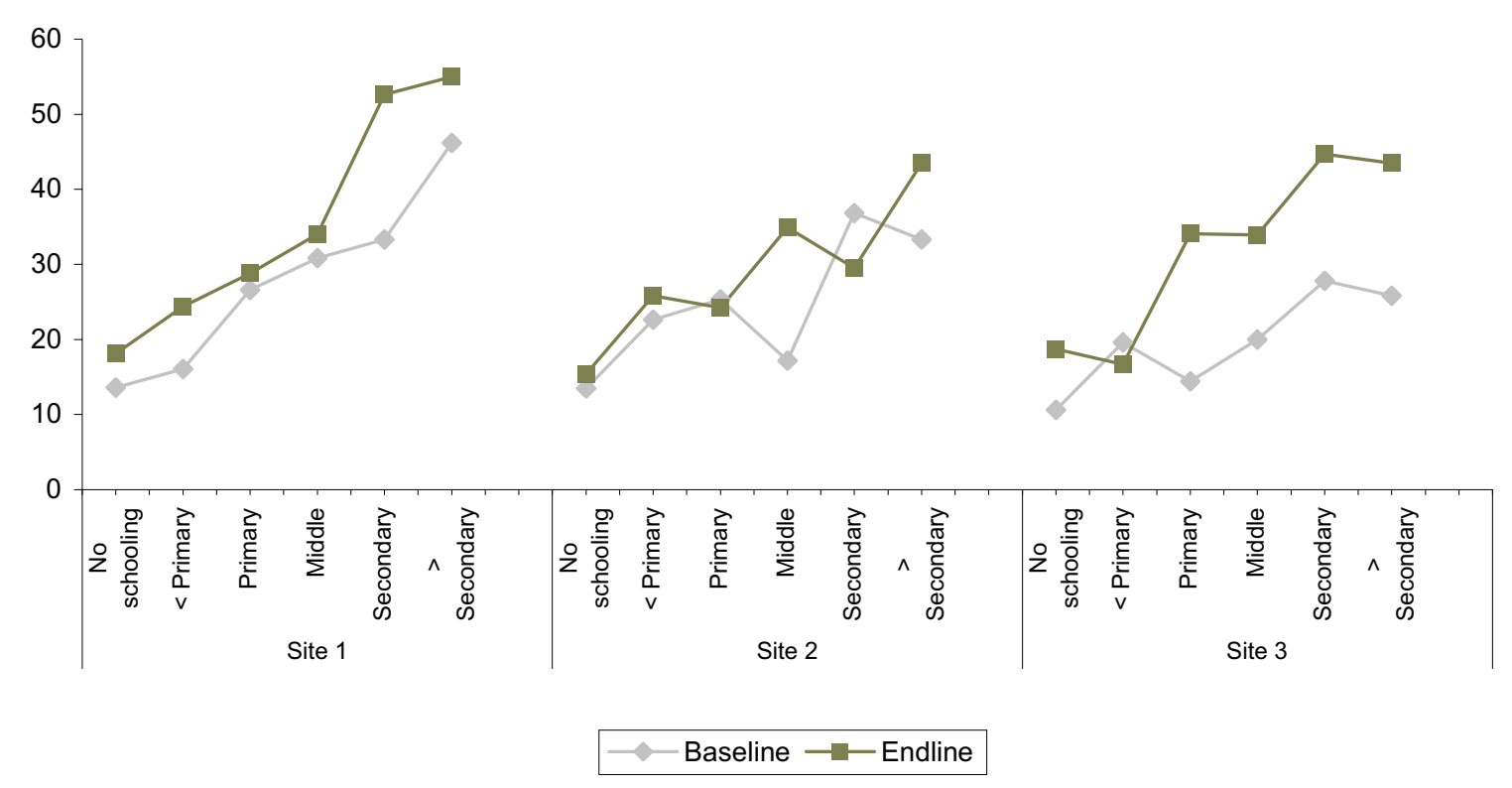

Figure 7.2d: Antenatal visits (3+) by language

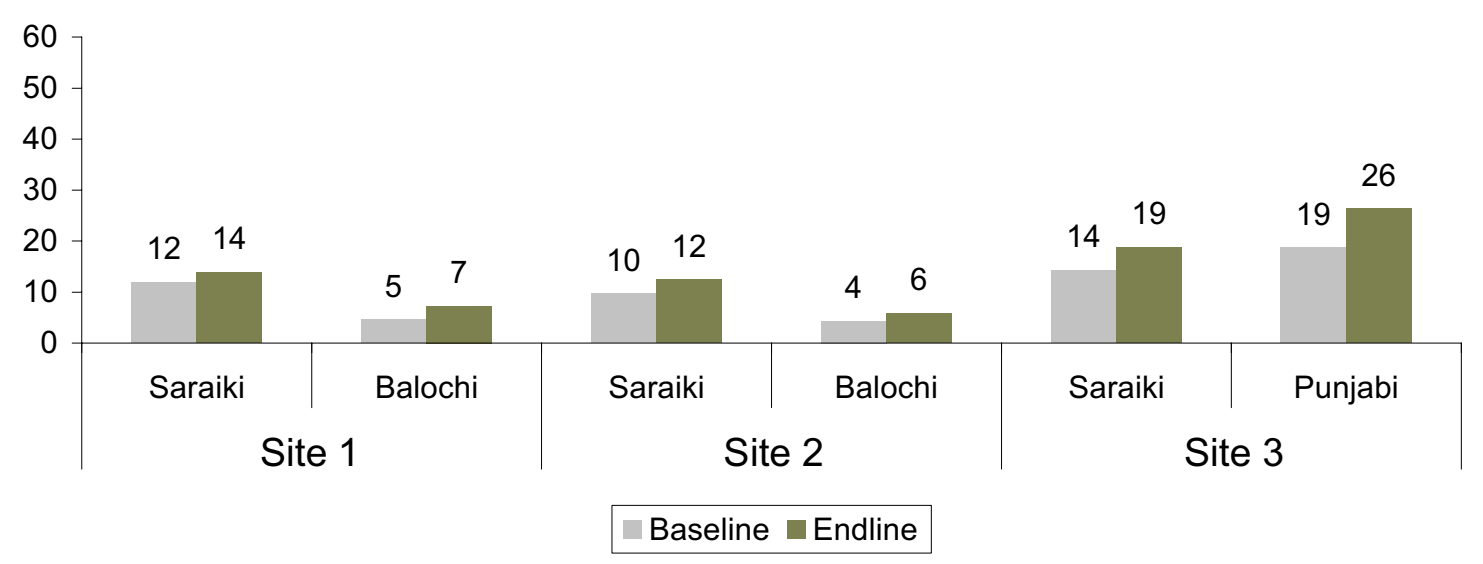


Figure 7.2e: Antenatal visits (3+) by wealth quintile

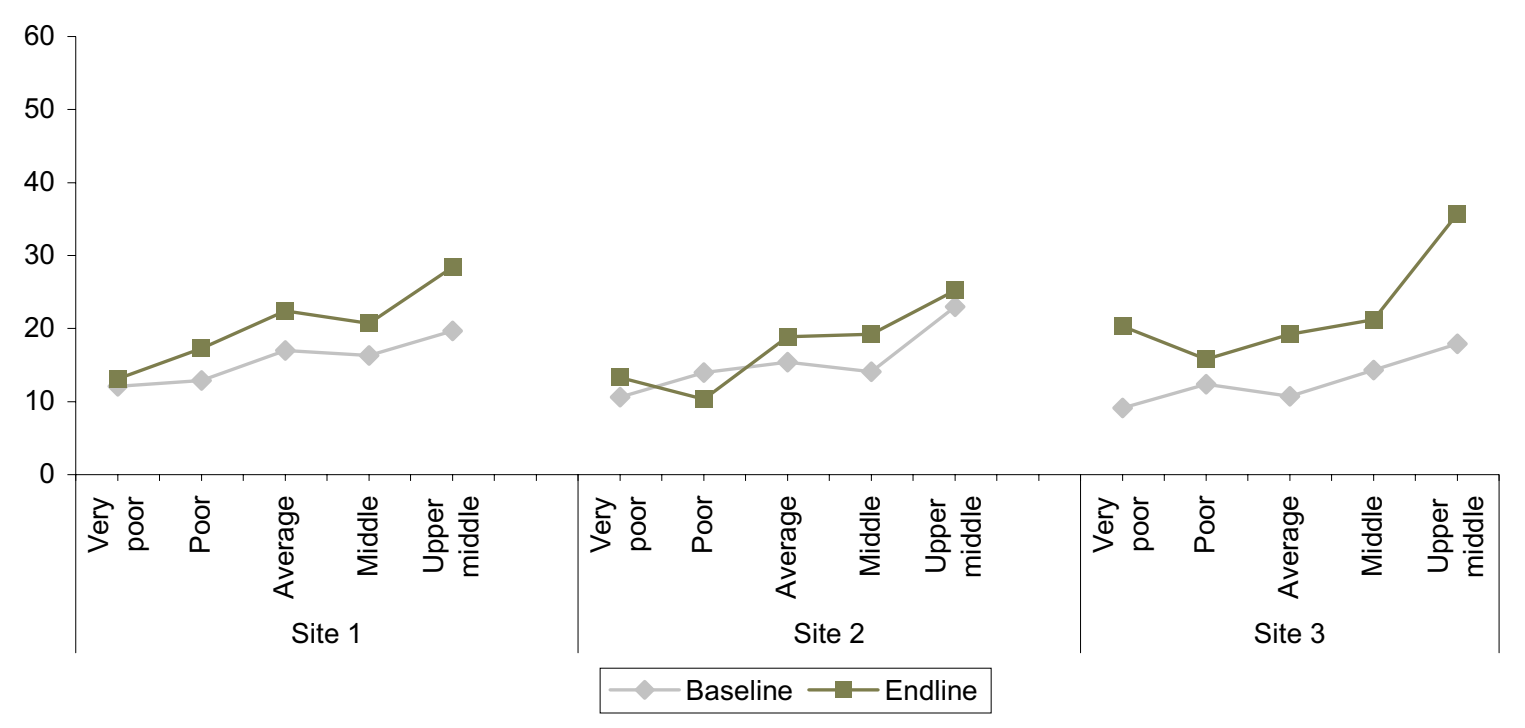

\section{Immunization against tetanus}

Since most of the deliveries are conducted at home under unhygienic conditions, it is important for women to be immunized against tetanus to improve maternal and newborn health and to reduce mortality, especially neonatal mortality. Hence it was a project objective to increase immunization rates against tetanus.

As shown in figure 7.3, fewer than half of the pregnant women in Dera Ghazi Khan and more than half in the control area (Layyah district) were immunized against tetanus (2 TT shots). There has been no change in women's immunization rates in the intervention area between the two surveys. However, there is some increase in the control area, from 54 percent in the baseline survey to 60 percent at endline. 
Figure 7.3: Percent of women with 2+ tetanus shots

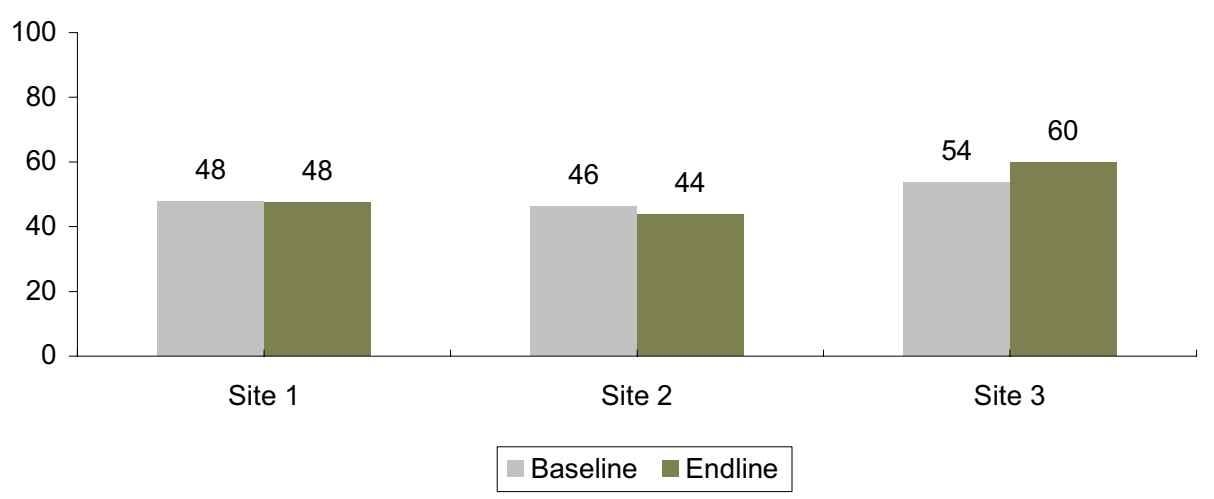

Data from the PSLM (Pakistan Social and Living Standard Measurement) Survey 2004-2005 show that 62 percent of pregnant women in rural DG Khan and 69 percent in rural Layyah had at least one TT shot. By comparison, our endline survey conducted during the first quarter of 2006 shows that 58 percent of women in DG Khan and 68 percent Layyah received one or more TT shots.

Immunization against tetanus is strongly related to the number of antenatal visits (figure 7.4). Women who make two or more antenatal visits are highly likely to have at least one TT shot.

Figure 7.4: Percent of women with one or more TT shot according to number of ANC visits, by site, HHS endline

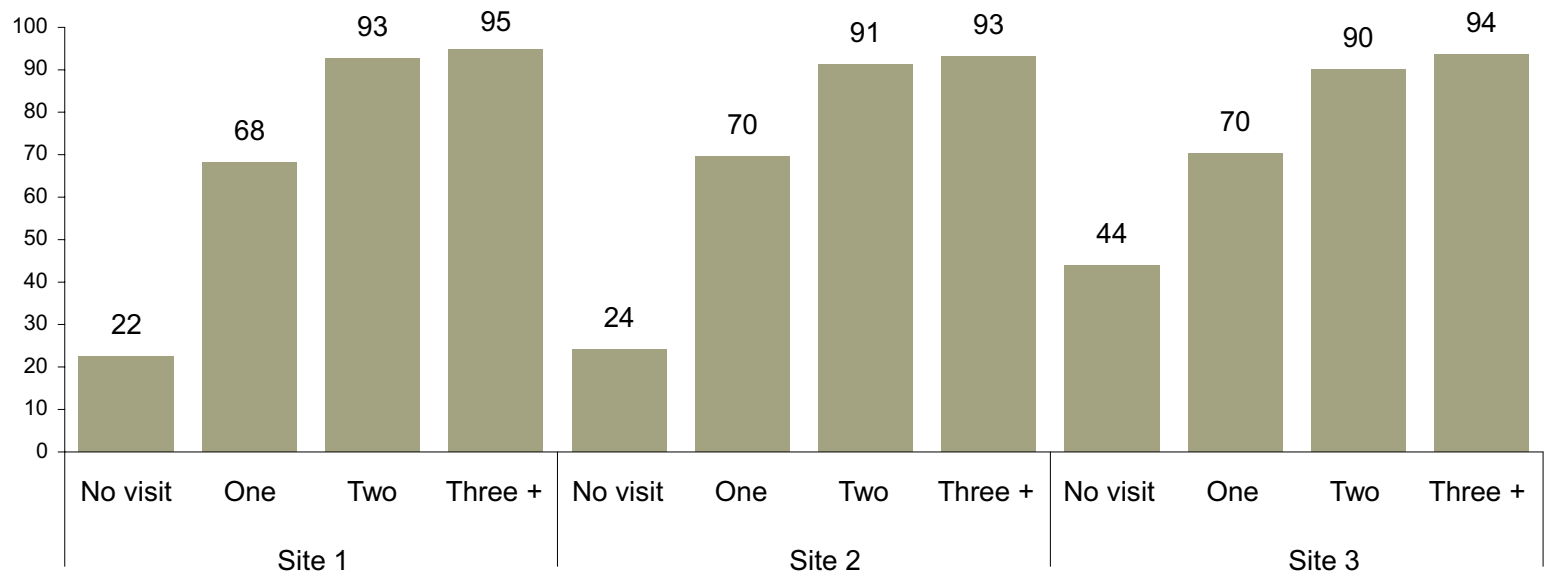


As table 7.3 illustrates, more than 80 percent of women receive their tetanus shots from a government health facility, compared with fewer than 10 percent of women who are immunized at a private facility. This pattern is similar in both districts.

There has been a shift in the use of government health facilities. Women at endline were more likely to go to RHCs/BHUs instead of tehsil or district hospitals. The percentage of women who received TT shots from RHCs/BHUs has increased from 49 percent to 63 percent in site 1 and 57 percent to 65 percent in site 2, while the proportions served by the DHQ or THQ hospital decreased.

Proportions reporting provision of TT shots from lady health workers (LHWs) declined by more than half in both sites in DG Khan, while it increased substantially (from a higher baseline level) in Layyah. Reasons for this are likely to be found in the LHW programs of the two districts.

Table 7.3: Percent distribution of wome $n$ by number of TT shots and source, by site and KAB round

\begin{tabular}{lrrrrrr}
\hline & \multicolumn{1}{c}{ Site 1 } & \multicolumn{3}{c}{ Site 2 } & \multicolumn{3}{c}{ Site 3 } \\
\cline { 2 - 7 } Pregnancy care & Baseline & Endline & Baseline & Endline & Baseline & Endline \\
\hline Tetanus toxoid shots & & & & & & \\
$\quad 0$ & 40.9 & 40.2 & 44.1 & 43.3 & 39.9 & 32.5 \\
1 & 11.4 & 12.3 & 9.7 & 12.9 & 6.3 & 7.8 \\
2 & 47.7 & 47.5 & 46.2 & 43.8 & 53.7 & 59.8 \\
Source of TT shots & & & & & & \\
BHU/RHC/MCH & 49.3 & 62.5 & 57.1 & 65.4 & 50.2 & 52.8 \\
DHQ/THQ hospital & 29.0 & 17.7 & 22.8 & 15.4 & 18.9 & 13.9 \\
Private hospital & 5.1 & 4.7 & 3.1 & 6.7 & 1.9 & 3.1 \\
LHW & 5.6 & 2.3 & 6.0 & 2.1 & 16.2 & 23.5 \\
Mobile teams & 6.0 & 5.4 & 5.2 & 2.3 & 5.2 & 2.2 \\
Others & 4.9 & 7.5 & 5.8 & 8.1 & 7.7 & 4.5 \\
No. of observations & 1232 & 1199 & 1135 & 1147 & 956 & 1107 \\
\hline
\end{tabular}

\section{Correlates of women's immunization}

Age. Immunization rates decrease as the age of women increases. This is true for both intervention and control areas and for both survey rounds (figure 7.5a). 
Parity. Immunization against tetanus is lowest among zero parity mothers and highest for those with one or two children, after which it declines steadily. This is true for mothers in both areas (intervention and control) and both surveys. There is little variation between baseline and endline rates, regardless of parity (figure 7.5b).

Education. Maternal education is strongly related to immunization against tetanus. As the education of mother increases, immunization rates increase. For example, 41 percent of illiterate mothers in CBI areas were immunized against tetanus, while 71 percent of mothers with secondary education were immunized at the time of the baseline survey (figure 7.5c). Similar patterns and trends in immunization rates by maternal education are observed in HSI and control sites in both surveys.

Ethnicity. Ethnicity has some relation with immunization rates. Data presented in figure $7.5 \mathrm{~d}$ illustrate that Saraiki mothers are more likely than Balochi mothers to be immunized in intervention areas. However, Saraiki and Punjabi mothers are similar in seeking care for tetanus in Layyah. No substantial change has been observed in coverage of TT shots between baseline and endline survey in any ethnic groups in any site.

Wealth quintile. Mothers with higher socio-economic status are more likely than mothers with low SES to be immunized against tetanus. This is true for all mothers in all three arms. Comparison of baseline survey data with endline survey data suggests that there has been no significant change observed in TT coverage by wealth quintile.

Figure 7.5a: Immunization against tetanus (TT 2) by age

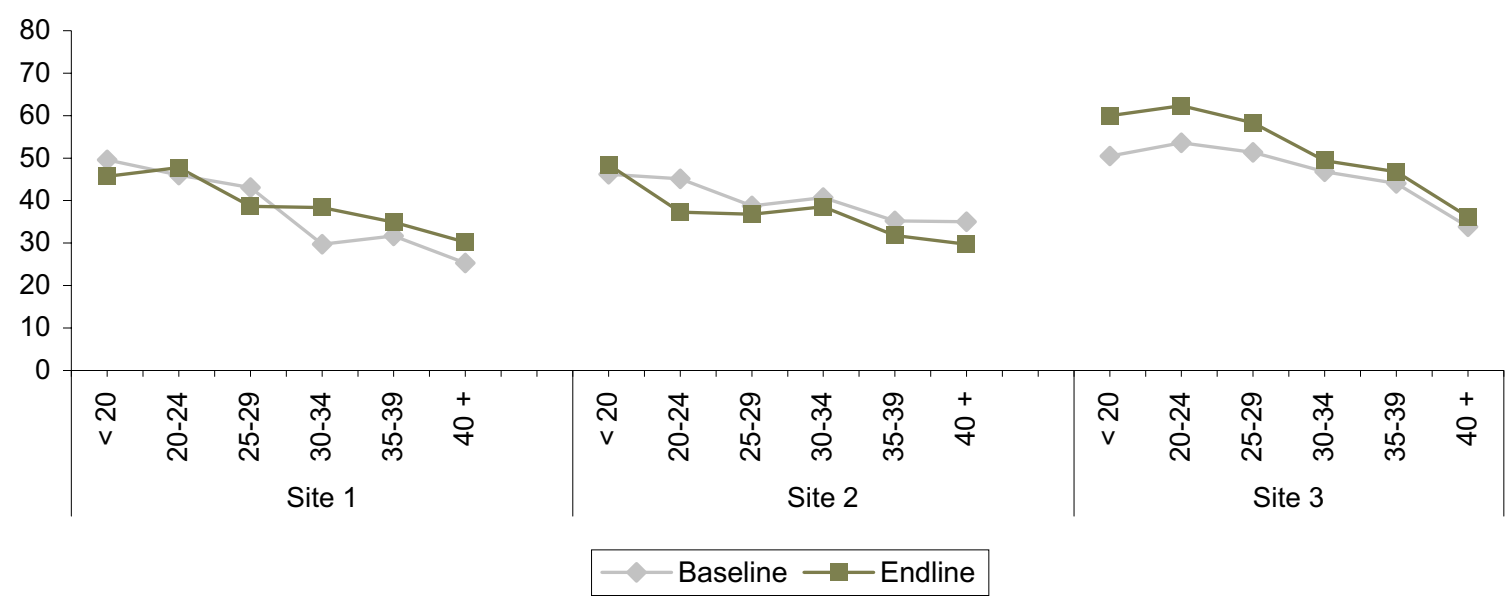


Figure $7.5 \mathrm{~b}$ : Immunization against tetanus (TT 2) by parity

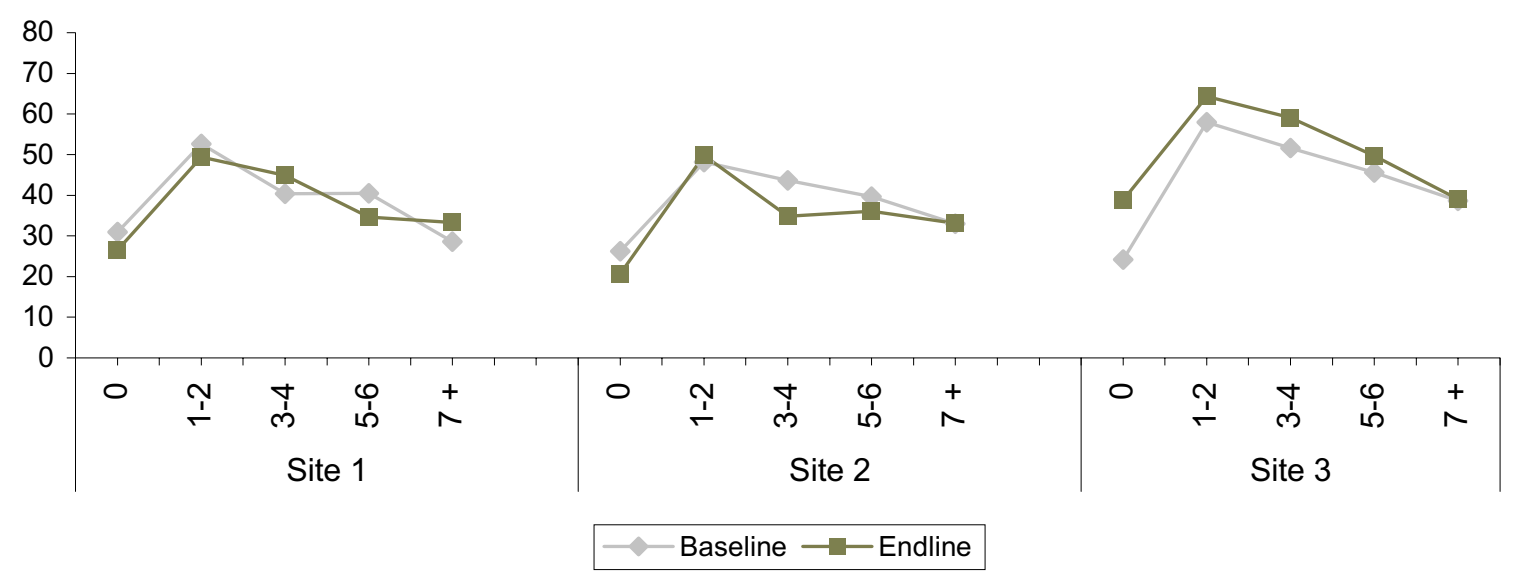

Figure 7.5c: Immunization against tetanus (TT 2) by education

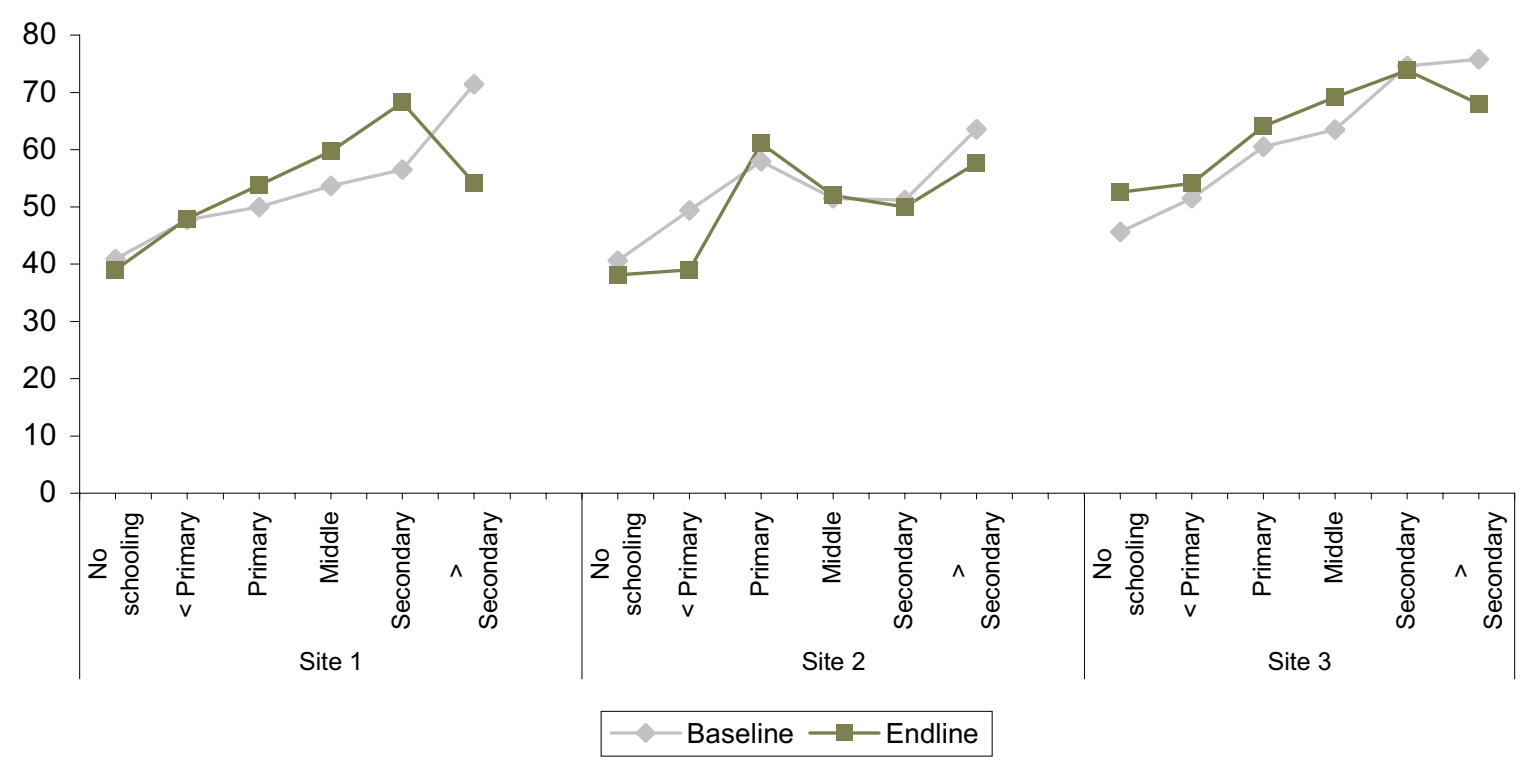


Figure 7.5d: Immunization against tetanus (TT 2) by language

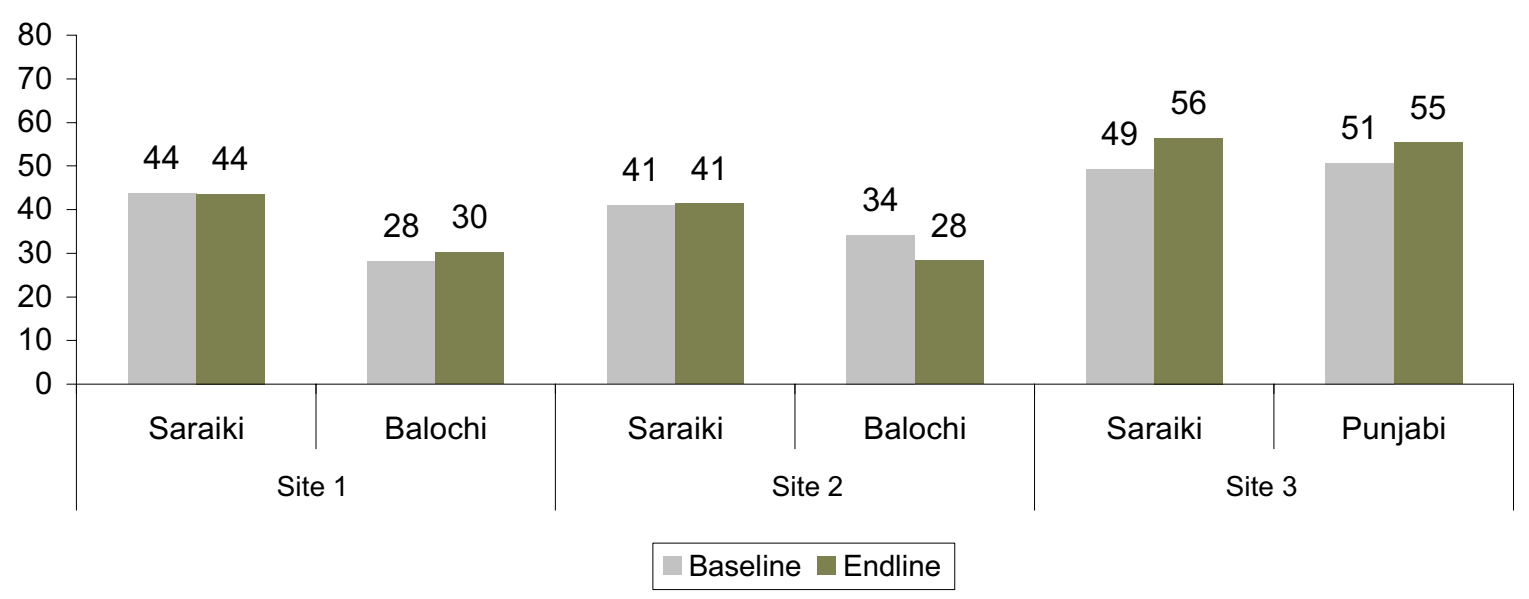

Figure 7.5e: Immunization against tetanus (TT 2) by wealth quintile

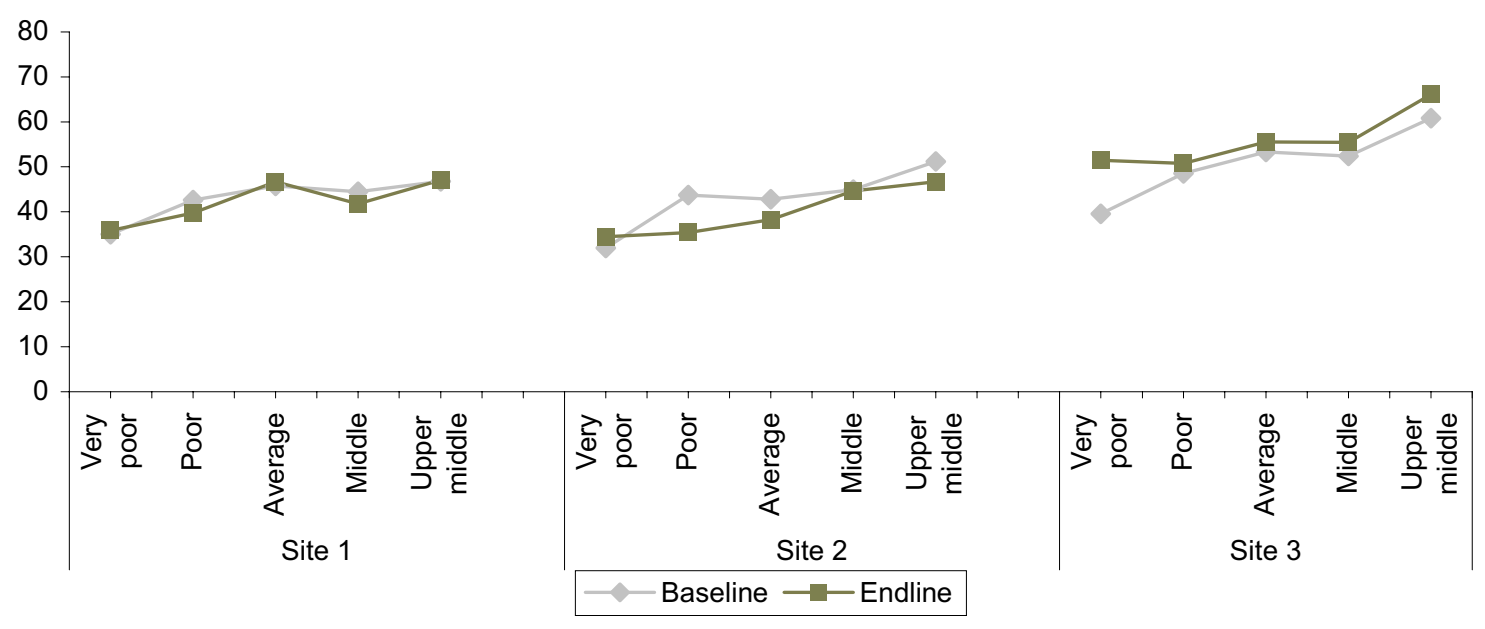

\section{Use of iron supplements}

Almost 40 percent of women in rural area of Pakistan suffer from iron deficiency $(<12$ $? g / \mathrm{ml})^{2}$. Anemic women are at higher risk of experiencing life-threatening complications and at higher risk of maternal as well as newborn mortality. Therefore, it is important for pregnant women to take iron supplements to reduce iron deficiency.

\footnotetext{
${ }^{2}$ National Nutrition Survey 2001-02 (PIDE)
} 
Figure 7.6: Percent of women receiving iron tablets

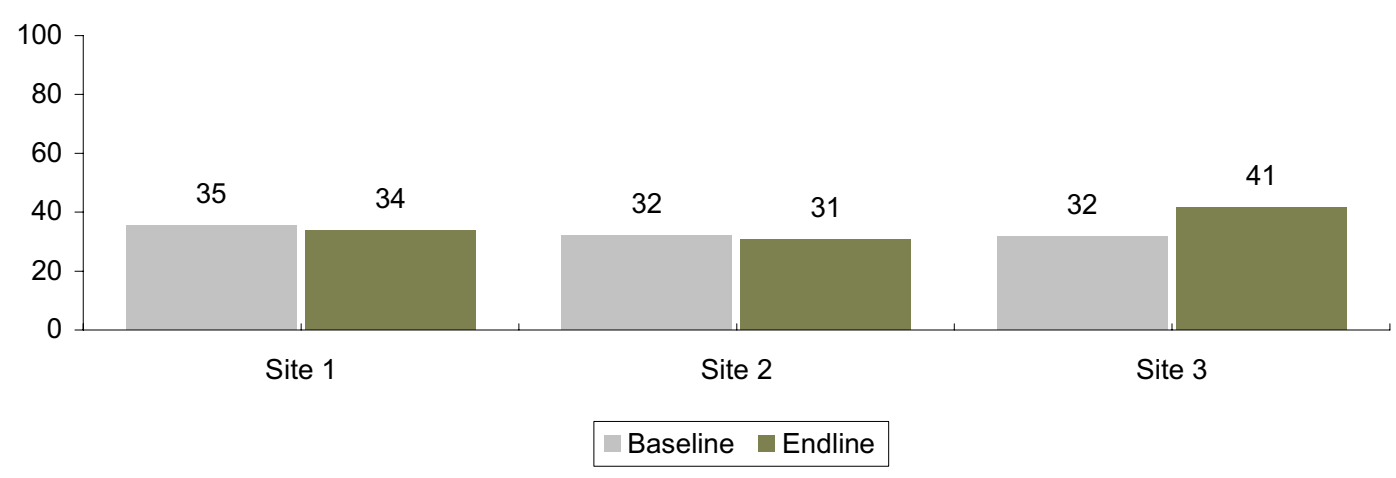

Data presented in figure 7.6 suggests that the use of iron supplements (iron and folic acid tablets) is low in all three arms. About one-third of women reported taking iron tablets during their last pregnancy in the year prior to the baseline survey.

Endline survey findings suggest that there has been no improvement in intake of iron supplements during pregnancy in either of the intervention areas, but its use increased by one-fourth in the control area.

In contrast to tetanus immunization, women who go to private health facilities for antenatal care are twice as likely to get iron supplements as women who go to a public facility (data not shown).

\section{Delivery care}

\section{Place of delivery}

As in rural areas of Pakistan generally, most deliveries in the study area take place at home. Before the start of the intervention, about 85 percent of deliveries in both intervention areas and 76 percent in the control area took place at home (see table 7.4). During the study period there was a decline in home deliveries in all areas, the greatest being in CBI areas. The proportion of home deliveries in CBI areas declined from 85 percent to 81 percent .

The PSLM Survey 2004-5 found that 10 percent of deliveries in rural D G Khan and 21 percent in rural Layyah were conducted at a health facility. This corresponds to our baseline estimates in 2004 of 14 percent and 23 percent, respectively. By the endline survey, which was conducted during first quarter of 2006, 17 percent of women in rural D G Khan and 26 percent Layyah district hadtheir babies at a health facility. 
The private sector plays an important role in providing institutional delivery facilities to rural women in the target population. In each site, between two-thirds and three-fourths of non-home deliveries took place in private facilities. Use of private health facilities for delivery increased between rounds in all three arms. This was particularly true in the CBI site, where use of private health facilities has increased by more than half between the two surveys.

\section{Birth attendant}

It is well-established internationally that maternal mortality and morbidity can be reduced substantially if all women get the assistance of a skilled health worker during pregnancy and delivery and have access to emergency medical care when complications arise. The presence of a skilled birth attendant can ensure timely management of complications either by himself/herself or by referral to a well-equipped health facility. Similarly, perinatal mortality can be reduced significantly by increased use of skilled birth attendants.

\section{Figure 7.7: Use of skilled birth attendant by site}

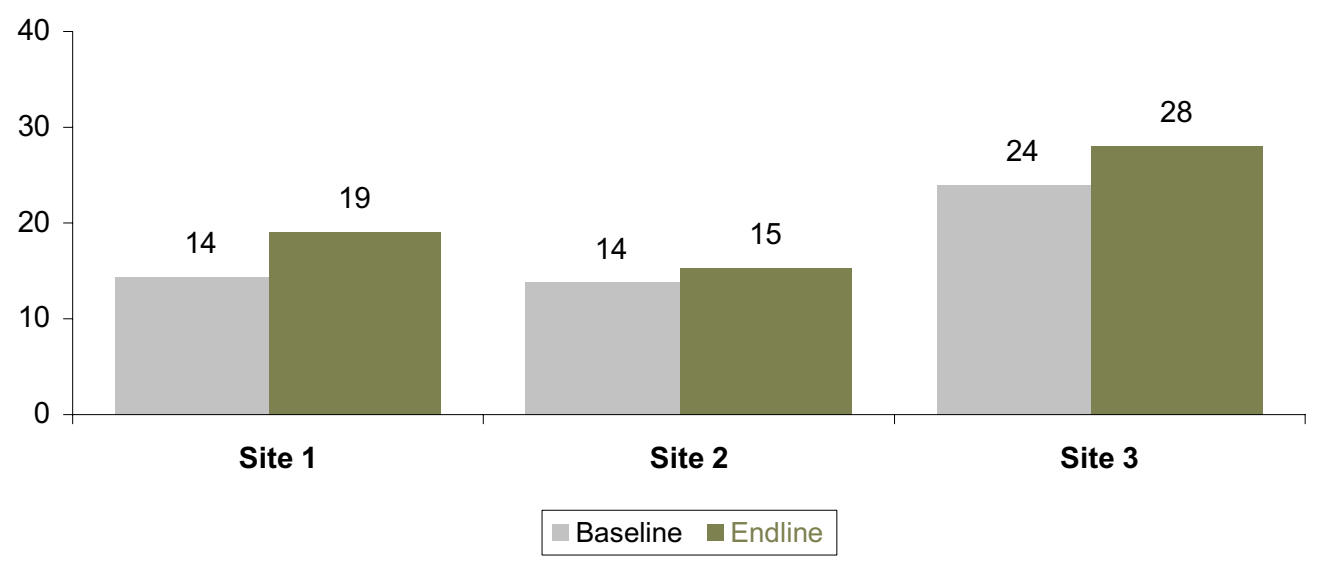

A skilled birth attendant is a person who has modern allopathic midwifery skills. Medical doctors, LHVs, nurses, and trained midwives are classified as skilled birth attendants, and this definition has been used for these surveys. (However, since substantial modern midwifery training has been imparted to "SMART dais", deliveries by these dais merit separate attention.) At baseline, use of skilled attendants at birth is very low -- about 14 percent of deliveries in intervention areas and 24 percent in the control area. This is quite close to the results of the PSLM of 2004-2005, which found 12 percent of deliveries in DG Khan and 21 percent in Layyah conducted by a SBA. 
There was a significant increase in the use of skilled attendance during the project period. This increase is greatest in the CBI site, particularly in percentage terms (table 7.4 and figure 7.7); but the increase in the control area was only slightly lower. Conversely, the use of dais and female relatives for delivery declined in all three sites.

Table 7.4: Delivery care according to location and attendant, by site and HHS round

\begin{tabular}{lrrrrrr}
\hline \multirow{2}{*}{ Delivery care } & \multicolumn{3}{c}{ Site 1 } & & Site 2 & Site 3 \\
\cline { 2 - 7 } & Baseline & Endline & Baseline & Endline & Baseline & Endline \\
\hline Place of delivery & & & & & & \\
Home & 85.2 & 81.0 & 84.9 & 84.5 & 76.4 & 72.8 \\
BHU/RHC/MCH & 2.7 & 1.3 & 2.9 & 1.6 & 3.3 & 2.4 \\
DHQ/THQ hospital & 1.8 & 2.5 & 1.9 & 1.5 & 3.0 & 3.5 \\
Private hospital & 9.7 & 14.9 & 9.7 & 12.1 & 17.0 & 20.3 \\
Other & 0.6 & 0.2 & 0.6 & 0.3 & 0.2 & 0.9 \\
& & & & & & \\
Type of Attendant & & & & & & \\
Skilled birth attendant & 14.4 & 19.1 & 13.8 & 15.1 & 24.0 & 28.1 \\
Nurse/LHV & 4.4 & 6.3 & 3.1 & 4.6 & 9.0 & 11.5 \\
$\quad$ Medical doctor & 10.0 & 12.8 & 10.7 & 10.5 & 15.0 & 16.7 \\
Unskilled birth attendant & 85.6 & 80.9 & 86.2 & 84.9 & 76.0 & 71.9 \\
$\quad$ TBA & 67.0 & 61.2 & 65.7 & 63.8 & 70.2 & 67.6 \\
$\quad$ Female relative & 18.0 & 15.9 & 19.6 & 18.4 & 4.5 & 2.6 \\
$\quad$ Other & 0.5 & 3.8 & 0.9 & 2.6 & 1.2 & 1.6 \\
Total & 100.0 & 100.0 & 100.0 & 100.0 & 100.0 & 100.0 \\
No. of births & 2048 & 2027 & 1993 & 2020 & 1607 & 1632 \\
\hline
\end{tabular}

\section{Correlates of use of skilled birth attendant}

Age: Younger women (less than 20 years of age) and older women (above 35) are at elevated risk of pregnancy complications, and it is particularly important that these women should get assistance from skilled attendants during the delivery process. However, there is no clear variation in birth attendance by age in any site, although in Layyah there is some increase in skilled birth attendance for older women (figure 7.8a).

Parity: On the whole, use of skilled birth attendant and parity are negatively associated; low parity women are more likely than high parity women to use a skilled birth attendant. The reason usually given for this association is that women with fewer previous births are 
more likely to be worried about the delivery process. Figure $7.8 \mathrm{~b}$ shows that use of skilled birth attendant is the highest among mothers with no living children in all three arms in both surveys. The proportion of deliveries conducted by skilled attendant decreases as parity increase in both surveys and in all sites.

Education: Education shows a strong positive association with use of skilled birth attendant. Educated women are more likely than uneducated ones to use the services of a skilled birth attendant, in all 3 sites and in both rounds (figure 7.8c). However, it will be recalled from chapter IV that fewer than 20 percent of women in either DG Khan or Layyah have any education at all, so the high use of skilled birth attendance by educated women does not have much effect on the overall proportion.

Ethnicity: Data presented in figure 7.8d indicates that use of skilled birth attendant is higher among Saraiki speaking mothers than Balochi speakers in intervention sites. On the other hand, in the control area Punjabi mothers are more likely than Saraiki mothers to use a skilled attendant at birth. There is some increase among Saraiki mothers in the CBI area and among Balochi mothers in the HSI area.

Wealth quintile: Use of skilled birth attendant increases as SES increases in all three sites (figure 7.8e). It appears that in the CBI site, there is more increase in the use of skilled attendance at birth among poor women than among those who are better off.

Figure 7.8a: Use of skilled birth attendant by age

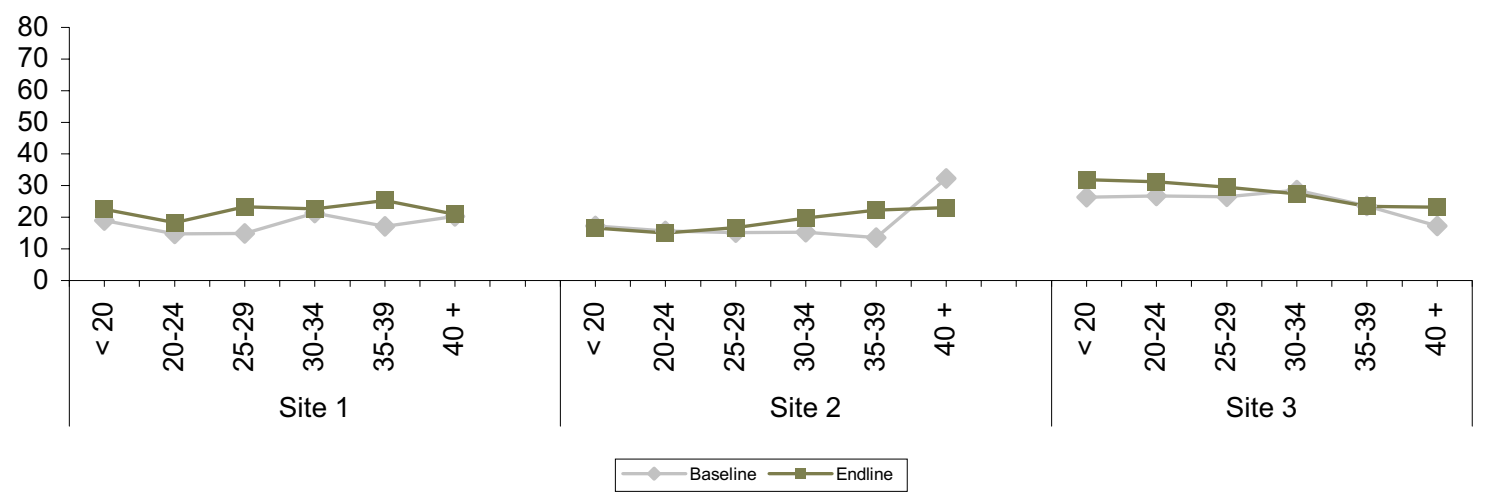


Figure 7.8b: Use of skilled birth attendant by parity

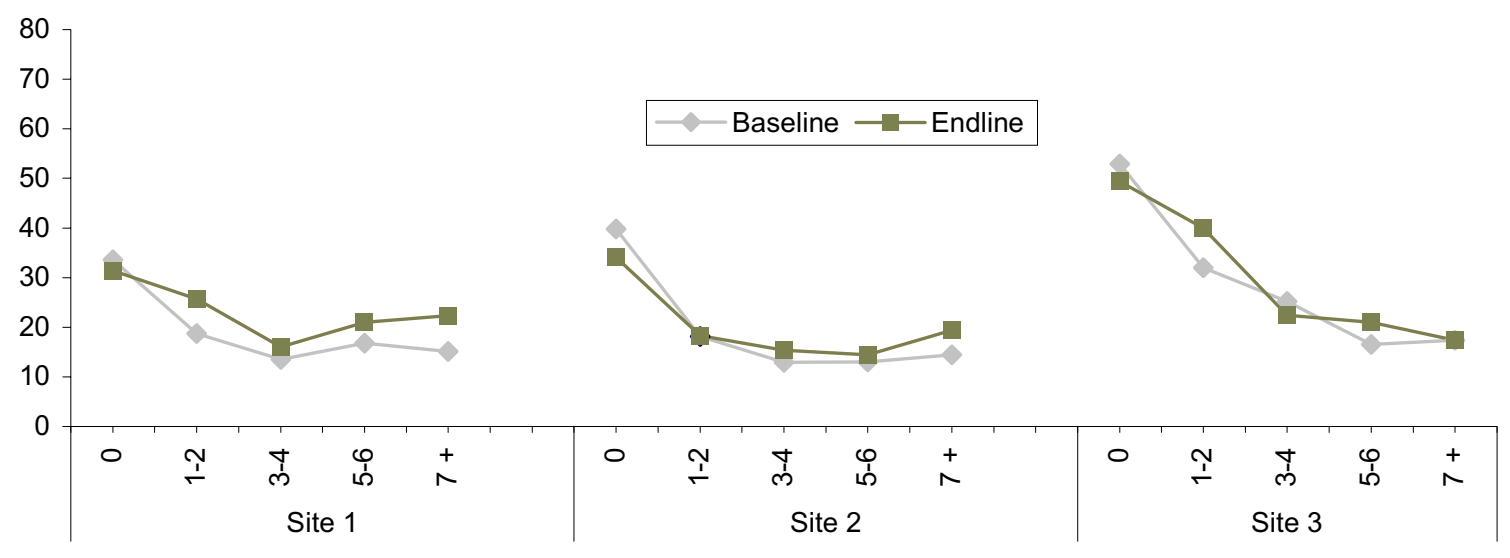

Figure 7.8c: Use of skilled birth attendant by education

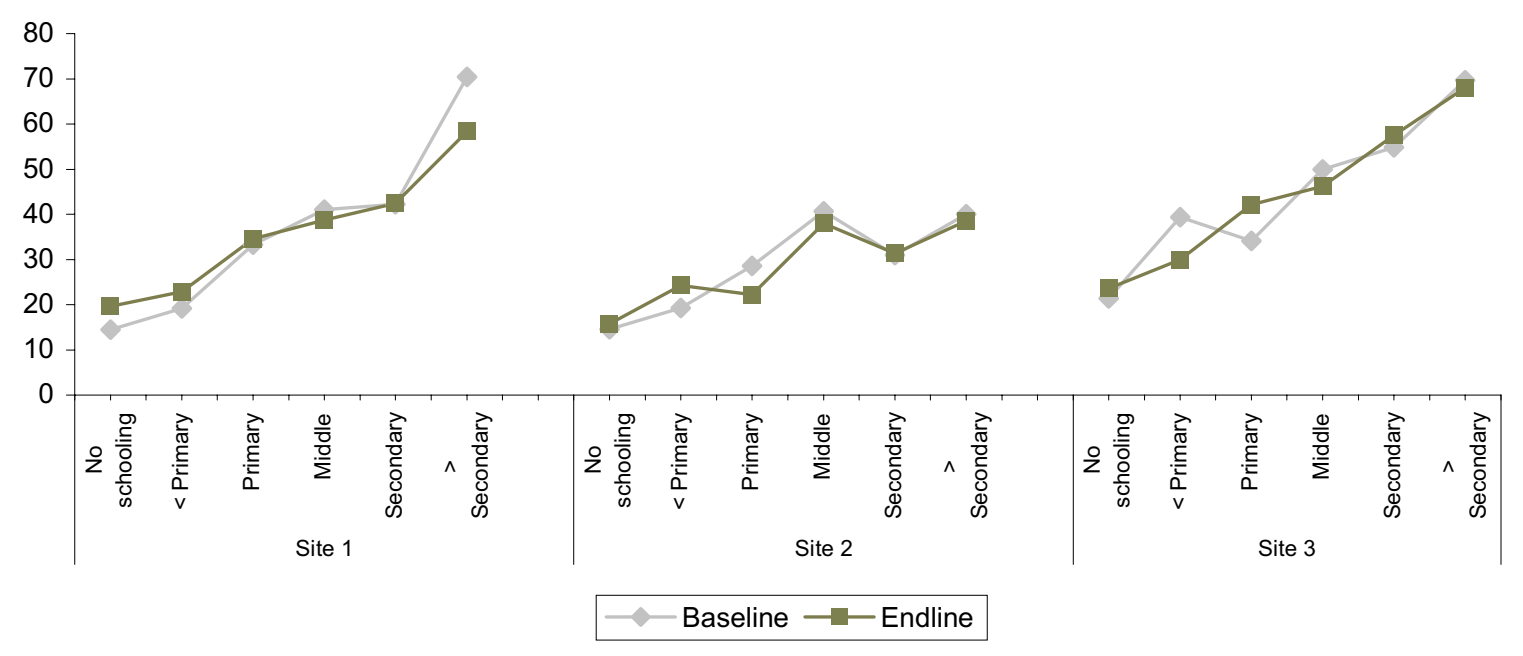

Figure 7.8d: Use of skilled birth attendant by language

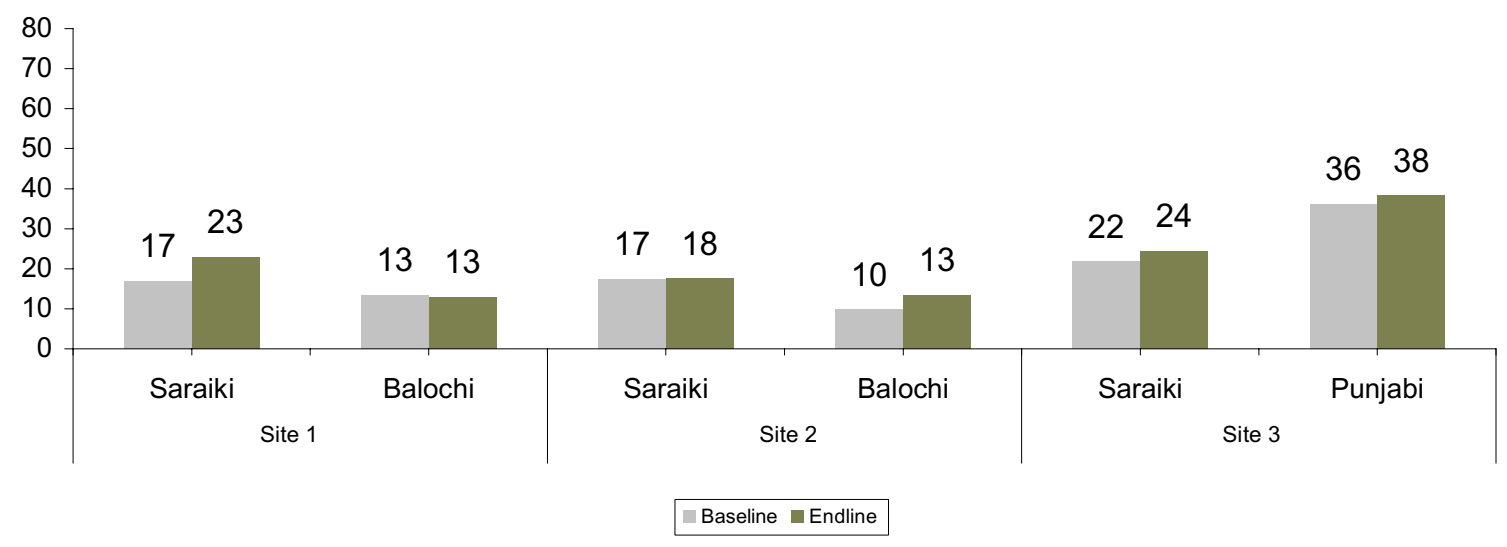


Figure 7.8e: Use of skilled birth attendant by wealth quintile

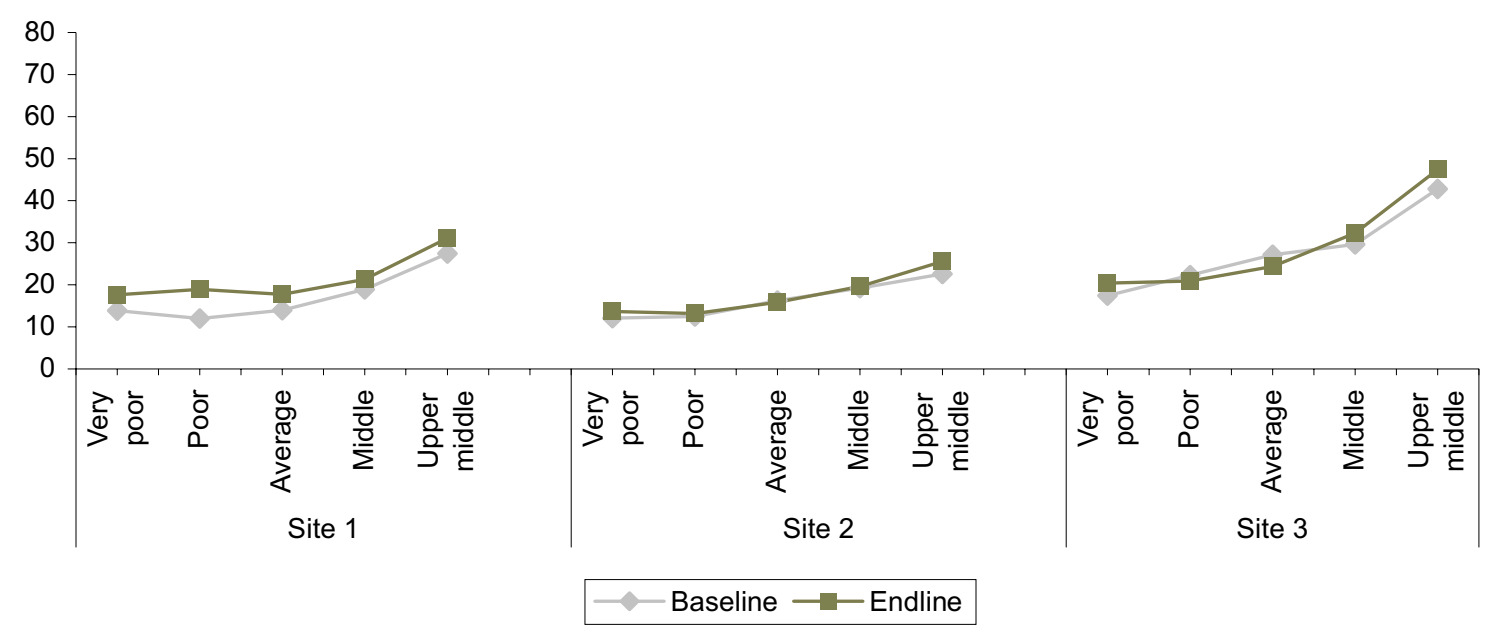

\section{Use of clean delivery kits (CDK)}

One of the major causes of maternal and neonatal death is infection, often introduced during a delivery conducted under unhygienic conditions. Women who choose to deliver at home with the help of unskilled birth attendants are at elevated risk of infection. This risk can be reduced if clean delivery kits are used for deliveries conducted at home. Mothers who delivered with the help of a traditional birth attendant (TBA) were asked whether the attendant used a clean delivery kit during the delivery process.

Figure 6.5: Use of clean delivery kit

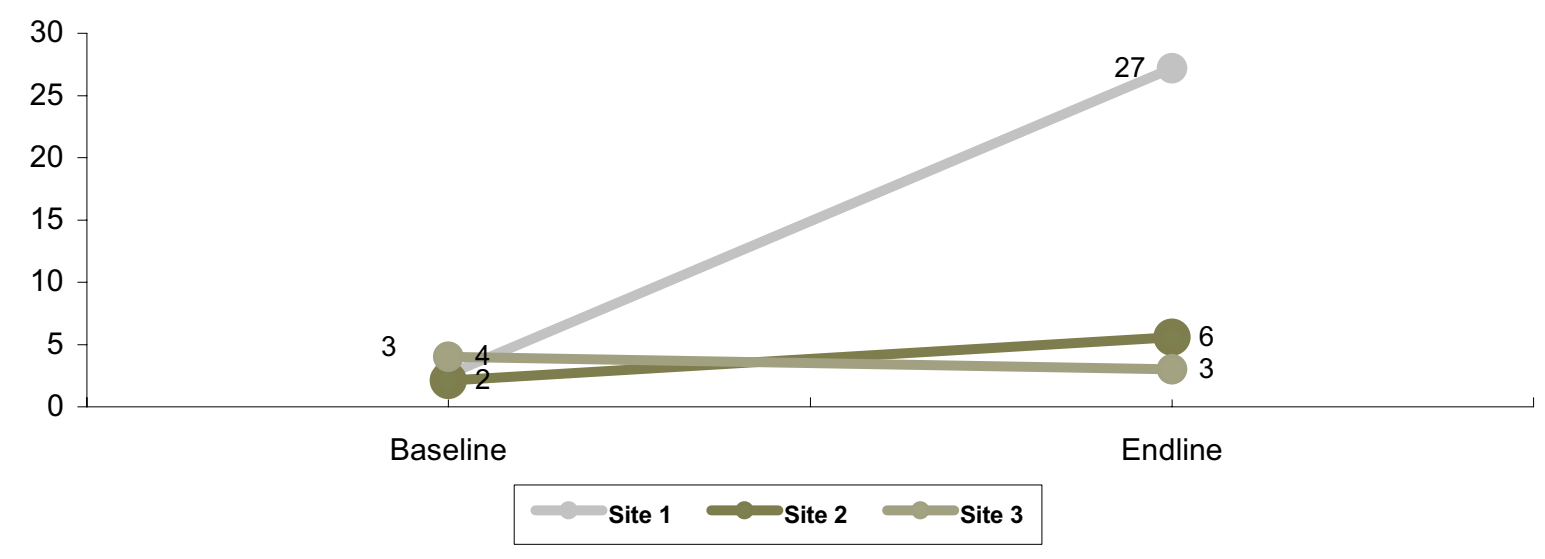


The use of clean delivery kits by traditional birth attendants was negligible in all three areas before the start of project. However, it increased substantially in CBI areas, whereas its use was still very low in non-CBI and control areas (figure 7.9). The increase in the use of delivery kits by traditional birth attendant in CBI areas was undoubtedly due to the training of dais by the SMART project, and provision of the kits to the dais directly and to local shops.

\section{Delivery cost}

Poverty is one of the main impediments to use of maternal health care services, especially to use of skilled birth attendants and appropriate emergency care. During the baseline and endline surveys, information was collected on expenses (in cash or kind) paid to the birth attendant for delivery purposes.

On average, a woman paid Rs 300 to the birth attendant in intervention areas and Rs 500 in the control area as reported in the baseline survey (see table 7.5). One quarter of the women paid as little as Rs 100 for their last delivery in the intervention area. The median delivery payment has increased by about Rs 100 per delivery in all three arms between survey rounds.

The cost of delivery varies by location; institutional deliveries are more expensive than home deliveries. A delivery at a BHU or RHC is several times more expensive than a home delivery; deliveries are even more expensive in the DHQ and THQ hospitals, and still more in the private sector

One possible explanation for high cost at facilities could be the greater likelihood of complicated deliveries being conducted at these facilities. Only 15 percent of normal vaginal deliveries reported in the household survey occurred at health facilities (predominantly in private facilities), whereas almost all of the assisted vaginal deliveries and caesarean sections occurred at health facilities (more than 80 percent at private facilities). A normal vaginal delivery at home costs Rs 300 compared with Rs 1500 to Rs 3000 at a health facility, depending on the type of facility. An assisted vaginal delivery will cost Rs 1700 to Rs 2700 at a public health facility and Rs 4700 at a private health facility. A caesarean section performed at a DHQ hospital costs Rs 12,000, and more than Rs 16,000 at a private health facility.

Within each place of delivery, there was no general tendency for the price of delivery to be increasing or decreasing over time. It appears that the increased average cost of delivery 
between baseline and endline could be attributed to a higher proportion of institutionalized deliveries.

From all the formative research and other community feedback received by the SMART project, it is evident that the cost of allopathic health care is a major impediment to seeking appropriate care for women and newborns. These data illustrate the reality of their situation. Until some means of financial relief is found for poor people to obtain treatment for obstetric emergencies, it is certain that many women will fail to obtain necessary care.

Table 7.5: Distribution of delivery cost and median costs according to place of delivery and type of attendant, by site and HHS round

\begin{tabular}{|c|c|c|c|c|c|c|c|c|c|}
\hline & \multicolumn{3}{|c|}{ Site 1} & \multicolumn{3}{|c|}{ Site 2} & \multicolumn{3}{|c|}{ Site 3} \\
\hline & & & Endline & & aseline & Endline & & aseline & Endline \\
\hline \multicolumn{10}{|l|}{ Delivery expenses in Rs } \\
\hline Up to 100 & & 5.7 & 26.6 & & 27.7 & 27.7 & & 12.2 & 9.7 \\
\hline $101-500$ & & 2.0 & 39.1 & & 42.0 & 38.9 & & 43.9 & 36.8 \\
\hline $501-1000$ & & 4.2 & 11.6 & & 12.0 & 12.8 & & 17.4 & 17.5 \\
\hline $1001-2000$ & & 5.8 & 7.6 & & 7.5 & 8.3 & & 10.7 & 13.8 \\
\hline More than 2000 & & 1.4 & 15.1 & & 10.9 & 12.2 & & 15.8 & 22.1 \\
\hline Average (median Rs) & & 00 & 400 & & 300 & 350 & & 500 & 600 \\
\hline \multicolumn{10}{|l|}{ Place of delivery } \\
\hline Home & & 00 & 250 & & 200 & 300 & & 400 & 500 \\
\hline $\mathrm{BHU} / \mathrm{RHC} / \mathrm{MCH}$ & & 00 & 1200 & & 2050 & 1590 & & 1900 & 2000 \\
\hline DHQ/THQ hospital & & 00 & 1500 & & 4000 & 1175 & & 3000 & 2500 \\
\hline Private hospital & & 00 & 3225 & & 4000 & 3000 & & 3000 & 3400 \\
\hline \multicolumn{10}{|l|}{ Birth attendant } \\
\hline Unskilled & 300 & 30 & & 250 & 300 & & 400 & 500 & \\
\hline Skilled & & 00 & 3000 & & 3300 & 2885 & & 2500 & 3000 \\
\hline
\end{tabular}

\section{Care of the newborn}

There are some recommended practices that need to be adopted at the time of birth for the better health of newborns. For example, the baby should be: put on clean cloth; wrapped immediately; put with mother to keep it warm; immediately breastfed, including "first milk" (colostrum); and not bathed for at least 6 hours after birth. Tables 7.6 to 7.9 present data on the practices of women who delivered a live birth during the 12 months prior to the 
survey. Data are derived from the more detailed KAB surveys, so numbers of observations are relatively small.

\section{Breastfeeding}

Breastfeeding saves infants' lives, provides the best nutrition for infants and young children, and benefits the health of mothers. Breastfeeding provides the best health benefits when started immediately after an infant's birth, continued exclusively for the first six months of life, and then continued along with suitable complementary feeding through age two or longer.

Newborns should be put to the breast within four hours of birth. This was not a common practice in either the intervention or the control areas (table 7.6). At baseline, 23 percent of newborns in site 1 and fewer than 20 percent in sites 2 and 3 reported initiation of breastfeeding within four hours of birth. Most women reported initiation of breastfeeding after 24 hours following delivery.

Table 7.6: Timing of initiating brea stfeeding, by site and KAB round

\begin{tabular}{lrrrrrr}
\hline & \multicolumn{2}{c}{ Site 1 } & \multicolumn{2}{c}{ Site 2 } & \multicolumn{2}{c}{ Site 3 } \\
\cline { 2 - 7 } Breastfeeding initiation & Baseline & Endline & Baseline & Endline & Baseline & Endline \\
\hline Within 4 hours of birth & 23.0 & 38.2 & 16.7 & 25.2 & 18.8 & 11.7 \\
4 hours to 24 hours & 26.2 & 22.1 & 20.5 & 26.9 & 5.9 & 24.8 \\
After 24 hours & 41.0 & 36.9 & 57.7 & 45.5 & 57.4 & 62.1 \\
Others & 9.8 & 2.7 & 6.1 & 2.4 & 16.8 & 1.4 \\
Total & 100.0 & 100.0 & 100.0 & 100.0 & 100.0 & 100.0 \\
No. of respondents & 61 & 149 & 78 & 167 & 101 & 141 \\
Pct. newborn given colostrum & 37.7 & 70.1 & 26.9 & 57.4 & 20.8 & 42.3 \\
\hline
\end{tabular}

The proportion of newborns breastfed immediately after birth increased in the intervention sites, especially in site 1, but declined in the control area (figure 7.10). In site 1, dai training as well as community education may have influenced initiation of breastfeeding. 
Figure 7.10: Percent change in newborns given breast milk with 4 hours of birth

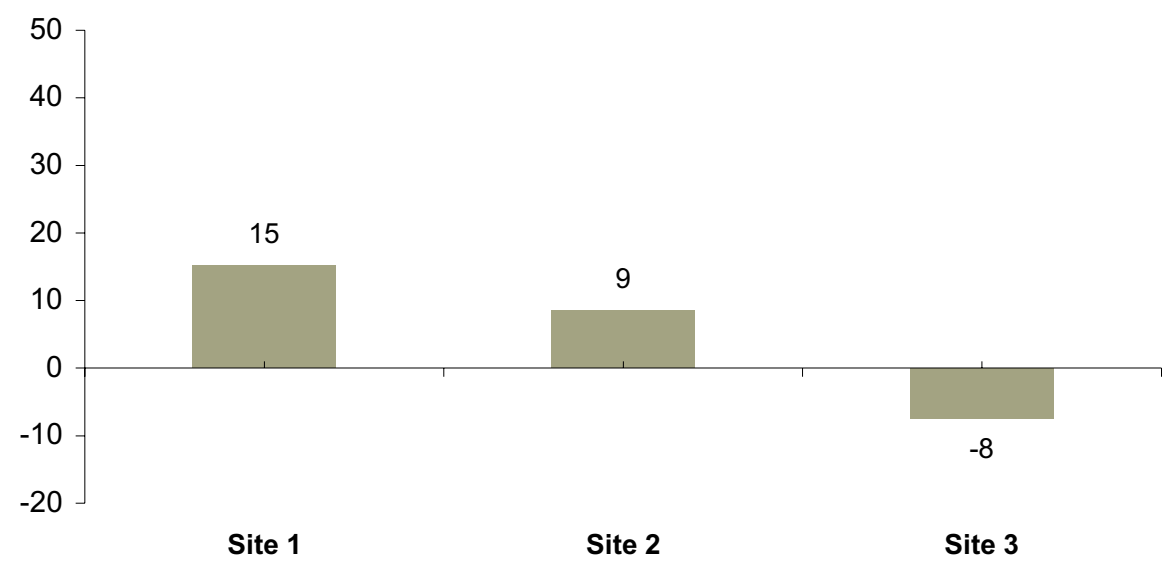

\section{Colostrum}

The very first milk produced by a mother is generally viscous, and is by tradition discarded in Pakistan, including the study area. However, it is rich in colostrum, which is important for infant nutrition and contains antibodies that help immune response development. Discarding of this "first milk" does not mean that the baby does not receive colostrum, which continues to be present in breast milk over the first two days or so. However, it denies the newborn a particularly rich source of this nutrient and delays the initiation of breastfeeding. The SMART project therefore encouraged mothers not to discard this "first milk", but to feed it to the baby.

The use of "first milk" was low at baseline and varied by site (table 7.6). Thirty-eight percent of newborns in arm 1 were given colostrum at baseline, the highest among all three sites. Use of colostrum increased in all three sites at endline, but the increase is greater in the intervention sites than in the control site (figure 7.11). Given the substantial increase in all three sites, however, it is possible that this topic is subject to some ascertainment bias. It is sometimes difficult to get across what is meant here; even the standard international survey literature is often confused on this point. 
Figure 7.11: Percent change in newborns given colostrum

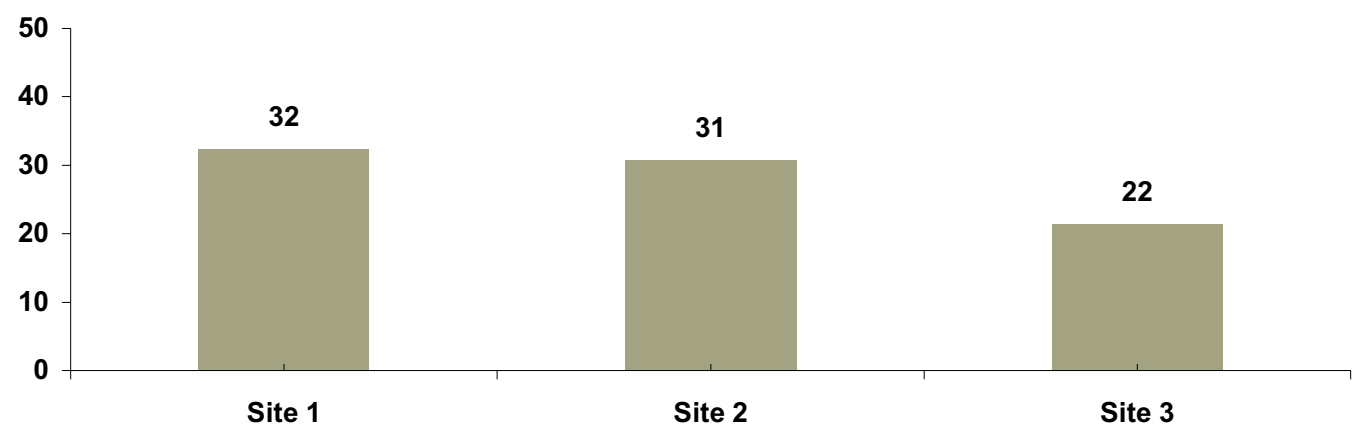

\section{Placement of newborn}

To protect newborns from getting cold (hypothermia) as well as to reduce postpartum hemorrhage, it is recommended that the newborn be placed with its mother immediately after birth. From table 7.7 and figure 7.12, it can be seen that few women reported putting their newborns with themselves at baseline, but the practice was more common by endline in all three sites. The sharpest increase was observed in the CBI communities.

A particularly dangerous practice is placing the newborn on the floor, which puts it at an elevated risk of morbidity and mortality. A newborn put on the floor not only runs a higher risk of infection, but is also at higher risk of hypothermia. At baseline, 21 percent of mothers in site 1 said that they had put their newborn on the floor after delivery, with smaller proportions reported in the other sites. By endline, this practice had almost disappeared in intervention areas, but not in the control area. 
Table 7.7: Placement of newborn immediately after birth, by site and KAB round

\begin{tabular}{lrrrrrr}
\hline & \multicolumn{2}{c}{ Site 1 } & \multicolumn{2}{c}{ Site 2 } & \multicolumn{2}{c}{ Site 3 } \\
\cline { 2 - 7 } $\begin{array}{l}\text { Place where baby } \\
\text { put after birth }\end{array}$ & Baseline & Endline & Baseline & Endline & Baseline & Endline \\
\hline On floor & 21.3 & 2.0 & 10.3 & 0.6 & 7.9 & 8.5 \\
On mattress & 6.6 & 2.7 & 7.7 & 4.2 & 9.9 & 18.4 \\
On cloth & 29.5 & 61.1 & 46.2 & 61.7 & 48.5 & 23.4 \\
With mother & 4.9 & 21.5 & 10.3 & 24.6 & 15.8 & 25.5 \\
Others & 31.1 & 4.7 & 19.2 & 4.2 & 16.8 & 12.1 \\
Do not know & 6.6 & 8.1 & 6.4 & 4.8 & 1.0 & 12.1 \\
Total & 100.0 & 100.0 & 100.0 & 100.0 & 100.0 & 100.0 \\
No. of respondents & 61 & 149 & 78 & 167 & 101 & 141 \\
\hline
\end{tabular}

Figure 7.12: Percent change in newborns put with their mothers immediately after birth

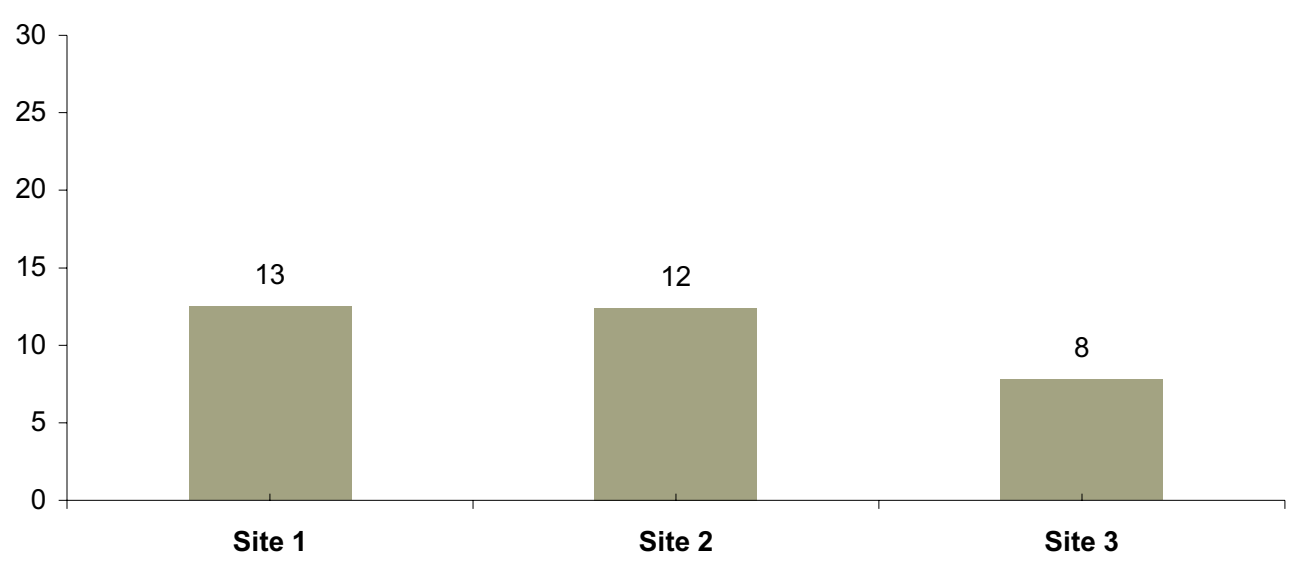

\section{Wrapping practices}

A newborn should be wrapped immediately after delivery to keep it warm and to prevent hypothermia. Women were asked for how many minutes the baby lay naked before being wrapped. About 42-45 percent of newborns were wrapped immediately after birth at baseline in the three sites (table 7.8). This practice improved at endline, particularly in the two intervention sites (figure 7.13); however, there was a large unexplained increase in the "don't know" category in site 3. In the intervention sites, the proportion of newborns left unwrapped for more than ten minutes was low at endline. 
Table 7.8: Timing of wrapping ne wborns by area and KAB round

\begin{tabular}{lrrrrrr}
\hline \multirow{2}{*}{ Timing of wrapping newborn } & \multicolumn{2}{c}{ Site 1 } & \multicolumn{2}{c}{ Site 2 } & \multicolumn{2}{c}{ Site 3 } \\
\cline { 2 - 7 } & Baseline & Endline & Baseline & Endline & Baseline & Endline \\
\hline Within 5 minutes & 43.8 & 52.3 & 45.1 & 55.1 & 41.7 & 44.0 \\
$5-10$ minutes & 14.1 & 28.2 & 18.3 & 28.7 & 11.7 & 12.1 \\
$11-30$ minutes & 15.7 & 8.7 & 15.9 & 6.0 & 29.2 & 9.8 \\
After 30 minutes & 10.9 & 0.7 & 6.1 & 0.6 & 4.9 & 0.7 \\
Do not know & 15.6 & 10.1 & 14.6 & 9.6 & 12.6 & 33.3 \\
Total & 100.0 & 100.0 & 100.0 & 100.0 & 100.0 & 100.0 \\
No. of respondents & 61 & 149 & 78 & 167 & 101 & 141 \\
\hline
\end{tabular}

Figure 7.13: Percent change in newborns wrapped immediately after birth

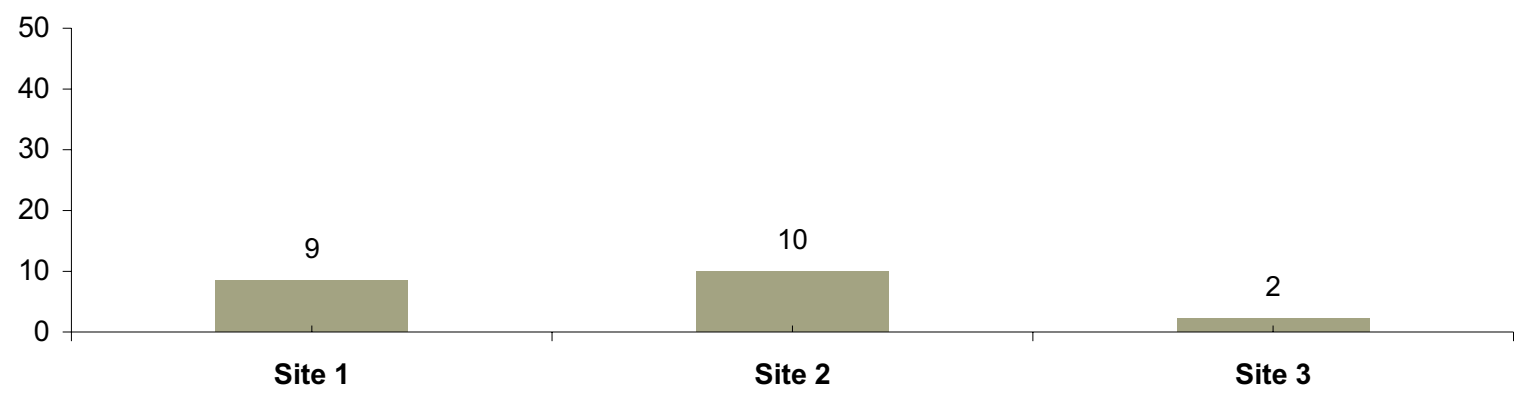

\section{Bathing practices}

Especially for premature and other frail babies, the first bath should be delayed for at least 6 hours after birth, or preferably until the next day. This practice, however, may be difficult to accept, since the baby appears "dirty". Few babies were bathed prior to attending to the placenta in any site or round (table 7.9 and figure 7.14), but many are bathed on the first day the placenta has been attended to. Roughly half of the women in DG Khan wait until the second day, compared with fewer than one-fifth in Layyah. It is not clear whether there was any real change in this; the lower proportion reporting bathing on the second day at baseline in site 2 could be a function of the small sample size. 
Table 7.9: Timing of newborn's first bath by arm and KAB round

\begin{tabular}{lrrrrrr}
\hline & \multicolumn{2}{c}{ Site 1 } & \multicolumn{2}{c}{ Site 2 } & \multicolumn{2}{c}{ Site 3 } \\
\cline { 2 - 7 } Timing of first bath & Baseline & Endline & Baseline & Endline & Baseline & Endline \\
\hline $\begin{array}{l}\text { Same day before attending to the } \\
\text { placenta }\end{array}$ & 1.6 & 0.0 & 2.6 & 1.2 & 6.9 & 0.0 \\
$\begin{array}{l}\text { Same day after attending to the } \\
\text { placenta }\end{array}$ & 42.6 & 40.3 & 61.5 & 46.1 & 80.2 & 79.4 \\
Second day of birth or later & & & & & & \\
Other & 55.8 & 53.7 & 32.1 & 48.5 & 12.8 & 17.0 \\
Total & 0.0 & 5.0 & 3.9 & 4.2 & 0.0 & 3.5 \\
No. of observations & 100.0 & 100.0 & 100.0 & 100.0 & 100.0 & 100.0 \\
& 61 & 149 & 78 & 167 & 101 & 141 \\
\hline
\end{tabular}

Figure 7.14: Percent change in newborns whose first bath was delayed until day after birth

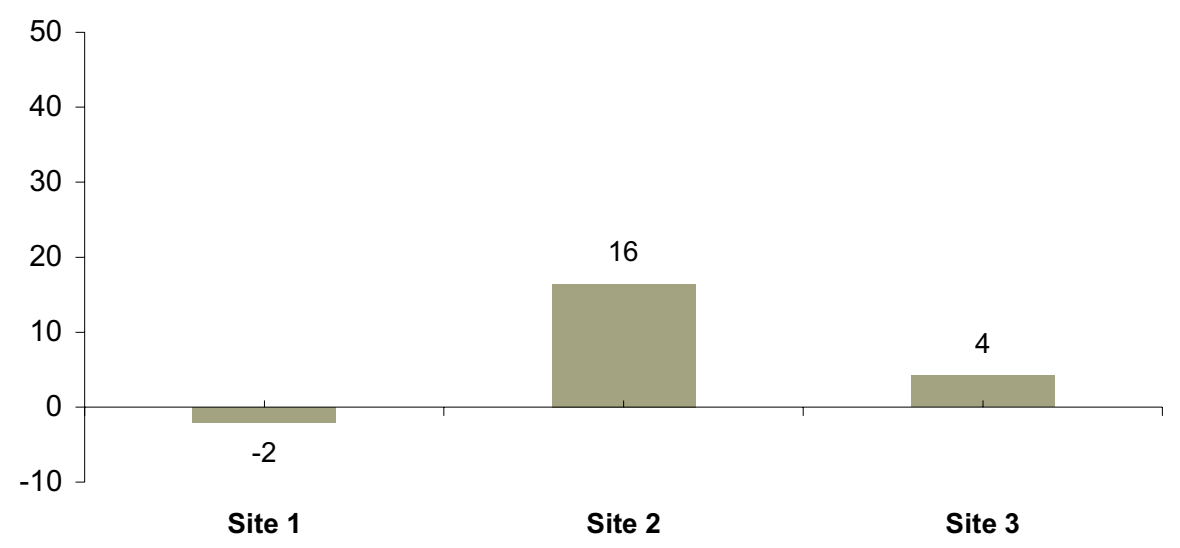

\section{Behavioral response to program inputs in site 1}

The interventions in the $\mathrm{CBI}$ areas - notably participation in support groups, exposure to IEEC materials, and training of LHWs and dais - were designed to lead to changes in maternal and neonatal practices, both on a routine basis and in case of emergency. Data on the specific exposure of respondents to these interventions was elicited in the KAB surveys; especially in the case of practices during the previous pregnancy, this resulted in relatively small sample sizes. The results in this section are therefore sometimes not conclusive, but are useful indicators of the nature and magnitude of responses to these interventions. Table 7.10 shows four key maternal health practices according to project exposure to support groups, IEEC items, and LHW visitation. 
Table 7.10: Maternal health practices by exposure to SMART activities, site 1, KAB round 3

\begin{tabular}{crrrr}
\hline Smart project activity & 3+ ANC visits & 2+ TT shots & Iron tablets & SBA \\
\hline Number of times attended WSG & & & & \\
Never & 17.5 & 46.0 & 23.8 & 17.5 \\
Once & 25.0 & 37.5 & 25.0 & 31.3 \\
2 or > & 28.6 & 50.0 & 42.9 & 21.4 \\
$\quad$ No & & & & \\
Yes & 10.0 & 30.0 & 20.0 & 35.0 \\
IEEC items received & 23.6 & 48.6 & 29.2 & 16.7 \\
LHW visited respondent in last 2 months & & & & \\
$\quad$ No & 12.0 & 46.0 & 26.0 & 22.0 \\
Yes & 30.2 & 44.2 & 27.9 & 18.6 \\
No. of observations & 19 & 42 & 25 & 19 \\
\hline
\end{tabular}

\section{Participation in women's support groups}

Women's and men's supports groups provided instruction and advice in their care seeking behavior. As can be seen from table 7.10 and figure 7.15, women who participated in meetings are more likely to receive antenatal care and take iron tablets than those who did not participate, and there is a smaller difference between these groups regarding immunization against tetanus and the use of skilled birth attendant. The smaller difference in immunization may be due to non-availability of TT shots during the reference period (about which there were anecdotal reports) and the small difference in use of skilled birth attendant could be because a delivery conducted by a skilled birth attendant is far more expensive than a delivery conducted by an unskilled attendant (see above). 
Figure 7.15: Percent of women who received antenatal care (3+visits), took iron tablets and used skilled birth attendant by number of support group meetings attended

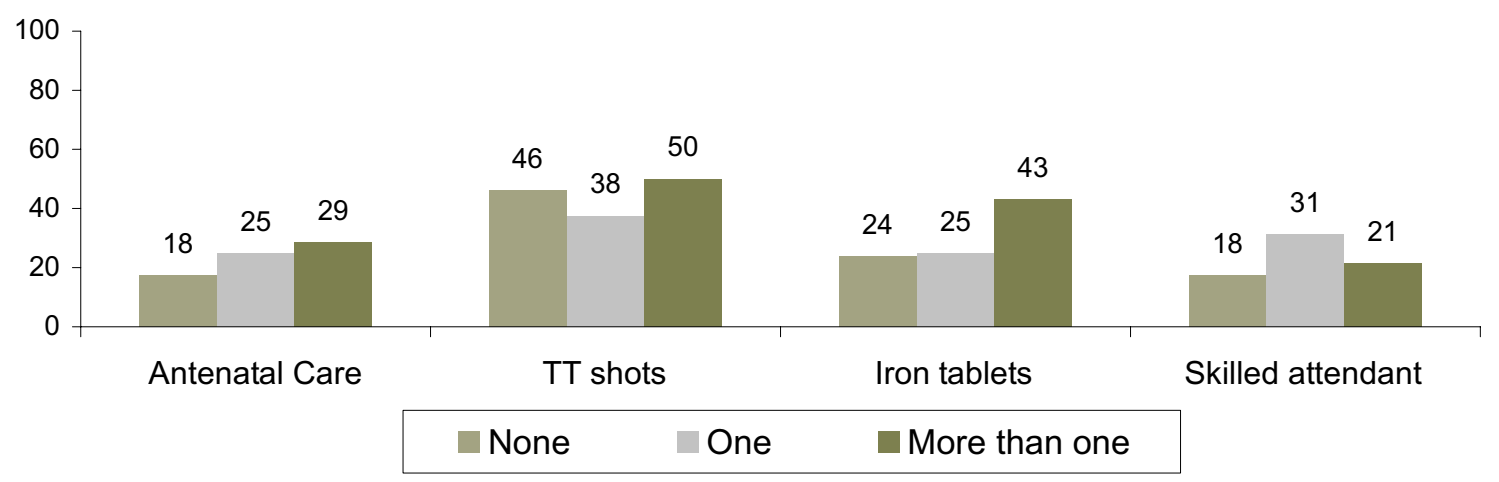

\section{Exposure to IEEC materials}

Exposure to IEEC material is also positively related to aspects of care-seeking behavior. Nearly all women who reported attending support groups also reported receiving or seeing IEEC materials; however, a substantial proportion of women who did not attend support groups also were exposed to these materials. Table 7.10 and figure 7.16 present data on the association between exposure to IEEC material and care received during pregnancy and delivery. Women who saw or received IEEC materials are more likely to have antenatal care, take iron tablets and get immunized against tetanus than those who did not. However, receipt of IEEC material was associated with lower use of skilled birth attendant.

Figure 7.16: Percent of women who received antenatal care $(3+$ visits), took iron tablets, used skilled birth attendant and received TT shots by IEEC items received

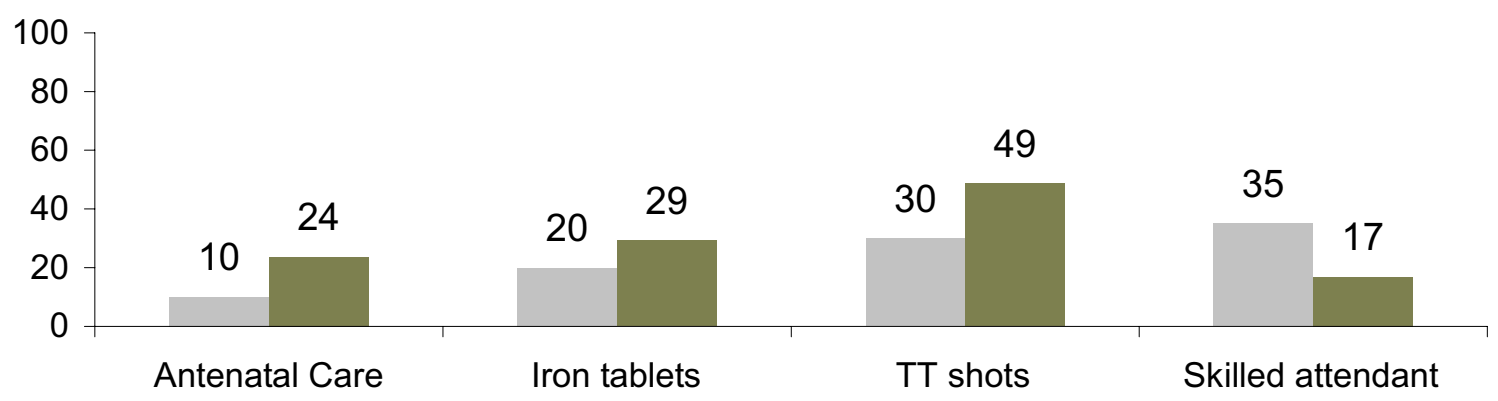

Did not receive Received 


\section{Lady Health Workers}

Among the LHW's duties is to provide iron tablets to pregnant women and to refer them to a qualified provider for TT shots and routine checkups during pregnancy. Data on relationship between an LHW's visit within the past two months and care-seeking behavior is presented in figure 7.17. LHW visitation during the last two months was positively related only to antenatal care. The proportion of women who took iron tablets and received TT shots is the same regardless of whether or not they were visited by an LHW.

Respondents visited by an LHW are slightly less likely to use skilled birth attendants than those who are not visited.

Figure 7.17: Percent of women who received antenatal care (3+ visits), took iron tablets, used skilled birth attendant and received TT shots, by LHW visitation

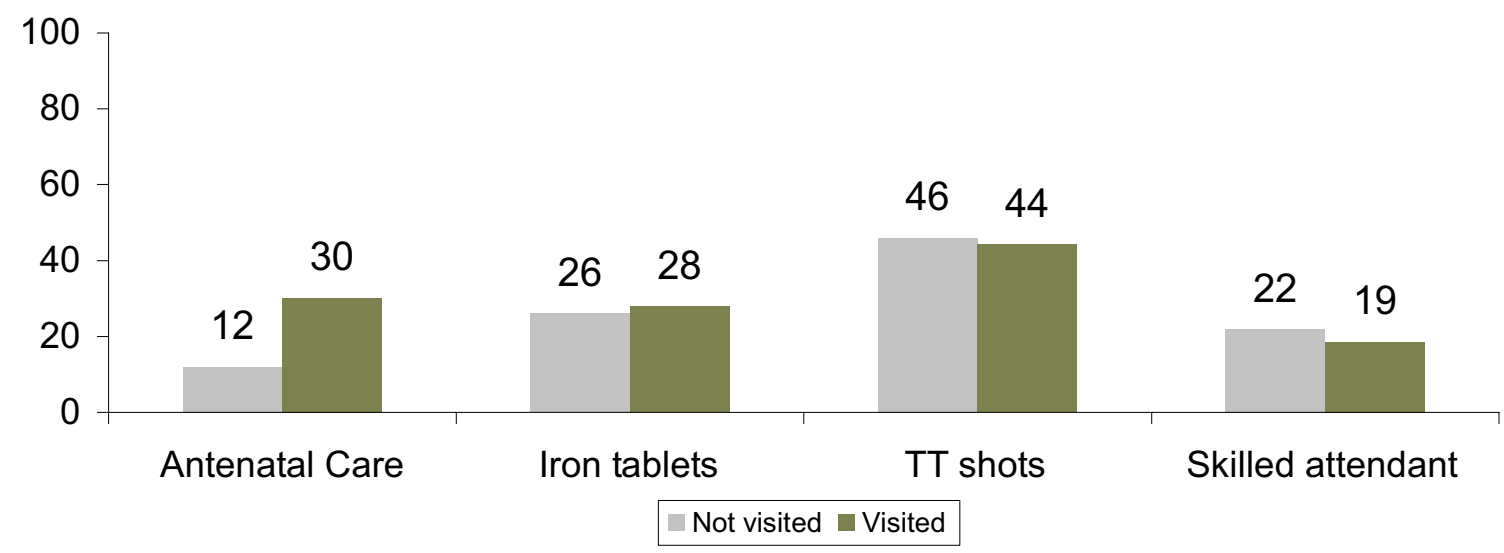

\section{Project-trained dais}

All traditional birth attendants (TBAs, or dais) in site 1 who met certain criteria (see report no. 2) were trained. A total of 288 dais were trained between August 2004 and May 2005. Training was imparted through an innovative approach designed by Population Council called "SMART dai" training, combining technical training with a participatory, respectful, client-centered approach. Dais were trained to:

- Recognize danger signs of pregnancy, delivery and postpartum, and refer to an appropriate health facility;

- Use clean delivery procedures and safe delivery kits;

- Provide appropriate care to newborns and give advice to mothers on breast-feeding and immunization; 
- Apply basic measures of resuscitation to an asphyxiated neonate;

- Recognize and refer complications in a newborn.

Delivery practices were elicited from respondents according to whether the dai was PCtrained or not (table 7.11). The accuracy of these reports was probably limited to the extent that a woman in the throes of labor and childbirth might not have noticed the details of the dai's practice. In addition, numbers are small. A more comprehensive study on the effect of dai training was conducted in a special operations research study (forthcoming).

Nonetheless, respondents' answers in the SMART KAB survey are of independent interest.

Table 7.11 shows practices at delivery as reported by the mothers for 32 deliveries by PCtrained dais compared with 28 untrained ones. The trained dais show a generally better profile of practices than untrained ones, but there are exceptions.

Table 7.11: Delivery practices by type of attendant for home deliveries, site $1 \mathrm{KAB} 3$.

\begin{tabular}{lrr}
\hline Category & PC trained DAI & Untrained DAI \\
\hline Use of clean delivery kit & 37.5 & 7.1 \\
Washing hands with soap & 81.3 & 64.3 \\
Reported delivery complications & 12.5 & 25.0 \\
Reported newborn complications & 3.1 & 14.3 \\
Used new blade for cord cutting & 96.9 & 78.6 \\
Used new thread for tying cord & 87.5 & 75.0 \\
Newborn was put with mother & 18.8 & 25.0 \\
Newborn wrapped immediately & 15.6 & 14.3 \\
Baby bathed second day & 59.4 & 50.0 \\
Baby was medically examined & 71.9 & 67.9 \\
First milk given to baby & 56.3 & 57.1 \\
Breastfeeding started within 4 hours & 37.5 & 32.1 \\
$\mathrm{~N}$ & 32 & 28 \\
\hline
\end{tabular}

\section{Delivery practices}

Traditional birth attendants were trained to follow clean delivery practices, including use of clean delivery kits, proper washing of hands, use of a clean surface for delivery, etc. Two of the more important practices that could reasonably be remembered by respondents were the use of clean delivery kits and washing of hands. "SMART dais" were reported to use clean 
delivery kits much more often than untrained dais, and were also more likely to have washed their hands before delivery.

\section{Complications of delivery and neonates}

The untrained dais reported a higher level of complications both at delivery and for neonates than the trained ones. However, the differences are not statistically significant, and could well reflect simple chance. On the other hand, this could also be the result of higher levels of referral by trained dais; we did not ascertain whether, if a woman delivered in a facility, she had previously been under the care of a dai. Alternatively, it could be that the respondents felt more secure with the trained dais, or perhaps wanted to give the "right" answer to the interviewers. The difference could also be partly due to better delivery practices by the trained dais.

\section{Infant care}

Most dais, trained or untrained, used new blades for cutting the umbilical cord and new threads for tying it. However, the proportions are somewhat higher for project-trained dais. Putting the baby with the mother and wrapping it immediately were not reported by high proportions in either group. Examining the baby, delaying bathing, and beginning breastfeeding within the first four hours were somewhat more common among PC-trained dais, but not markedly so. There was no difference in whether initial colostrum was given to the baby.

On the whole, these data suggest better care on the part of the project-trained dais than untrained dais, but not markedly so. However, these data represent a smaller sample and less careful investigation than the OR study previously referred to, and that study, when completed, should give more definitive results on this topic.

\section{Women's autonomy and MNH care}

The three dimensions of women's autonomy (decision making, financial control, and mobility) elicited in the KAB survey were compared with the four key elements of $\mathrm{MNH}$ behavior. 


\section{Decision making}

Women's involvement in the decision-making process does not appear to have any positive relation to maternal care practices in DG Khan, but in Layyah a consistent positive relationship emerges (figure 7.18).

Figure 7.18: Percentage of women who received ANC, TT shots (2+), iron tablets and use of skilled birth attendant by decision-making power by district

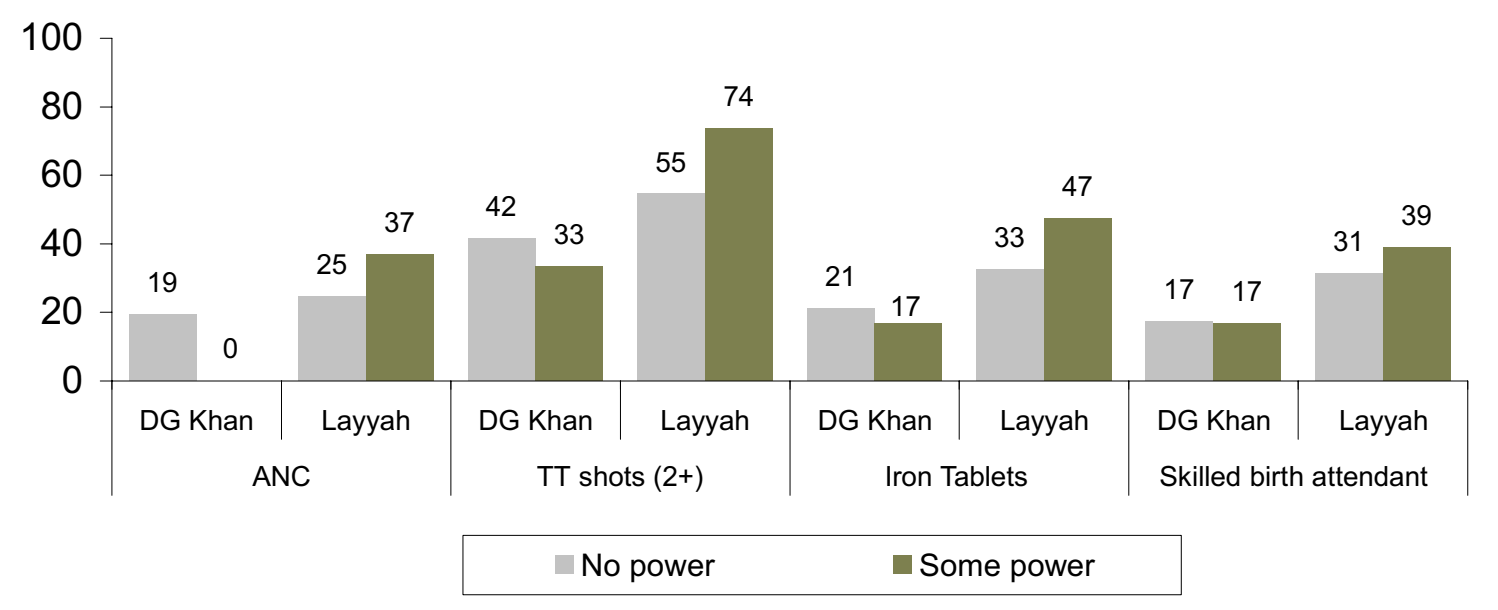

\section{Control over finances}

Figure 7.19 presents data on the relationship between women's control over finances and care-seeking behavior during pregnancy and delivery. The degree of control over finances has relatively little relationship to maternal health practice, except for the taking of iron tablets in both districts, and perhaps the use of skilled birth attendants in Layyah. 
Figure 7.19: Percentage of women who received ANC, TT shots (2+), iron tablets and use of skilled birth attendant by control over finances by district

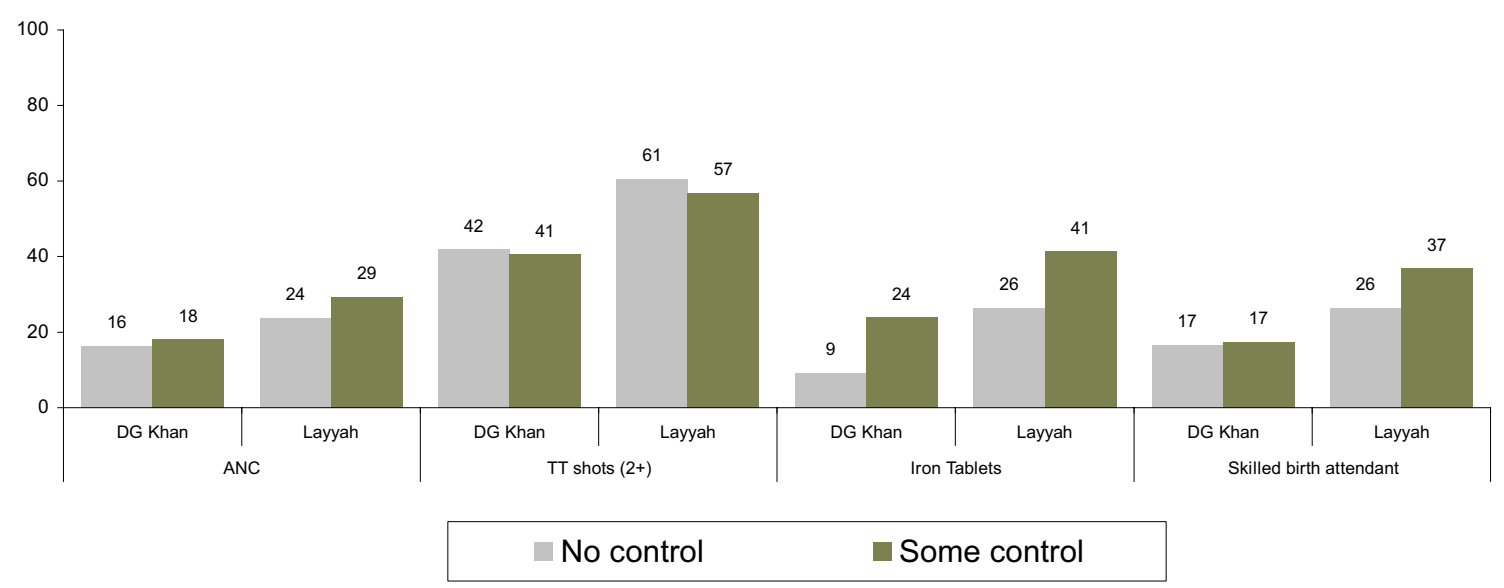

\section{Female mobility}

Female mobility, which is positively associated with MNH knowledge (see chapter 6) is not positively associated with maternal health care-seeking behavior in either district, and in fact seems negatively associated with some aspects of behavior in Layyah (figure 7.20) However, although numbers are small, full mobility (which specifically involves freedom to visit health facilities) does seem to be positively associated with maternal health seeking behaviors (data not shown).

Figure 7.20: Percentage of women who received ANC, TT shots (2+), iron tablets and use of skilled birth attendant by level of mobility by district

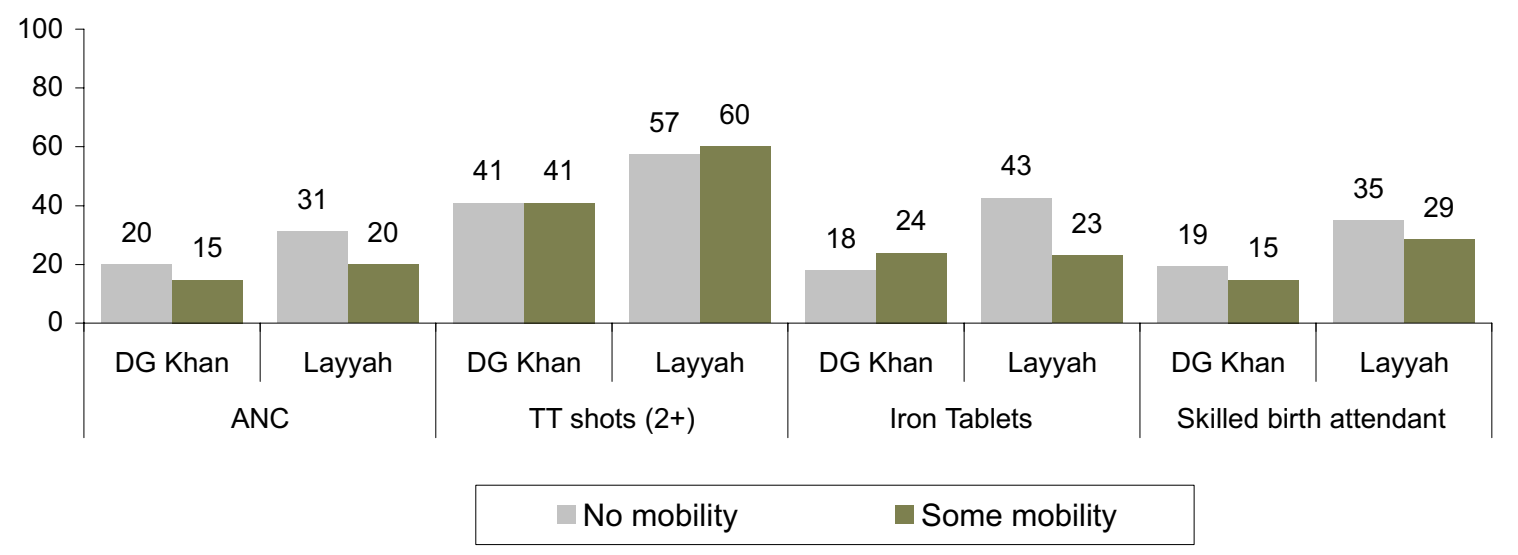




\section{VIII: Maternal and Newborn Emergencies}

\section{Experience of life threatening maternal complications}

Women who delivered during the 12 months prior to the household survey were asked whether they had experienced any complications during pregnancy, delivery and within 40 days after delivery (post-partum period). If so, they were asked what those problems were (spontaneous and probed). Certain complications of pregnancy were classified as potentially severe, including: blurring of eyes (sign of acute vitamin A deficiency etc); swelling of the face; spotting or heavy vaginal bleeding; fits or convulsions; and unconsciousness. Severe complications of delivery are: prolonged labor (labor lasting more than 12 hours); bleeding before labor begins; premature rupture of membrane; delay in delivery of the placenta; excessive bleeding; tears in the cervix or uterus; prolapsed uterus; and breech delivery. Severe postpartum complications are: excessive vaginal bleeding after delivery; fits or convulsions; unconsciousness; prolapsed uterus; and high fever.

In most contexts, the correlation between respondents' replies to such questions and the diagnoses of physicians is problematic. Women in DG Khan do not know medical terminology, and interpret physical events differently than doctors would. Hence, answers to these questions represent women's perceptions regarding their problems, which the interviewers put into specific medical terminology.

An international rule of thumb is that about 45 percent of all pregnancies experience some complication and that one-third of these complications require intervention or treatment. In these surveys, proportions were substantially higher. At baseline, 87.6 percent, 82.9 percent, and 82.4 percent of mothers in sites 1, 2 and 3 respectively reported some complication at some point (data not shown). At endline those proportions were 68.3 percent, 69.7 percent, and 69.9 percent, respectively. Hence while the proportions reporting "problems" declined between rounds 1 and 2, they were always substantially higher than the "rule of thumb".

The overall decline between baseline and endline is reflected in each period (pregnancy, delivery, postpartum, and neonatal - see Tables 8.1 to 8.3). No project interventions are likely to have caused such decreases, nor could other improvements during the period account for them. It is possible that, especially in site 1 (where the decreases are greatest) 
education has led respondents to be more clear about what is meant by a "problem". It may also be that in all areas some combination of more experienced interviewers and sensitized respondents has led respondents to a more limited definition of "problems".

\section{Pregnancy}

Table 8.1 shows the levels of reported complications during pregnancy at baseline and endline, spontaneous and probed, by specific complication. Overall, more women reported at least one severe complication during pregnancy (67 percent) than during delivery (55 percent) or the postpartum period (47 percent). At both baseline and endline and in all sites, the most commonly reported complications were blurring of vision and facial swelling, symptoms for which the level of danger involved depends on the detailed nature and severity of the symptom, which could not be effectively elicited in a household survey. Other symptoms, which are more unambiguously severe complications, were less commonly reported. Fits/convulsions and unconsciousness were mainly elicited through probing, and declined very sharply between baseline and endline.

Table 8.1: Percentage of women re porting severe complications of pregnancy, by site and HHS round

\begin{tabular}{|c|c|c|c|c|c|c|}
\hline \multirow[b]{2}{*}{ Pregnancy complication } & \multicolumn{2}{|c|}{ Site 1} & \multicolumn{2}{|c|}{ Site 2} & \multicolumn{2}{|c|}{ Site 3} \\
\hline & Baseline & Endline & Baseline & Endline & Baseline & Endline \\
\hline \multicolumn{7}{|c|}{$\begin{array}{l}\text { Experienced at least one severe } \\
\text { complication }\end{array}$} \\
\hline Spontaneous & 21.6 & 15.0 & 16.4 & 17.3 & 20.6 & 11.6 \\
\hline Probed & 57.9 & 26.9 & 56.8 & 28.3 & 52.1 & 33.9 \\
\hline Any & 70.4 & 42.6 & 65.5 & 45.2 & 64.1 & 43.2 \\
\hline Blurring of eyes & 59.2 & 27.2 & 52.8 & 29.0 & 54.2 & 27.1 \\
\hline Spontaneous & 14.5 & 8.8 & 10.0 & 11.0 & 15.5 & 4.7 \\
\hline Probed & 44.8 & 18.3 & 42.6 & 18.0 & 38.5 & 22.4 \\
\hline Facial swelling & 29.7 & 15.0 & 28.3 & 17.5 & 26.2 & 18.2 \\
\hline Spontaneous & 6.6 & 5.0 & 5.1 & 4.8 & 4.4 & 4.2 \\
\hline Probed & 23.0 & 10.0 & 23.1 & 12.7 & 21.8 & 14.7 \\
\hline Spotting & 6.1 & 3.4 & 6.4 & 4.0 & 7.7 & 4.2 \\
\hline Spontaneous & 1.9 & 2.0 & 1.6 & 2.3 & 2.0 & 1.3 \\
\hline Probed & 4.2 & 1.3 & 4.7 & 1.7 & 5.8 & 2.9 \\
\hline
\end{tabular}




\begin{tabular}{lrrrrrr}
\hline & \multicolumn{2}{c}{ Site 1 } & \multicolumn{2}{c}{ Site 2 } & \multicolumn{2}{c}{ Site 3 } \\
Pregnancy complication & Baseline & Endline & Baseline & Endline & Baseline & Endline \\
\hline & & & & & & \\
Heavy vaginal bleeding & 6.2 & 2.5 & 5.6 & 3.1 & 3.7 & 2.9 \\
$\quad$ Spontaneous & 2.4 & 1.7 & 2.0 & 1.8 & 1.5 & 1.6 \\
Probed & 3.8 & 0.8 & 3.6 & 1.3 & 2.1 & 1.5 \\
& & & & & & \\
Fits or convulsions & 7.9 & 0.3 & 6.7 & 1.6 & 7.2 & 1.5 \\
$\quad$ Spontaneous & 0.7 & 0.2 & 1.0 & 0.2 & 1.1 & 0.4 \\
$\quad$ Probed & 7.3 & 0.1 & 5.6 & 1.4 & 6.1 & 1.1 \\
& & & & & & \\
Unconsciousness & 8.3 & 1.3 & 6.5 & 1.6 & 5.6 & 3.5 \\
$\quad$ Spontaneous & 1.3 & 0.5 & 0.9 & 0.7 & 0.6 & 1.0 \\
$\quad$ Probed & 7.0 & 0.8 & 5.6 & 0.9 & 5.0 & 2.5 \\
No. of respondents & 2082 & 2028 & 2028 & 2023 & 1613 & 1634 \\
\hline
\end{tabular}

For nearly all complications, spontaneous reporting either did not decline or declined less than probed complications, suggesting some change in the way that interviewers probed or recorded probed responses, as shown in figure 8.1. Overall and for some individual symptoms, declines were slightly greater in site 1 than for other sites, but this trend was not consistent.

Figure 8.1: Percentage of women reporting at least one serious complication of pregnancy, spontaneous or probed

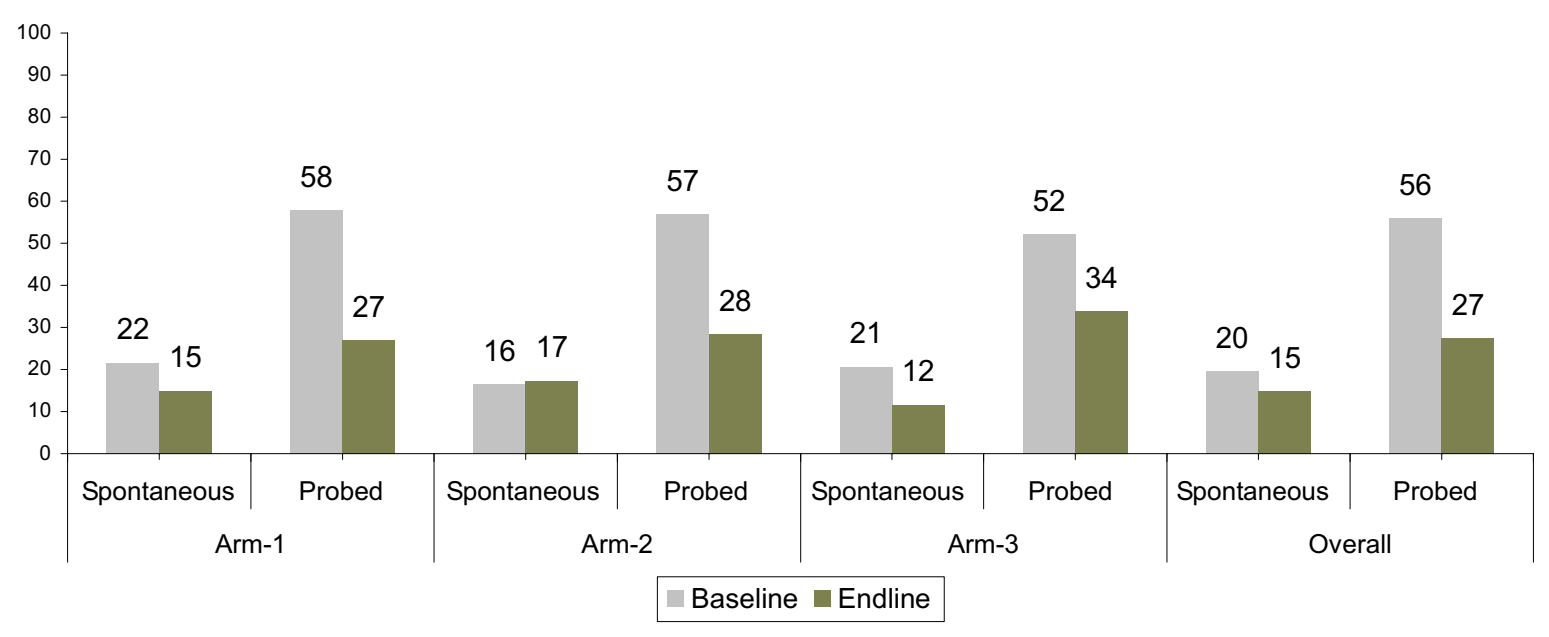




\section{Delivery}

Overall, reports of severe complications at delivery were more widely scattered over a range of complications than for pregnancy (table 8.2). However, among spontaneously reported complications, prolonged labor was mentioned much more often than other complications. Other relatively commonly reported complications at delivery include bleeding prior to labor, premature rupture, and delay in delivering the placenta.

Figure 8.2 shows changes in the proportions of respondents reporting one or more symptoms at baseline and endline, according to whether the reporting was spontaneous or probed. Overall and for most individual symptoms, there was relatively little decline in spontaneous reporting of complications, while probed reports declined sharply, in all three sites. As with pregnancy, declines in reported complications were slightly greater in site 1 than in other sites, primarily due to sharper declines in probed complications, but this was not consistent across symptoms.

Table 8.2: Percentage of women report ing severe complications of delivery, by site and HHS round.

\begin{tabular}{lrrrrrr}
\hline \multirow{2}{*}{ Delivery complication } & \multicolumn{2}{c}{ Site 1 } & \multicolumn{2}{c}{ Site 2 } & \multicolumn{2}{c}{ Site 3 } \\
\cline { 2 - 7 } & Baseline & Endline & Baseline & Endline & Baseline & Endline \\
\hline Experienced at least one severe & & & & & & \\
complication* & & & & & & \\
$\quad$ Spontaneous & 19.7 & 17.6 & 14.7 & 16.7 & 21.4 & 16.6 \\
$\quad$ Probed & 51.5 & 17.7 & 43.2 & 21.0 & 38.3 & 18.1 \\
$\quad$ Any & 61.9 & 37.2 & 51.9 & 37.4 & 50.3 & 32.9 \\
& & & & & & \\
Prolonged labor (> 12 hours) & 28.6 & 16.4 & 23.0 & 16.3 & 22.9 & 12.9 \\
$\quad$ Spontaneous & 12.9 & 9.2 & 9.2 & 9.4 & 13.1 & 9.1 \\
$\quad$ Probed & 15.7 & 7.1 & 13.8 & 6.9 & 9.7 & 3.8 \\
& & & & & & \\
Bleeding before labor begins & 10.7 & 4.9 & 10.3 & 5.2 & 10.9 & 5.4 \\
$\quad$ Spontaneous & 2.9 & 3.0 & 3.2 & 2.6 & 3.5 & 2.4 \\
$\quad$ Probed & 7.8 & 1.9 & 7.1 & 2.7 & 7.4 & 3.1 \\
& & & & & & \\
Premature rupture of membranes & 19.5 & 10.0 & 17.2 & 9.8 & 18.2 & 6.5 \\
$\quad$ Spontaneous & 3.8 & 3.7 & 3.0 & 3.0 & 5.2 & 2.2 \\
$\quad$ Probed & 15.8 & 6.2 & 14.2 & 6.8 & 13.1 & 4.3 \\
& & & & & & \\
Delay in delivery of placenta & 17.4 & 5.0 & 13.6 & 6.4 & 10.9 & 3.4 \\
Spontaneous & 3.6 & 2.4 & 2.4 & 2.5 & 2.3 & 1.2 \\
Probed & 13.9 & 2.7 & 11.2 & 4.0 & 8.6 & 2.2 \\
\hline
\end{tabular}




\begin{tabular}{lrrrrrr}
\hline \multirow{2}{*}{ Delivery complication } & \multicolumn{2}{c}{ Site 1 } & \multicolumn{2}{c}{ Site 2 } & \multicolumn{2}{c}{ Site 3 } \\
\cline { 2 - 7 } & Baseline & Endline & Baseline & Endline & Baseline & Endline \\
\hline Tears in cervix or uterus & & & & & & \\
$\quad$ Spontaneous & 8.2 & 1.4 & 7.0 & 1.6 & 4.4 & 1.5 \\
$\quad$ Probed & 1.3 & 0.5 & 0.7 & 0.3 & 1.0 & 0.5 \\
& 6.8 & 0.9 & 6.3 & 1.3 & 3.4 & 1.0 \\
Prolapsed uterus & & & & & & \\
$\quad$ Spontaneous & 6.8 & 0.7 & 7.0 & 2.0 & 4.3 & 3.1 \\
$\quad$ Probed & 0.7 & 0.1 & 0.5 & 0.6 & 1.3 & 0.5 \\
& 6.0 & 0.6 & 6.5 & 1.4 & 3.0 & 2.6 \\
Breech delivery & & & & & & \\
$\quad$ Spontaneous & 5.7 & 3.2 & 4.7 & 3.8 & 2.8 & 4.7 \\
$\quad$ Probed & 1.2 & 1.7 & 1.0 & 2.0 & 1.2 & 2.4 \\
No. of respondents & 4.5 & 1.5 & 3.7 & 1.8 & 1.6 & 2.3 \\
\hline
\end{tabular}

* Includes excessive vaginal bleeding, which could be reported either at delivery or postpartum

Figure 8.2: Percentage of women reporting at least one serious complication of delivery, spontaneous or probed

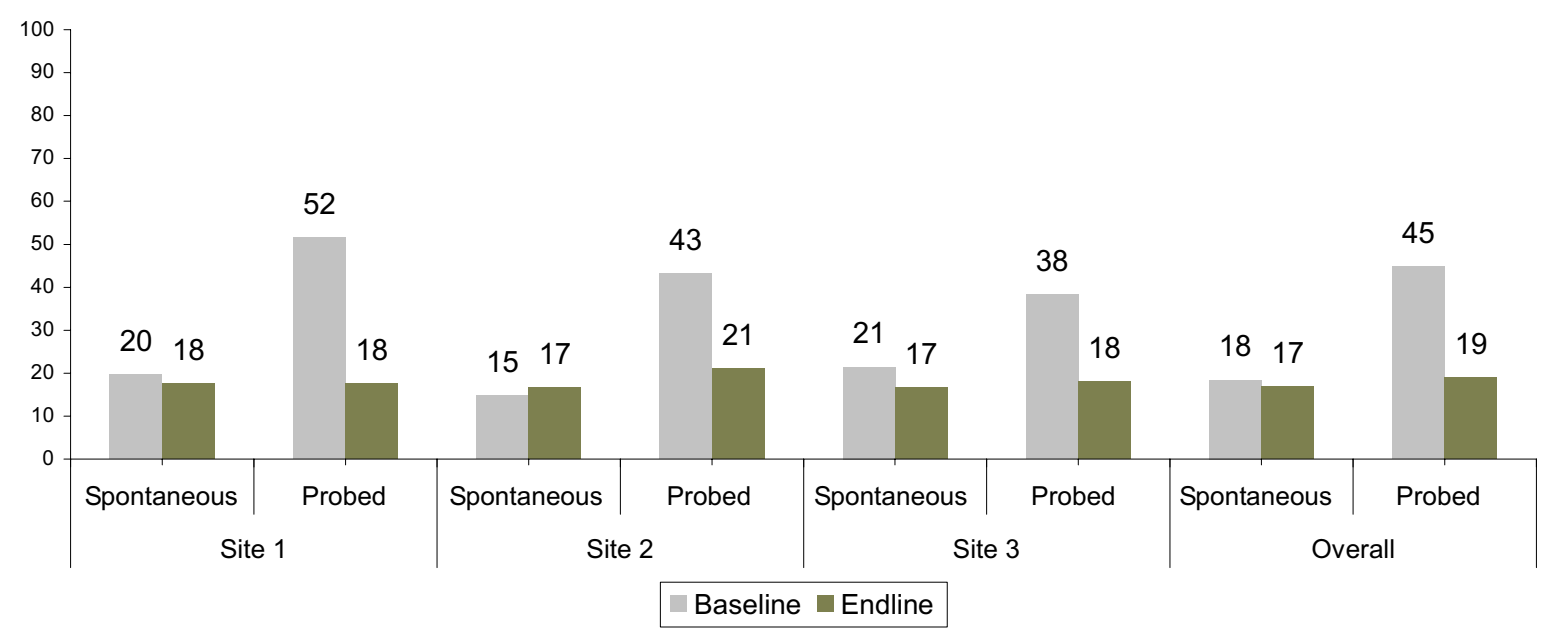

\section{Postpartum}

Table 8.3 shows the reporting of symptoms during the postpartum period at baseline and endline, again by arm and according to whether the response was spontaneous or probed, and for individual complications. The most commonly reported complications were high fever, excessive bleeding and (primarily probed) fits or convulsions. High fever and excessive postpartum bleeding are in fact expected to be more common than the other 
symptoms, and both are indicators of common causes of maternal mortality. Declines in postpartum complications between baseline and endline are noticeably greater in site 1 than in the other sites, for both probed and spontaneous reports (which in fact increased overall in sites 2 and 3.) It is possible that this reflects better knowledge of complications among the women of site 1 , the area with a strong community education component.

Spontaneous reporting of excessive bleeding was relatively uncommon, but those reports must be combined with excessive bleeding as a complication of the postpartum period.

Table 8.3: Percentage of women reporting severe complications in the postpartum period, by site and HHS round

\begin{tabular}{|c|c|c|c|c|c|c|}
\hline \multirow[b]{2}{*}{ Postpartum complication } & \multicolumn{2}{|c|}{ Site 1} & \multicolumn{2}{|c|}{ Site 2} & \multicolumn{2}{|c|}{ Site 3} \\
\hline & Baseline & Endline & Baseline & Endline & Baseline & Endline \\
\hline \multicolumn{7}{|l|}{$\begin{array}{l}\text { Experienced at least one severe } \\
\text { complication }\end{array}$} \\
\hline Spontaneous & 18.8 & 18.0 & 13.4 & 17.8 & 18.6 & 19.4 \\
\hline Probed & 38.5 & 16.3 & 33.5 & 18.3 & 33.0 & 22.2 \\
\hline Any & 51.3 & 33.2 & 42.5 & 34.1 & 45.6 & 38.7 \\
\hline Excessive vaginal bleeding* & 36.1 & 17.2 & 29.7 & 18.2 & 31.2 & 15.2 \\
\hline Spontaneous & 11.0 & 8.3 & 8.1 & 8.0 & 10.0 & 7.5 \\
\hline Probed & 25.1 & 8.9 & 21.6 & 10.0 & 21.0 & 7.6 \\
\hline Fits or convulsions & 12.4 & 1.5 & 10.0 & 3.1 & 10.9 & 3.2 \\
\hline Spontaneous & 0.9 & 0.5 & 0.8 & 0.8 & 2.3 & 0.6 \\
\hline Probed & 11.6 & 1.0 & 9.2 & 2.3 & 8.6 & 2.6 \\
\hline Unconsciousness & 5.0 & 1.1 & 3.5 & 1.4 & 4.3 & 2.1 \\
\hline Spontaneous & 0.9 & 0.5 & 0.5 & 0.4 & 1.2 & 0.3 \\
\hline Probed & 4.1 & 0.6 & 3.0 & 1.0 & 3.0 & 1.8 \\
\hline Prolapsed of uterus & 8.0 & 1.9 & 7.4 & 2.6 & 5.6 & 4.4 \\
\hline Spontaneous & 1.2 & 0.6 & 1.1 & 1.0 & 0.7 & 1.0 \\
\hline Probed & 6.8 & 1.2 & 6.3 & 1.5 & 4.8 & 3.4 \\
\hline High fever & 34.1 & 23.3 & 28.2 & 23.8 & 30.5 & 30.6 \\
\hline Spontaneous & 10.8 & 14.0 & 8.3 & 12.3 & 12.7 & 14.7 \\
\hline Probed & 23.4 & 9.3 & 19.3 & 11.5 & 17.7 & 15.9 \\
\hline No. of respondents & 2082 & 2028 & 2028 & 2023 & 1613 & 1634 \\
\hline
\end{tabular}

* Includes bleeding reported as a complication of delivery 
There is little overall indication of change in spontaneous reporting of postpartum complications (see figure 8.3). However, table 8.3 indicates that spontaneous reporting of individual symptoms does decline for several symptoms, but increases for high fever in all three sites. As with pregnancy and delivery, there are substantial declines overall and for all individual symptoms in the frequency of probed reports of complications.

Figure 8.3: Percentage of women reporting at least one serious complication of postpartum period, spontaneous or probed

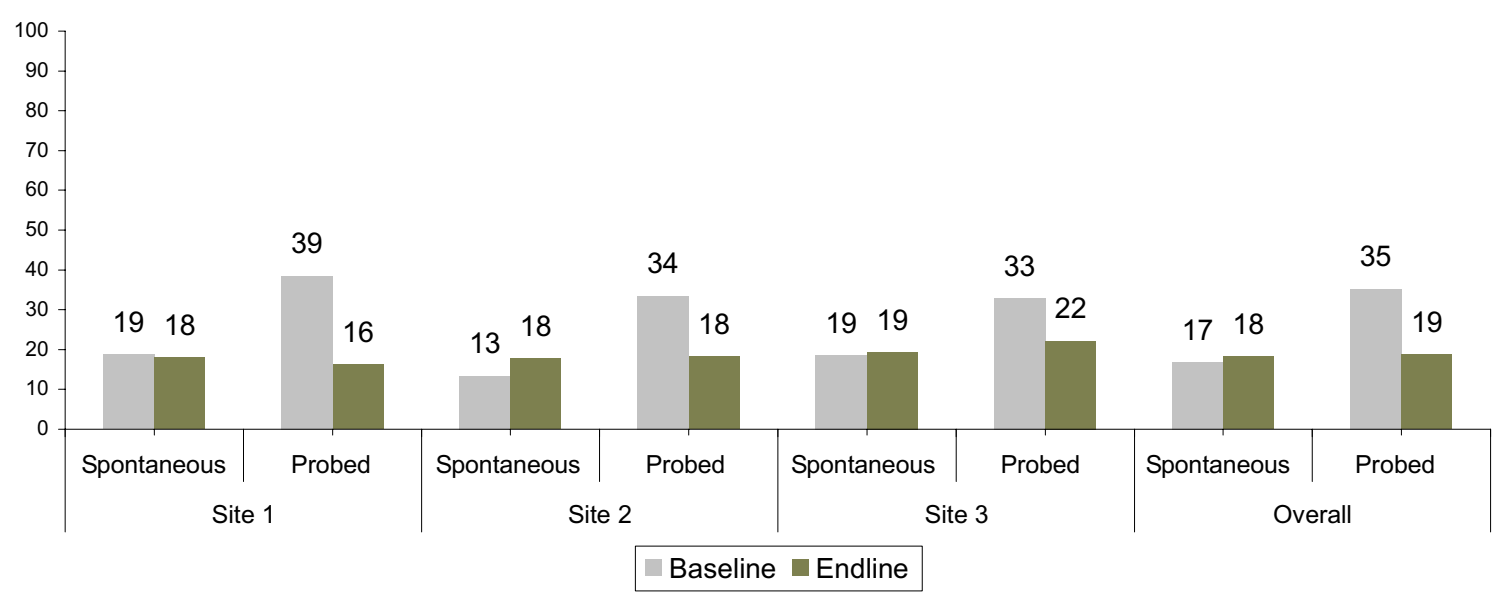

\section{Health problems of the newborn}

For the newborn, questions comparable to those about maternal complications were not asked in the household survey, but they were asked in the KAB. Mothers who had delivered a live birth during the six months prior to the baseline survey and 12 months prior to the endline survey were asked about a specific list of health problems the newborn might have had at birth and within one week after birth. Hence these responses are more like the "probed" responses regarding maternal health. Because these are KAB data and apply only to the subset of respondents reporting complications, numbers here are quite small.

\section{Health problems at birth}

Table 8.4 presents health problems of newborns in the previous 6 months, as reported by mothers. Several types of problems are relatively common throughout, including breathing problems, no or weak cry, blue or yellow skin, hypothermia, and difficulty in sucking. All of these can be signs of serious problems that may lead to neonatal death. 
At the time of the baseline survey, 27 percent of newborns in site 1, 36 percent in site 2, and 15 percent in site 3 had suffered from at least one health problem at birth. Table 8.4 and figure 8.4 illustrate the rapid decline between rounds in the proportions reporting complications in sites 1 and 2, to numbers similar to those of site 3 . The reported declines in individual problems are generally greater than the decline in "any" problem, including in site 3 where the overall decline is minimal.

The observed declines in neonatal complications, especially in site 1, could be at least partly due to project activities, as better education and treatment at delivery could have reduced neonatal problems. However, it is also plausible that the interview process in round 3 was more conservative in recording problems than previously.

Table 8.4: Percentage of newborns who experienced health problems at birth, by study site and KAB round

\begin{tabular}{|c|c|c|c|c|c|c|}
\hline \multirow[b]{2}{*}{ Neonatal complication at birth } & \multicolumn{2}{|c|}{ Site 1} & \multicolumn{2}{|c|}{ Site 2} & \multicolumn{2}{|c|}{ Site 3} \\
\hline & Baseline & Endline & Baseline & Endline & Baseline & Endline \\
\hline $\begin{array}{l}\text { Experience at least one } \\
\text { complication }\end{array}$ & 27.1 & 14.6 & 35.9 & 11.2 & 14.9 & 14.6 \\
\hline No or weak cry & 8.2 & 7.0 & 18.2 & 4.6 & 10.9 & 6.0 \\
\hline No or difficult breathing & 8.2 & 3.2 & 9.1 & 4.6 & 5.0 & 4.0 \\
\hline Fast and difficult breathing & 6.6 & 4.4 & 18.2 & 0.6 & 5.9 & 2.7 \\
\hline Yellow skin (jaundice) & 4.9 & 1.3 & 13.0 & 0.6 & 4.0 & 1.3 \\
\hline Blue skin & 13.1 & 3.8 & 10.4 & 4.0 & 5.0 & 1.3 \\
\hline $\begin{array}{l}\text { Baby is very cold/shivering } \\
\text { (hypothermia) }\end{array}$ & 9.8 & 0.6 & 6.5 & 2.3 & 3.0 & 0.7 \\
\hline Unable to suck or feeble sucking & 8.2 & 0.6 & 5.2 & 2.3 & 2.0 & 4.7 \\
\hline Skin lesion or (blister) & 0.0 & 0.0 & 0.0 & 0.6 & 0.0 & 0.0 \\
\hline $\begin{array}{l}\text { Fits/ abnormal or jerky } \\
\text { movements }\end{array}$ & 3.3 & 0.6 & 2.6 & 0.0 & 0.0 & 0.0 \\
\hline Red and swollen eyes & 9.8 & 0.0 & 6.5 & 1.2 & 2.0 & 0.7 \\
\hline No. of respondents & 61 & 158 & 77 & 173 & 101 & 149 \\
\hline
\end{tabular}


Figure 8.4: Percentage of newborns who suffered from at least one complication at birth

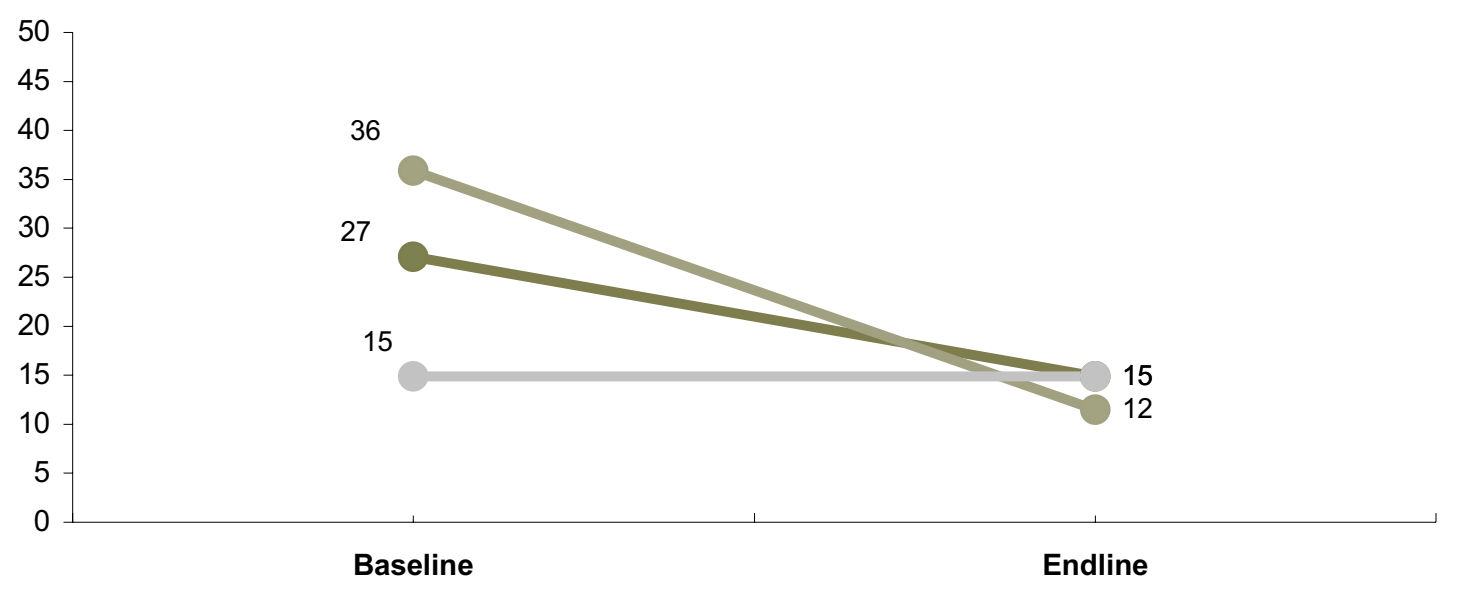

Arm $1-$ Arm $2-$ Arm 3

\section{Health problems within one week after birth}

The situation regarding health symptoms during the week after birth was broadly similar to the reporting of problems at birth. Somewhat more problems were reported, especially at endline. Some of the same problems were prominent, but there were fewer reports of breathing problems during the week, while problems with urine and stools, and possible cord infection, began to be noticed.

There was also a similar tendency for rapid declines in reported problems between baseline and endline, especially in sites 1 and 2 . As before, declines in individual symptoms were generally greater than the overall decline. We are inclined to believe that at least some form of ascertainment bias is involved in these declines, but some project effect is also possible. 
Table 8.5: Percentage of newborns wh o experienced health problems within 7 days after birth, by site and KAB round

\begin{tabular}{lrrrrrr}
\hline & \multicolumn{2}{c}{ Site 1 } & \multicolumn{2}{c}{ Site 2 } & \multicolumn{2}{c}{ Site 3 } \\
\cline { 2 - 7 } Complication within one week & Baseline & Endline & Baseline & Endline & Baseline & Endline \\
\hline Experienced at least one & 32.8 & 16.7 & 34.6 & 20.2 & 19.8 & 18.5 \\
complication & & & & & & \\
$\quad$ Fast and difficult breathing & 1.7 & 2.5 & 6.8 & 0.0 & 2.1 & 0.7 \\
$\quad$ Yellow skin (jaundice) & 16.7 & 6.3 & 17.6 & 7.5 & 1.0 & 2.0 \\
$\quad$ Blue skin & 6.7 & 2.5 & 8.1 & 2.9 & 6.2 & 0.0 \\
Baby is very cold/shivering & 5.0 & 1.9 & 5.4 & 1.2 & 7.2 & 1.3 \\
Unable to suck or feeble sucking & 3.3 & 3.2 & 12.2 & 3.5 & 0.0 & 3.4 \\
Skin lesion or blister & 6.7 & 1.3 & 8.1 & 0.6 & 4.1 & 2.0 \\
Fits & 1.7 & 1.3 & 5.4 & 0.6 & 1.0 & 0.7 \\
$\quad$ Red and swollen eyes & 6.7 & 3.2 & 5.4 & 0.6 & 2.1 & 2.7 \\
$\quad$ Failure to pass urine & 5.0 & 0.6 & 10.8 & 1.2 & 3.1 & 2.7 \\
$\quad$ Frequent watery stools/or stools & 5.0 & 3.8 & 12.2 & 1.7 & 7.2 & 3.4 \\
$\quad$ with blood or mucus & & & & & & \\
$\quad$ Redness and discharge around & 5.0 & 1.9 & 5.5 & 4.0 & 1.0 & 3.4 \\
$\quad$ the cord & & & & & & \\
No. of respondents & 60 & 158 & 74 & 173 & 97 & 149 \\
\hline
\end{tabular}

\section{Care-seeking behavior for problems}

Every pregnant woman is at risk of experiencing complications; the important thing is whether those who develop complications seek treatment. Ideally, women who experience something they believe might be a complication should at least obtain medical advice as to whether treatment is needed or not. Tables 8.6 to 8.8 present data on the proportion of those women reporting complications (spontaneous or probed) who sought treatment from a skilled care provider according to the nature of the problem, from HHS data. For neonates, where data are available only in the $\mathrm{KAB}$, numbers by problem category are too small to be useful in analyzing the treatment of specific problems, but data are available both on the type of provider and the nature of the service center.

For these purposes a "skilled health care provider" is a person who is qualified and has skills to treat such complications; medical doctors (male and female), lady health visitors (LHV), nurses, midwives and dispensers are classified as skilled health care providers. 


\section{Pregnancy}

Each of the problems listed in table 8.6 is potentially life-threatening, and care should be sought for them. For most of the listed problems, substantial proportions of women did seek care, but large proportions did not. In general, care was least likely to be sought for facial swelling; presumably, since some level of edema is normal, it is difficult for women to determine at what level this becomes problematic. Similarly, it may be difficult to know when blurring of the eyes reaches a dangerous level. For other less ambiguous signs, such as spotting or heavy bleeding, the tendency to seek help is stronger. It would be useful to study such situations in more detail to try to determine whether failure to seek care represents lack of recognition of the seriousness of the problem, or financial or social constraints facing the woman.

In sites 1 and 2, there were general increases between baseline and endline in the proportions seeking care for specific problems. These increases tend to counteract the decreases in reported problems shown above, and suggest that by the endline there was a tendency to report fewer problems not considered serious, and therefore not requiring care.

Table 8.6: Percentage of women who sought treatment from skilled health care providers for pregnancy complications, by site and HHS round

\begin{tabular}{|c|c|c|c|c|c|c|c|c|c|c|c|c|}
\hline \multirow{3}{*}{$\begin{array}{l}\text { Signs and } \\
\text { symptoms }\end{array}$} & \multicolumn{4}{|c|}{ Site 1} & \multicolumn{4}{|c|}{ Site 2} & \multicolumn{4}{|c|}{ Site 3} \\
\hline & \multicolumn{2}{|c|}{ Baseline } & \multicolumn{2}{|c|}{ Endline } & \multicolumn{2}{|c|}{ Baseline } & \multicolumn{2}{|c|}{ Endline } & \multicolumn{2}{|c|}{ Baseline } & \multicolumn{2}{|c|}{ Endline } \\
\hline & Pct. & No. & Pct. & No. & Pct. & No. & Pct. & No. & Pct. & No. & Pct. & No. \\
\hline Blurring of eyes & 25.9 & 1365 & 33.0 & 589 & 21.9 & 1161 & 32.6 & 636 & 32.7 & 936 & 29.4 & 456 \\
\hline Facial swelling & 21.0 & 642 & 39.5 & 305 & 14.5 & 585 & 30.0 & 356 & 22.7 & 434 & 28.1 & 315 \\
\hline Spotting & 35.5 & 183 & 52.0 & 129 & 35.7 & 187 & 50.4 & 129 & 48.0 & 169 & 55.4 & 94 \\
\hline $\begin{array}{l}\text { Heavy vaginal } \\
\text { bleeding }\end{array}$ & 56.3 & 218 & 49.1 & 175 & 50.9 & 182 & 48.3 & 172 & 70.7 & 114 & 52.6 & 80 \\
\hline Fits or convulsions & 31.3 & 196 & 33.3 & 6 & 41.2 & 148 & 62.9 & 35 & 54.9 & 121 & 50.0 & 27 \\
\hline Unconsciousness & 29.9 & 194 & 53.1 & 32 & 38.9 & 152 & 50.0 & 38 & 54.4 & 100 & 49.1 & 59 \\
\hline
\end{tabular}

\section{Delivery}

Proportions of women seeking care for reported problems at delivery (table 8.7) are broadly similar in level and variability to problems during pregnancy. Women most frequently sought treatment for tears in the cervix or uterus, bleeding before labor, prolonged labor, and breech delivery. Premature rupture of membranes, delay in the delivery of the placenta, excessive bleeding, and uterine prolapse were less likely to result in treatment. Excessive 
bleeding, which is the single greatest cause of maternal death, deserves further study. While it may be difficult to determine or report "excessive" bleeding, it is commonly thought in DG Khan and Layyah that heavy bleeding after delivery has a positive value in cleaning out the uterus. It is probable that delays in seeking treatment for this problem, coupled with difficulties in reaching a facility with appropriate blood supply, leads to many maternal deaths in the project area.

As with pregnancy complications, increasing care seeking generally offsets reduced reporting of complications, suggesting that at the endline women are more likely to report only those complications considered serious enough to warrant treatment. The increases were similar for all sites, but most pronounced in the CBI area. On the other hand, at both baseline and endline the proportions of women seeking care for complications of delivery were highest in Layyah.

Table 8.7: Percentage of women who sought treatment from skilled health care providers for delivery complications, by site and HHS round

\begin{tabular}{|c|c|c|c|c|c|c|c|c|c|c|c|c|}
\hline \multirow{3}{*}{$\begin{array}{l}\text { Signs and } \\
\text { symptoms }\end{array}$} & \multicolumn{4}{|c|}{ Site 1} & \multicolumn{4}{|c|}{ Site 2} & \multicolumn{4}{|c|}{ Site 3} \\
\hline & \multicolumn{2}{|c|}{ Baseline } & \multicolumn{2}{|c|}{ Endline } & \multicolumn{2}{|c|}{ Baseline } & \multicolumn{2}{|c|}{ Endline } & \multicolumn{2}{|c|}{ Baseline } & \multicolumn{2}{|c|}{ Endline } \\
\hline & Pct. & No. & Pct. & No. & Pct. & No. & Pct. & No. & Pct. & No. & Pct. & No. \\
\hline $\begin{array}{l}\text { Prolonged labor (> } \\
12 \text { hours) }\end{array}$ & 33.8 & 657 & 45.3 & 333 & 34.2 & 503 & 43.1 & 326 & 40.8 & 393 & 60.5 & 209 \\
\hline $\begin{array}{l}\text { Bleeding before } \\
\text { labor begins }\end{array}$ & 30.5 & 356 & 42.5 & 226 & 40.6 & 325 & 37.8 & 209 & 54.3 & 266 & 52.3 & 135 \\
\hline $\begin{array}{l}\text { Premature rupture } \\
\text { of membranes }\end{array}$ & 21.4 & 444 & 34.8 & 205 & 22.4 & 374 & 26.4 & 196 & 34.5 & 311 & 50.0 & 105 \\
\hline $\begin{array}{l}\text { Delay in delivery of } \\
\text { placenta }\end{array}$ & 17.2 & 391 & 20.4 & 109 & 21.7 & 297 & 24.5 & 143 & 32.6 & 186 & 44.1 & 59 \\
\hline Excessive bleeding & 16.9 & 548 & 33.9 & 292 & 18.8 & 403 & 24.9 & 261 & 22.6 & 296 & 41.0 & 141 \\
\hline $\begin{array}{l}\text { Tears in cervix or } \\
\text { uterus }\end{array}$ & 31.9 & 184 & 65.6 & 32 & 39.9 & 151 & 65.8 & 39 & 52.2 & 75 & 62.5 & 25 \\
\hline Prolapsed uterus & 18.2 & 150 & 37.5 & 16 & 18.2 & 147 & 20.0 & 40 & 44.9 & 71 & 15.7 & 51 \\
\hline Breech delivery & 27.6 & 126 & 50.0 & 65 & 39.4 & 96 & 44.7 & 76 & 48.9 & 48 & 62.0 & 76 \\
\hline
\end{tabular}

\section{Postpartum}

In general, fewer women go for treatment for postpartum problems - both in numbers and proportions than for delivery (table 8.8). The reported problems for which treatment is most likely to be sought are loss of consciousness and high fever, but even for these the 
proportion seeking care does not reach much above half at most. Treatment seeking is noticeably uncommon for uterine prolapse and fits/convulsions.

As with pregnancy and delivery, increased proportions seeking care for reported complications offset decreasing proportions reporting complications. There is no clear tendency for levels to be higher or increases greater in any of the three sites.

Table 8.8: Percentage of women who sought treatment from skilled health care provider for postpartum complications, by site and HHS round

\begin{tabular}{|c|c|c|c|c|c|c|c|c|c|c|c|c|}
\hline \multirow{3}{*}{$\begin{array}{l}\text { Signs and } \\
\text { symptoms }\end{array}$} & \multicolumn{4}{|c|}{ Site 1} & \multicolumn{4}{|c|}{ Site 2} & \multicolumn{4}{|c|}{ Site 3} \\
\hline & \multicolumn{2}{|c|}{ Baseline } & \multicolumn{2}{|c|}{ Endline } & \multicolumn{2}{|c|}{ Baseline } & \multicolumn{2}{|c|}{ Endline } & \multicolumn{2}{|c|}{ Baseline } & \multicolumn{2}{|c|}{ Endline } \\
\hline & Pct. & No. & Pct. & No. & Pct. & No. & Pct. & No. & Pct. & No. & Pct. & No. \\
\hline $\begin{array}{l}\text { Excessive vaginal } \\
\text { bleeding }\end{array}$ & 12.3 & 477 & 31.3 & 294 & 15.3 & 322 & 26.5 & 274 & 20.0 & 295 & 34.4 & 133 \\
\hline Fits or convulsions & 13.0 & 288 & 17.6 & 34 & 12.6 & 226 & 19.7 & 71 & 20.6 & 188 & 30.2 & 53 \\
\hline Unconsciousness & 26.2 & 112 & 52.2 & 24 & 24.3 & 81 & 54.3 & 36 & 44.9 & 81 & 48.5 & 33 \\
\hline Prolapsed uterus & 8.5 & 182 & 19.5 & 41 & 10.3 & 158 & 28.6 & 58 & 27.0 & 102 & 12.2 & 75 \\
\hline High fever & 42.2 & 757 & 33.1 & 506 & 33.9 & 610 & 36.6 & 518 & 50.8 & 522 & 50.8 & 523 \\
\hline
\end{tabular}

\section{Neonatal care}

For neonatal problems, data were elicited only in the KAB study, and numbers for any particular type of problem are too small for useful analysis. However, data are available for whether care is sought and for the type of facility from which care is sought.

Although the numbers are small, it appears that the proportions of those reporting problems at birth declined, but not of those reporting problems within the first week. For those seeking care, it is striking that very few went to a public facility. More than half went to a private facility, and one-third to a paramedic, presumably under her/his private capacity. 
Table 8.9: Sources of treatment for newborn complications experienced at birth and within 7 days after birth

\begin{tabular}{lrrrrrr}
\hline \multirow{2}{*}{ Source of treatment } & \multicolumn{2}{c}{ Site 1 } & \multicolumn{2}{c}{ Site 2 } & \multicolumn{2}{c}{ Site 3 } \\
\cline { 2 - 6 } & Baseline & Endline & Baseline & Endline & Baseline & Endline \\
\hline At birth & & & & & & \\
No treatment & & & & & & \\
Sought treatment & 5.9 & 45.0 & 37.0 & 58.8 & 33.3 & 52.6 \\
$\quad$ Government facility & 94.1 & 55.0 & 63.0 & 61.2 & 66.7 & 47.4 \\
$\quad$ Private health facility & 0.0 & 0.0 & 3.7 & 0.0 & 6.7 & 21.1 \\
$\quad$ Nurse/LHV/Dispenser & 47.1 & 40.0 & 33.3 & 11.8 & 26.7 & 21.1 \\
$\quad$ Other & 41.2 & 5.0 & 22.2 & 23.5 & 33.3 & 0.0 \\
Total & 5.9 & 10.0 & 3.7 & 5.9 & 0.0 & 5.3 \\
No. of observations & 100.0 & 100.0 & 100.0 & 100.0 & 100.0 & 100.0 \\
& 17 & 20 & 27 & 17 & 15 & 19 \\
Within 7 days after birth & & & & & & \\
No treatment & & & & & & \\
Sought treatment & 10.5 & 18.2 & 25.9 & 15.0 & 30.0 & 22.2 \\
$\quad$ Government facility & 89.5 & 81.8 & 74.1 & 85.0 & 70.0 & 77.8 \\
Private health facility & 0.0 & 3.0 & 3.7 & 2.5 & 5.0 & 18.5 \\
$\quad$ Nurse/LHV/Dispenser & 21.1 & 60.6 & 33.3 & 60.0 & 35.0 & 40.7 \\
Other & 57.9 & 12.1 & 29.6 & 22.5 & 25.0 & 18.5 \\
Total & 10.5 & 6.1 & 7.4 & 0.0 & 5.0 & 0.0 \\
No. of observations & 100.0 & 100.0 & 100.0 & 100.0 & 100.0 & 100.0 \\
\hline & 19 & 33 & 27 & 40 & 20 & 27 \\
\hline
\end{tabular}




\section{Mortality}

The ultimate goal of this project was to reduce maternal and neonatal mortality. Since sample sizes sufficient to measure maternal mortality could not be obtained, we chose perinatal mortality (stillbirths plus early neonatal deaths per 1,000 live births) as our key indicator, but maternal, neonatal, and infant deaths are still of interest. Definitions are as follows:

Perinatal mortality rate $(\mathrm{PMR})=$ stillbirths $(22+$ weeks $)$ plus early neonatal deaths $\left(1^{\text {st }}\right.$ week $)$ /(live births + stillbirths)

Neonatal mortality rate $(\mathrm{NMR})=$ deaths in the first 28 days/live births Early neonatal mortality rate $(E N M R)=$ deaths in the first week/live births Stillbirth rate $(\mathrm{SBR})=$ stillbirths $/$ (stillbirths + live births) Infant mortality rate $(\mathrm{IMR})=$ infant deaths $/$ births $^{3}$

Our household survey obtained reports of deaths over the preceding 12 months. A longer reference period would have been possible, but for the endline this would have produced rates consisting of deaths both before and after project implementation. As it is, some mortality captured at the endline would have occurred prior to complete project implementation in the given community, and most stillbirths and neonatal deaths resulted from pregnancies that began before project implementation. Hence any project effect on mortality would be understated in these calculations. Table 9.1 shows the numbers of relevant vital events. Table 9.2 shows the corresponding rates, with 95 percent confidence intervals.

\footnotetext{
${ }^{3}$ Infant mortality data are taken from the full household roster, rather than from index births to respondents. Consequently the numbers of births are different from those shown elsewhere.
} 
Table 9.1: Vital events recorded by the SMART project household survey in the previous 12 months at baseline and endline, by study arm

\begin{tabular}{lrrrrrrrr}
\hline & \multicolumn{2}{c}{ Site 1 } & \multicolumn{2}{c}{ Site 2 } & \multicolumn{2}{c}{ Site 3 } & \multicolumn{2}{c}{ Total } \\
\cline { 2 - 9 } Vital Event & Base & End & Base & End & Base & End & Base & End \\
\hline Live births & 2001 & 1946 & 1969 & 1955 & 1531 & 1542 & 5501 & 5443 \\
Perinatal deaths & 170 & 127 & 136 & 141 & 149 & 150 & 455 & 418 \\
$\quad$ Stillbirths & 88 & 70 & 62 & 62 & 81 & 86 & 231 & 218 \\
$\quad$ Early neonatal deaths & 82 & 57 & 74 & 79 & 68 & 64 & 224 & 200 \\
Neonatal deaths & 94 & 75 & 97 & 96 & 75 & 69 & 266 & 240 \\
Postneonatal deaths & 60 & 47 & 62 & 41 & 47 & 35 & 169 & 123 \\
Infant deaths & 154 & 122 & 159 & 137 & 122 & 104 & 435 & 363 \\
Maternal deaths & 6 & 4 & 3 & 2 & 4 & 2 & 13 & 8 \\
\hline
\end{tabular}

Table 9.2: Vital rates and selected $95 \%$ confidence intervals at baseline and endline, by study arm

\begin{tabular}{|c|c|c|c|c|c|c|c|c|}
\hline \multirow[b]{2}{*}{ Vital Rate } & \multicolumn{2}{|c|}{ Site 1} & \multicolumn{2}{|c|}{ Site 2} & \multicolumn{2}{|c|}{ Site 3} & \multicolumn{2}{|c|}{ Total } \\
\hline & Base & End & Base & End & Base & End & Base & End \\
\hline $\begin{array}{l}\text { Perinatal mortality } \\
\text { rate }\end{array}$ & 81.7 & 63.4 & 66.6 & 69.8 & 92.7 & 92.5 & 79.5 & 74.0 \\
\hline $95 \%$ C.I. & $\begin{array}{r}(70.8- \\
94.2)\end{array}$ & $\begin{array}{r}(54.0- \\
74.2)\end{array}$ & $\begin{array}{r}(54.9- \\
80.6)\end{array}$ & $\begin{array}{r}(59.3- \\
82.0)\end{array}$ & $\begin{array}{l}(79.9- \\
107.4)\end{array}$ & $\begin{array}{l}(80.4- \\
106.3)\end{array}$ & $\begin{array}{r}(72.4- \\
87.1)\end{array}$ & $\begin{array}{r}(67.8- \\
80.0)\end{array}$ \\
\hline Stillbirth rate & 42.3 & 35.1 & 30.1 & 30.7 & 50.4 & 53.3 & 40.3 & 38.8 \\
\hline 95\% C.I. & $\begin{array}{r}(32.9- \\
54.2)\end{array}$ & $\begin{array}{r}(26.2- \\
47.1)\end{array}$ & $\begin{array}{r}(24.6- \\
36.7)\end{array}$ & $\begin{array}{r}(25.0- \\
37.6)\end{array}$ & $\begin{array}{r}(40.9- \\
62.0)\end{array}$ & $\begin{array}{r}(44.0- \\
64.4)\end{array}$ & $\begin{array}{r}(35.3- \\
45.9)\end{array}$ & $\begin{array}{r}(34.0- \\
44.3)\end{array}$ \\
\hline $\begin{array}{l}\text { Early neonatal mort. } \\
\text { rate }\end{array}$ & 41.2 & 29.2 & 37.6 & 40.3 & 44.6 & 41.5 & 40.8 & 36.7 \\
\hline 95\% C.I. & $\begin{array}{r}(32.0- \\
52.8)\end{array}$ & $\begin{array}{r}(22.5- \\
38.0)\end{array}$ & $\begin{array}{r}(28.0- \\
50.5)\end{array}$ & $\begin{array}{r}(30.9- \\
52.5)\end{array}$ & $\begin{array}{r}(35.5- \\
55.8)\end{array}$ & $\begin{array}{r}(31.6- \\
54.1)\end{array}$ & $\begin{array}{r}(35.2- \\
47.3)\end{array}$ & $\begin{array}{r}(31.5- \\
42.7)\end{array}$ \\
\hline $\begin{array}{l}\text { Neonatal mortality } \\
\text { rate }\end{array}$ & 47.2 & 38.5 & 49.3 & 49.0 & 49.1 & 44.7 & 48.5 & 44.0 \\
\hline $95 \%$ C.I. & $\begin{array}{r}(37.6- \\
59.0)\end{array}$ & $\begin{array}{r}(30.8- \\
48.0)\end{array}$ & $\begin{array}{r}(38.9- \\
62.3)\end{array}$ & $\begin{array}{r}(38.5- \\
62.2)\end{array}$ & $\begin{array}{r}(39.8- \\
60.5)\end{array}$ & $\begin{array}{r}(33.9- \\
58.6)\end{array}$ & $\begin{array}{r}(42.7- \\
55.1)\end{array}$ & $\begin{array}{r}(38.3- \\
50.6)\end{array}$ \\
\hline Infant mortality rate & 72.2 & 67.1 & 77.0 & 71.9 & 72.4 & 66.8 & 73.9 & 68.7 \\
\hline $95 \%$ C.I. & $\begin{array}{l}(58.0- \\
86.4)\end{array}$ & $\begin{array}{r}(54.9- \\
79.3)\end{array}$ & $\begin{array}{r}(65.0- \\
88.9)\end{array}$ & $\begin{array}{r}(57.3- \\
86.6)\end{array}$ & $\begin{array}{r}(60.4- \\
84.4)\end{array}$ & $\begin{array}{r}(54.1- \\
79.5)\end{array}$ & $\begin{array}{r}(66.5- \\
81.4)\end{array}$ & $\begin{array}{l}(61.0- \\
76.5))\end{array}$ \\
\hline $\begin{array}{l}\text { Maternal mortality } \\
\text { ratio* }\end{array}$ & 300 & 206 & 152 & 102 & 261 & 130 & 236 & 147 \\
\hline
\end{tabular}

*Confidence intervals not calculated because all numbers are less than 15 .

Infant mortality rates at baseline were comparable to estimates for Pakistan generally, and declined in all sites during the project period. Neonatal deaths are generally slightly over 60 
percent of all infant deaths, as might be expected. Stillbirth rates were generally at about 3 to 5 percent of all births, slightly lower than neonatal mortality rates. Perinatal mortality at baseline ranged by site between 67 and 93 per 1000 live births plus stillbirths. Changes in perinatal mortality and its components, stillbirths and early neonatal deaths, are shown in figure 9.1.

Figure 9.1: Perinatal, stillbirth, and early neonatal mortality rates by arm

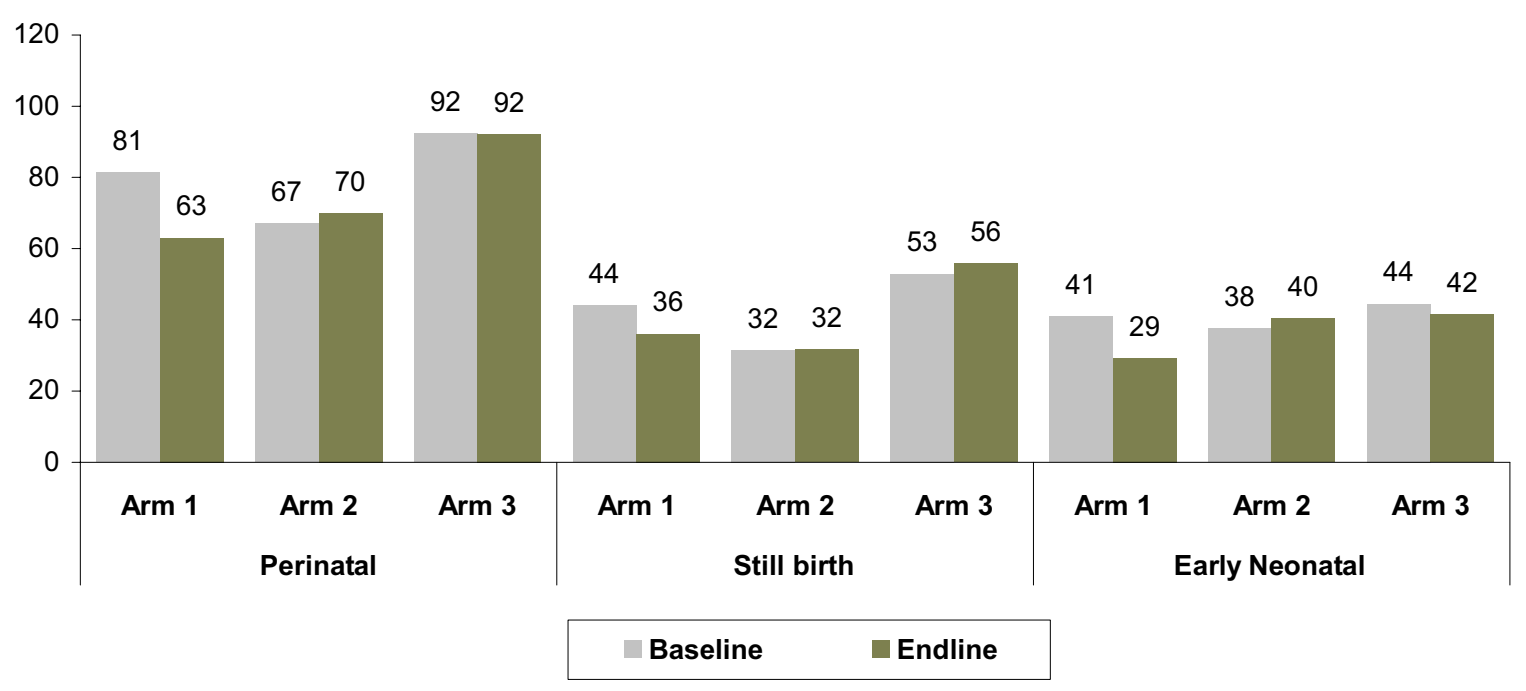

There was a statistically significant decline in perinatal mortality $(\mathrm{p}=.017)$, in site 1 but not in either site 2 or site 3 (figure 9.2), involving substantial but non-significant declines in both stillbirths and neonatal deaths. No other mortality declines were statistically significant. Standard errors were calculated taking into account the sample design, using the STATA command "svymean". Design effects for mortality variables, in contrast to most social, economic and health variables, were uniformly near unity. 
Figure 9.2: Perinatal mortality rate by area

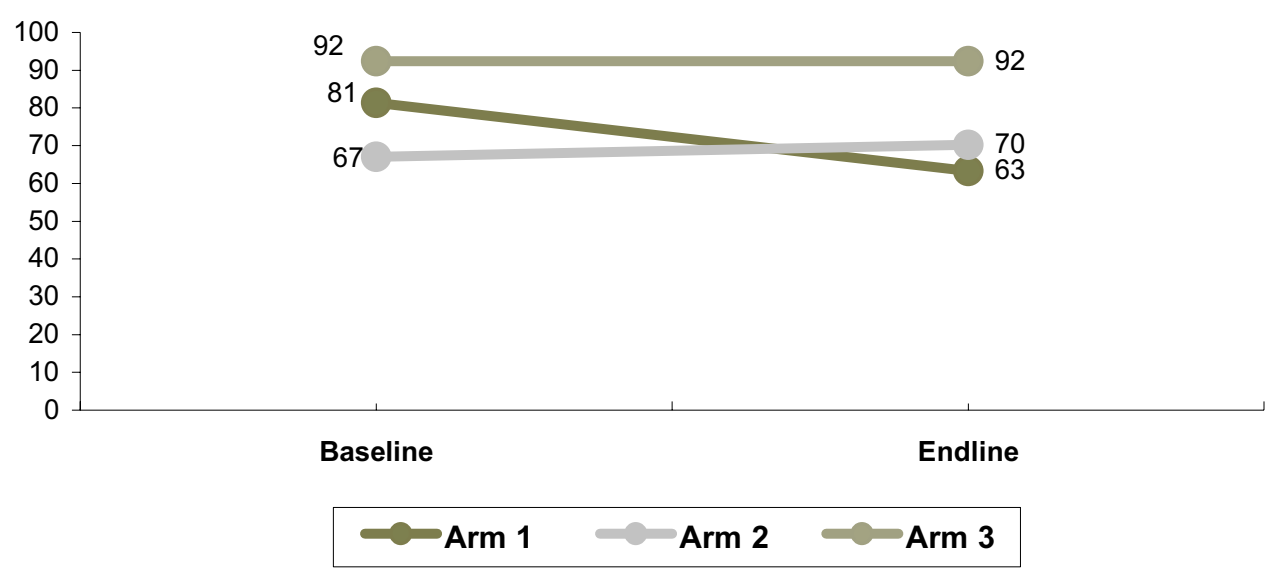

Given that perinatal mortality in site 2 began and remained not far above the levels found in site 1 at endline, it is possible that the observed decline in site 1 is a statistical anomaly. On the other hand, it is likely that the actual decline in site 1 may have been greater than we were able to measure, since a substantial part of the mortality experience measured in the survey occurred prior to full project implementation.

Maternal mortality is relatively low compared with most national estimates in all arms at baseline and endline. Fewer maternal deaths were observed at endline than at baseline in all arms, although the numbers do not approach statistical significance. It is possible that maternal mortality is relatively low in these areas given their level of development, or that national estimates are overestimated, or that the numbers are misleading due to small sample sizes. 
APPENDIX 


\section{Appendix I. Site Selection}

Dera Ghazi Khan was selected as the intervention area and Layyah as the control area after many discussions and site visits and through factor analysis of existing data. The aim was to select an "average" district of Pakistan, which was predominantly rural and had an adjacent district having similar indicators. After excluding the predominantly urban districts, the total number of districts included in the factor analysis was 94.The factor analysis was carried out on SPSS using the principal components method.

The following district level variables were included in the factor analysis (Source: NIPS District Profile):

- Area (sq. km.) per basic health facility

- Population per basic health facility

- Child-woman ratio

- Percentage of women 10+ years of age who are literate

- Percentage of all persons 10+years of age who are literate

- Percentage of households having piped water

- Percentage of households having electricity

- Percentage of households having television

- Weighted factor score* (WHS) from Ghaus, et al.

The regression method for estimating the components was used; the components were saved as variables. The analysis resulted into the production of three components, having eigenvalues of 4.85, 1.33 and1.04 respectively. The first component, having the highest eigenvalue, was selected for ranking, while the remaining two were discarded. The selected component correlated well with all variables with the exception of percentage of households having piped water and population per basic health facility, which had correlation coefficients of 0.28 and 0.39 respectively. The other correlation coefficients ranged from 0.69 to 0.94 . The diagnostics for the factor analysis were well within acceptable limits: the KaiserMeyer-Olkin (KMO) measure of sampling adequacy was 0.825 and the Bartlett's test of sphericity was significant $(\mathrm{P}<0.01)$. 
The selected components were then used to rank the districts, in order identify the ones lying in the median (+/- 10 percent) band. Eighteen districts were identified, from which those districts were excluded where maternal intervention projects were already being implemented.

The following districts were identified:

- Ghotki

- Bannu

- Dera Ghazi Khan

- Khairpur

- Tank

- Lodhran

- Larkana

- Dadu

- Hangu

- Ziarat

- Layyah

The districts Dadu and Tank were excluded from further consideration due to high security risk, while the other districts were personally visited by a team from Population Council. The following criteria were used to make the final selection:

- Scatter of villages

- Security situation, in terms of implementation of intervention

- Accessibility in terms of time, effort and cost to reach from Islamabad

- Feasibility of implementation of community-based interventions

- Feasibility of implementation of health-facility-based intervention

- Logistics and operational issues (setting up office, finding staff, etc.)

DG. Khan and Layyah, after detailed discussions, were selected as intervention and control districts respectively. 


\section{Appendix 2. District Profile}

\section{Dera Ghazi Khan}

Dera Ghazi Khan is a district of southern Punjab, bordering NWFP and Balochistan and just north of Sindh. Its area of 11,922 sq. km. encompasses a difficult and varied terrain - plains, sandy areas, riverbeds, hills and mountains.

According to the 1998 censes, the population of DG. Khan is16,43,118, comprising 52 percent males and 48 percent females. The sex ratio (males per 100 females) is 108 . Fourteen percent of the population is urban, while 86 percent is rural. The population density is 137.8 per sq. $\mathrm{km}$. and the average household size is 7.9. The population of de-excluded (tribal) area is about $7 \%$ of the entire population. The predominant language is Seraiki, followed by Balochi.

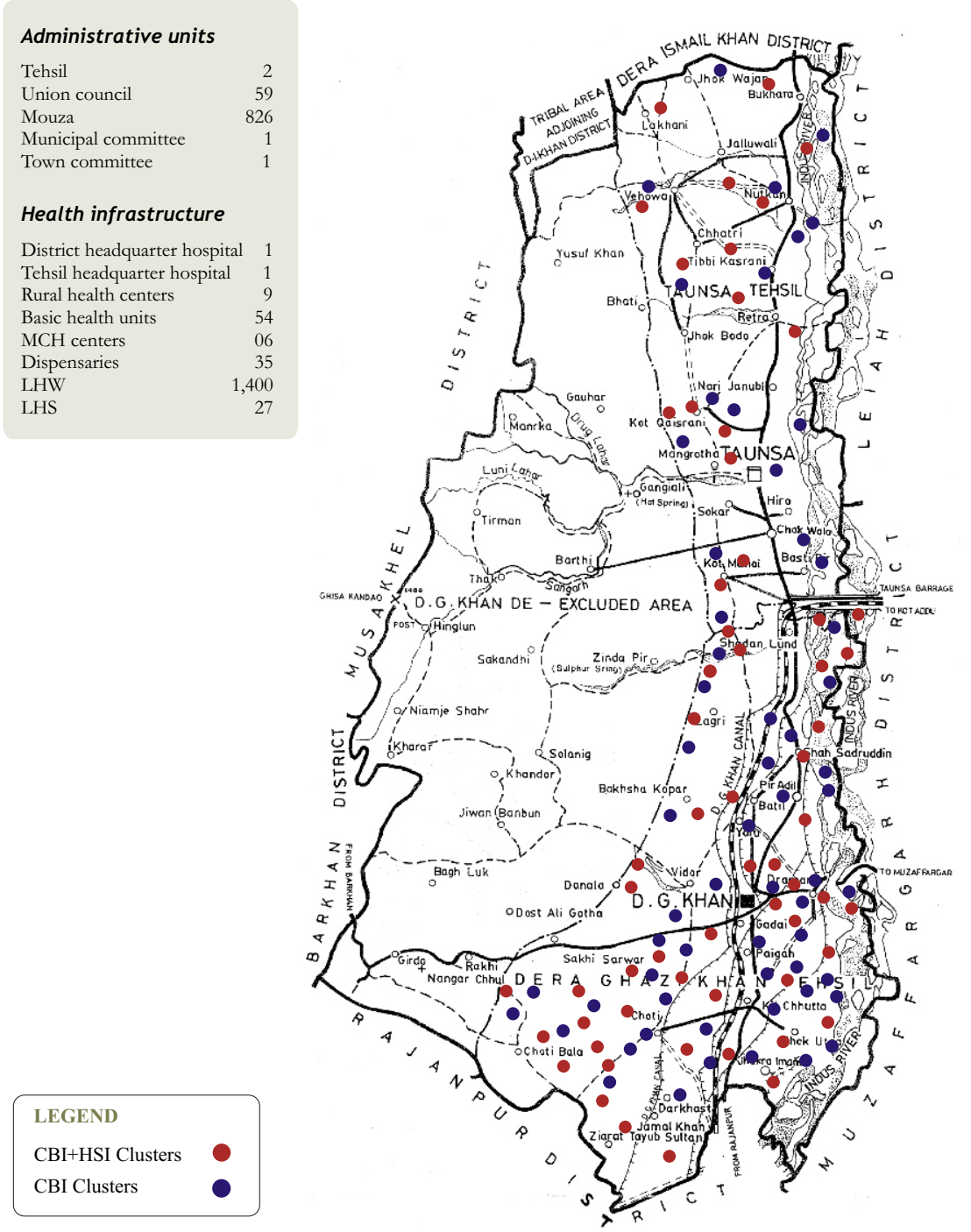




\section{Layyah}

Layyah is also a district of lower Punjab, having an area of 6,291 kilometers; the terrain is mostly plain and sandy. According to the 1998 census, the population of the district is 11,20,951, comprising 52 percent males and 48 percent females. The sex ratio (males per 100 females) is 106.8 . The population is 13 percent urban, 87 percent rural. The population density is 178.2 per sq. $\mathrm{km}$. The languages predominantly spoken are Seraiki and Punjabi.

\section{Administrative units}

Tehsil

Union council

Mouza

\section{Health infrastructure}

District headquarter hospital 1 Tehsil headquarter hospital 2

Rural health centers

Basic health units

$\mathrm{MCH}$ center

LHW

LHS

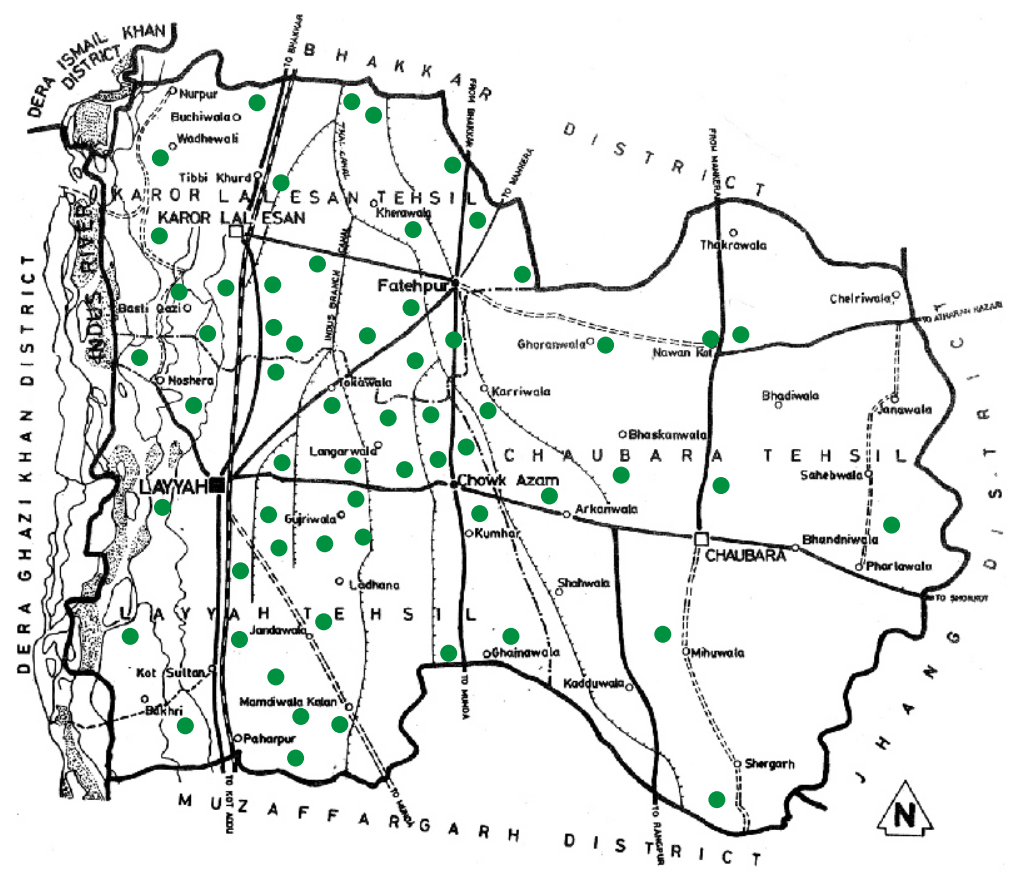




\section{Appendix 3. Staff of HHS and KAB surveys}

\begin{tabular}{|c|c|c|c|}
\hline Name & Designation & Name & Designation \\
\hline Muhammad Shafiq Arif & Lead Person & Farhana Nousheen & Interviewer \\
\hline Nayyar Munir & Lead Person & Najama Bibi & Interviewer \\
\hline Shagufta Naheed & PC - Isb. & Ruqia Perveen & Interviewer \\
\hline M. Tayyab Farooq & Sr. Field Coordinator & Perveen Akhtar & Interviewer \\
\hline Kamran Shafi Bhutta & Field Coordinator & Rana Tahira Fatima & Interviewer \\
\hline Asma Nausheen & Assistant Supervisor & Mehvish Ansari & Interviewer \\
\hline Abdul Qadir Malik & Logistic Coordinator & Munazza Saeed & Interviewer \\
\hline Rehmat Ullah & Logistic Coordinator & Naghmana Noureen & Interviewer \\
\hline Faheem Nawaz & Logistic Coordinator & Naheed Mustafa & Interviewer \\
\hline Altaf Javed (Listing) & Logistic Coordinator & Naila Fakhr & Interviewer \\
\hline Imdad Ullah (Listing) & Logistic Coordinator & Nasreen Bokhari & Interviewer \\
\hline Sajid Mukhtar (Listing) & Logistic Coordinator & Nazia Qureshi & Interviewer \\
\hline Amir Khurshid (Lisiting) & Interviewer & Rubina Qadir & Interviewer \\
\hline Ayaz Karim (Listing) & Interviewer & Rukhsana Akhtar & Interviewer \\
\hline Azam Shahzad (Listing) & Interviewer & Samina Mustafa & Interviewer \\
\hline Azra Noureen & Facilitator & Sarwar Mai & Interviewer \\
\hline Erum Baloch & Facilitator & Shahida Shaheen & Interviewer \\
\hline Rabia Ishaque & Facilitator & Shakeela Bano & Interviewer \\
\hline Shabana Sharif & Facilitator & Shazia Fatima & Interviewer \\
\hline
\end{tabular}




\begin{tabular}{llll}
\hline Name & Designation & Name & Designation \\
\hline Shahnila Bibi & Facilitator & Shazia Malik & Interviewer \\
Summera Mushtaq & Facilitator & Summera Bibi & Interviewer \\
Afshan Noreen & Interviewer & Zahida Parveen & Interviewer \\
Aliya Imam & Interviewer & Faisal Amin & Interviewer \\
Anila Yasmeen & Interviewer & Karman Rafique & Interviewer \\
Asma Rashid & Interviewer & M. Ismaeel Leghari & Interviewer \\
Falak Naz & Interviewer & Shahid lqbal & Interviewer \\
Fouzia Iqbal & Interviewer & Farzana Tahseen & Editor \\
Fouzia Shahzad & Interviewer & Fehmina Anwar & Editor \\
Ghazala Shafi & Interviewer & Makia Ajmal & Editor \\
Gul Bano & Interviewer & Interviewer & Editor \\
Khadeeja Mai & Interviewer & Editor & \\
\hline Khadeeja Tul Kubra & & & \\
\hline
\end{tabular}


Knowledge, Attitude \& Behavior - II

\begin{tabular}{|c|c|c|c|}
\hline Name & Designation & Name & Designation \\
\hline Mumraiz Khan & Lead Person & Shazia Fatima & Interviewer \\
\hline Nayyer Munir & $P C-I s b$ & Shazia Malik & Interviewer \\
\hline Asma Nousheen & Assistant Coordinator & Sumaira Bibi & Interviewer \\
\hline Asma Farooq & Interviewer & Abid Hussain & Interviewer \\
\hline Asma Umair & Interviewer & Azam Shahzad & Interviewer \\
\hline Azra Tahir & Interviewer & Imdad Ullah & Interviewer \\
\hline Faiza Ansari & Interviewer & ; M. Wasim Nawaz & Interviewer \\
\hline Naheed Mustafa & Interviewer & Sajid Mukhtar & Interviewer \\
\hline Rubina Qadir & Interviewer & : Nazia Qureshi & Interviewer \\
\hline Rukhsana Akhtar & Interviewer & Fahmina Anwar & Editor \\
\hline Saima Ashraf & Interviewer & Razia Naz & Editor \\
\hline Saima Naz & Interviewer & Moazzam Ibrahim & Editor \\
\hline Samina Rafiq & Interviewer & Rahman Razzaq & Editor \\
\hline Samreen Islam & Interviewer & 7 & \\
\hline
\end{tabular}

Data Entry Verbal Autposy \& KAB-II

\begin{tabular}{ll|ll}
\hline Name & Designation & Name & Designation \\
\hline Rehan Niazi & PC - Isb & Shazia Naureen & Data Operator \\
Zia ul Islam & PC - Isb & Muhammad Bilal & Data Operator \\
\hline
\end{tabular}

Endline Survey - Household + KAB III

\begin{tabular}{ll:ll}
\hline Name & Designation & Name & Designation \\
\hline Muhammad Shafique Arif & Lead Person & Naila Fakhar & Interviewer \\
Nayyer Munir & Lead Person & Saima Naz & Interviewer \\
Samina Mustafa & Asst Coordinator & Saira Parveen & Interviewer \\
Shaheen Naz Islam & Asst Coordinator & Tehmina Riaz & Interviewer \\
Afshan Noreen & Supervisor & Shulam Zainab & Interviewer \\
Anila Yasmeen & Supervisor & Samina Mubarak
\end{tabular}




\begin{tabular}{|c|c|c|c|}
\hline Name & Designation & Name & Designation \\
\hline Sadia Sharif & Supervisor & Zainab Tangwani & Interviewer \\
\hline Nazia Qureshi & Supervisor & Farhat Javed & Interviewer \\
\hline Safia Zafar & Supervisor & Shaheen Bibi & Interviewer \\
\hline Nazish Batool & Supervisor & Ammara Abdul Karim & Interviewer \\
\hline Mohsian Kahkashan & Supervisor & Asma Ahmed & Interviewer \\
\hline Farzana Parveen & Supervisor & Naheed Arshad & Interviewer \\
\hline Saima Ashraf & Interviewer & Sadia Shaukat & Interviewer \\
\hline Asma Umair & Interviewer & Samina Shabbir & Interviewer \\
\hline Samina Rafique & Interviewer & Rizwana Kousar & Interviewer \\
\hline Nasreen Bukhari & Interviewer & Saima Zartash & Interviewer \\
\hline Rukhsana Akhter & Interviewer & Batool Bibi & Interviewer \\
\hline Sarwar Mai & Interviewer & Umaima & Interviewer \\
\hline Summera Bibi & Interviewer & M. Waseem Nawaz & Male Logistic Coordinator \\
\hline Naheed Mustafa & Interviewer & Moazzam Ibrahim & Male Logistic Coordinator \\
\hline Munazza Saeed & Interviewer & Fakhar Mansoor & Male Logistic Coordinator \\
\hline Rukhsana Batool & Interviewer & Rehmat Ullah Shakir & Male Logistic Coordinator \\
\hline Rubina Qadir & Interviewer & Sajid Ahmed & Male Logistic Coordinator \\
\hline Kashifa Naz & Interviewer & Ismael Leghari & Male Logistic Coordinator \\
\hline Shaheen Allah Bukhsh & Interviewer & Abdul Qadir & Male Logistic Coordinator \\
\hline Rehana Tahseen & Interviewer & Rehman Razzaq Qaim & Male Logistic Coordinator \\
\hline Saima Wahid & Interviewer & Fehmina Anwer & Editor \\
\hline Shazia Malik & Interviewer & Shazia Fatima & Editor \\
\hline Tahira Bibi & Interviewer & Shagufta Qureshi & Editor \\
\hline Rubina Bibi & Interviewer & Umm-e-Ammara & Editor \\
\hline
\end{tabular}




\begin{tabular}{ll:ll}
\hline Name & Designation & Name & Designation \\
\hline Shagufta Noreen & Interviewer & Riffat Hameed & Editor \\
Imran Hafiz & Typist & Tahira Kalsoom & Editor \\
Zaitoon Baloch & Interviewer & Hina Sahar & Editor \\
Amna Munir & Interviewer & & \\
Bushra Ahmed & Interviewer & & \\
\hline
\end{tabular}

Data Entry for Endline Survey, KAB-III

\begin{tabular}{ll|ll}
\hline Name & Designation & Name & Designation \\
\hline Irfan Masood & Data Management & Muhammad Imran & Data Entry Operator \\
Muhammad Bilal & Data Entry Operator & Muhammad Imran Hafiz & Data Entry Operator \\
Imran Ali Qureshi & Data Entry Operator & Uzma Noureen & Data Entry Operator \\
Tariq Mehmood & Data Entry Operator & & \\
\hline
\end{tabular}




\section{Appendix 4. Sampling errors and design effects}

The following table provides estimates of standard errors, confidence intervals, and design effects for selected statistics taken from the HHS and KAB surveys, based on the actual sample design. The design effects "deft" represent the ratio of the actual standard errors to those calculated on the assumption that the data are from a simple random sample.

Table: Sample values, standard errors, 95 percent confidence intervals, and design effects for selected HHS and KAB variables

\begin{tabular}{lccccc}
\hline Variable & Value & SE & \multicolumn{2}{c}{ Cl } & Deft \\
\cline { 4 - 5 } & & & Lower & Upper & \\
\hline HHS (all sites combined, baseline) & & & & & \\
Perinatal Mortality rate & .0795 & .0037 & .0724 & .0871 & 1.031 \\
Stillbirth rate & .0403 & .0027 & .0353 & .0459 & 1.029 \\
Neonatal Mortality rate & .0485 & .0031 & .0427 & .0551 & 1.073 \\
Pct 3+ ANC visits & .1447 & .0068 & .1317 & .1587 & 1.461 \\
Pct 2+ TT shots & .4434 & .0106 & .4225 & .4646 & 1.699 \\
Pct iron tablets & .3217 & .0096 & .3030 & .3410 & 1.629 \\
Pct with SBA & .1694 & .0076 & .1549 & .1850 & 1.516 \\
Pct own agriculture land & .5042 & .0126 & .4791 & .5293 & 3.458 \\
Pct with TV & .1744 & .0103 & .1548 & .1958 & 3.700 \\
Pct with sewing machine & .3598 & .0110 & .3383 & .3820 & 3.121 \\
Pct with mobile phone & .0249 & .0016 & .0219 & .0283 & 1.406 \\
Pct with flush toilet & .3161 & .0181 & .2813 & .3531 & 5.289 \\
Pct with electricity & .6623 & .0182 & .6253 & .6975 & 5.242 \\
Pct with motorcycle & .0999 & .0039 & .0924 & .1080 & 1.777 \\
Pct MWRA ever been to school & .1478 & .0091 & .1307 & .1667 & 3.896 \\
Pct working for income & .5032 & .0186 & .4663 & .5400 & 5.672 \\
Pct using FP & .1253 & .0047 & .1162 & .1350 & 2.170 \\
Children ever born & 4.411 & .0306 & 4.350 & 4.472 & 1.395 \\
Reported 1+ severe complication & & & & & \\
$\quad$ Pregnancy & .6746 & .0146 & .2972 & .3550 & 2.472 \\
$\quad$ Delivery & .5744 & .0123 & .5499 & .5986 & 1.976 \\
$\quad$ Postpartum & .4676 & .0103 & .4472 & .4882 & 1.648 \\
KAB (site 1, round 3) & & & & & \\
Women's decision making & .1160 & .0254 & .0734 & .1786 & 2.026 \\
Women's financial control & .7722 & .0590 & .6308 & .8705 & 3.596 \\
Women's mobility & .4962 & .0533 & .3891 & .6036 & 2.729 \\
Knowledge 3 + danger signs & & & & & \\
$\quad$ Pregnancy & .3444 & .0429 & .2627 & .4365 & 2.323 \\
\hline
\end{tabular}




\begin{tabular}{cccccc}
\hline Variable & Value & SE & \multicolumn{2}{c}{ Cl } & Deft \\
\cline { 4 - 5 } & & & Lower & Upper & \\
\hline Delivery & .1767 & .0184 & .1422 & .2175 & 1.241 \\
Postpartum & .1042 & .0206 & .0690 & .1545 & 1.737 \\
Newborn & .3807 & .0391 & .3046 & .4631 & 2.071 \\
Pct attended women support group & .3157 & .0279 & .2616 & .3753 & 1.545 \\
Pct saw/received IEEC material & .6565 & .0263 & .6010 & .7081 & 1.420 \\
Pct visited by LHW last 2 months & .4819 & .0334 & .4144 & .5500 & 1.719 \\
Pct delivered by PC trained Dai & .4324 & .0662 & .3034 & .5713 & 1.145 \\
Pct breastfed within 4 hours & .3529 & .0487 & .2597 & .4590 & .9372 \\
Pct bath delayed until next day & .6512 & .0483 & .5459 & .7435 & .9372 \\
\hline
\end{tabular}


